\section{Reference}

NAT'L INST. OF STAND \& TECH R.IC.

A 1 1 105 891155

? 81-2210
NBS

Publi-

cations

\title{
Onsite Wastewater Systems -- Current Practices and a Proposed Basis for Evaluation
}

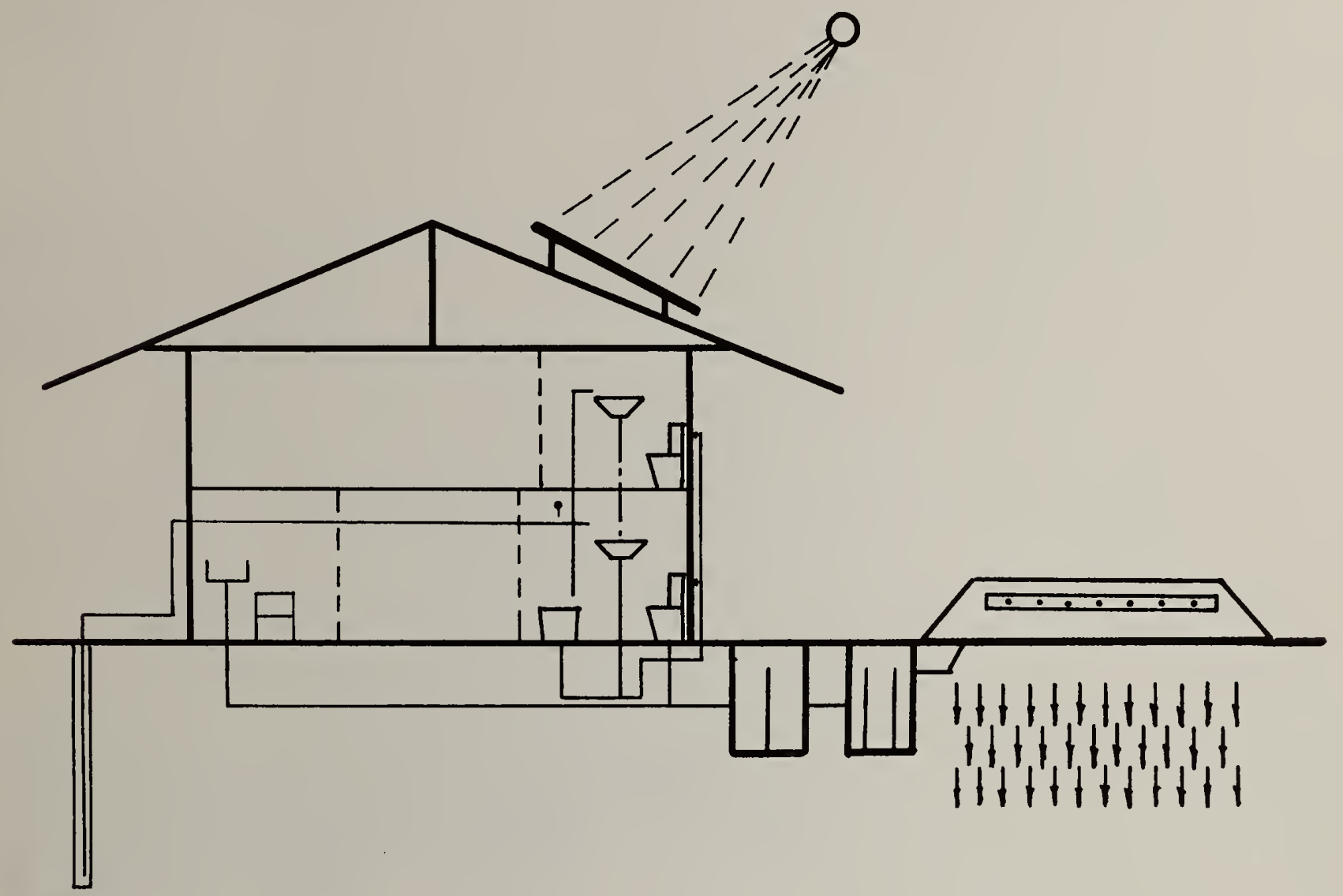

March 1981

Fred Winter

'enter for Building Technology ational Engineering Laboratory .S. Department of Commerce ational Bureau of Standards lashington, DC 20234 

Fred Winter

Center for Building Technology National Engineering Laboratory U.S. Department of Commerce National Bureau of Standards Washington, DC 20234

March 1981

Prepared for

Department of Housing and Urban Development

Division of Energy, Building Technology and Standards

Office Policy Development and Research

Washington, DC 20410

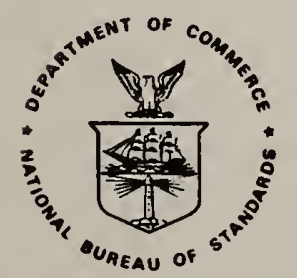

U.S. DEPARTMENT OF COMMERCE, Malcolm Baldrige, Secretary NATIONAL BUREAU OF STANDARDS, Ernest Ambler, Director 

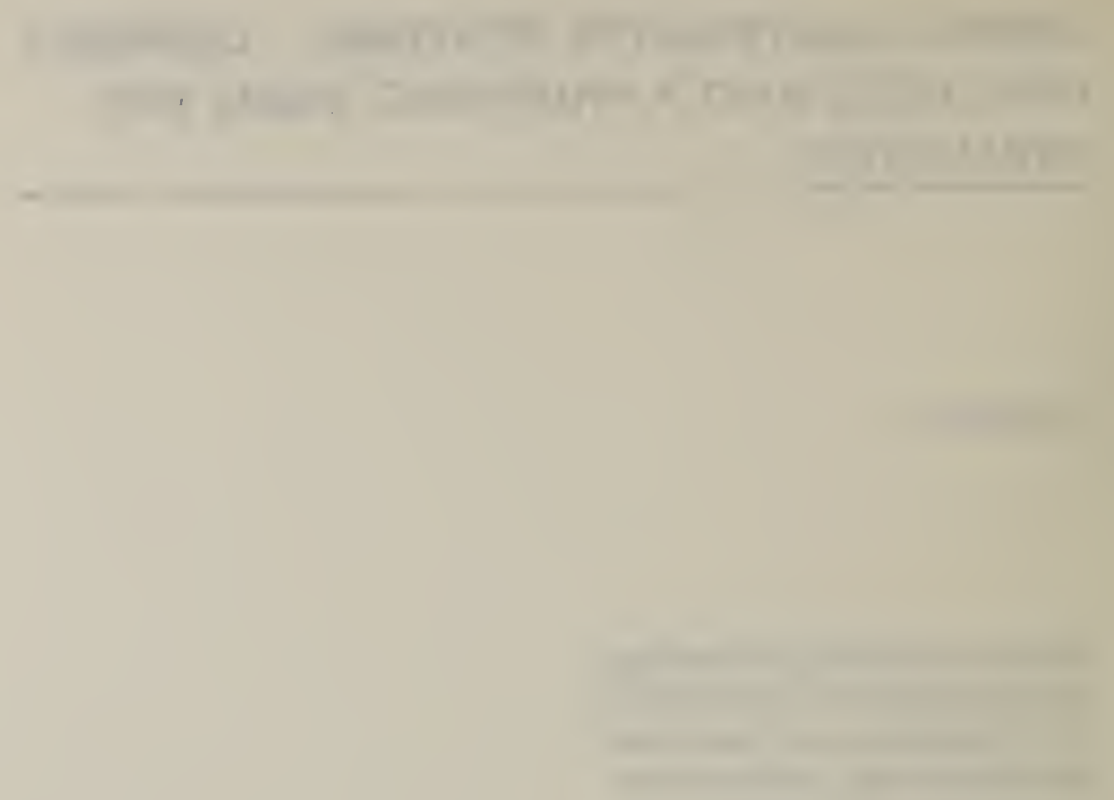

(n) 


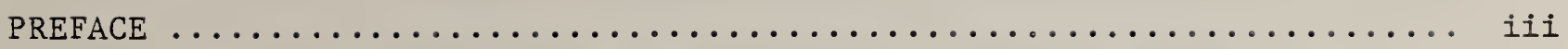

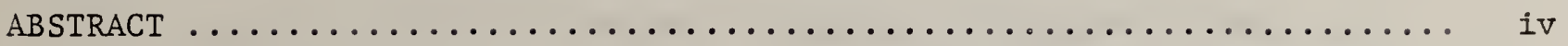

ACKNOWLEDG

1. INTRODUCTION $\ldots \ldots \ldots \ldots \ldots \ldots \ldots \ldots \ldots \ldots \ldots \ldots \ldots \ldots \ldots \ldots \ldots \ldots \ldots \ldots$

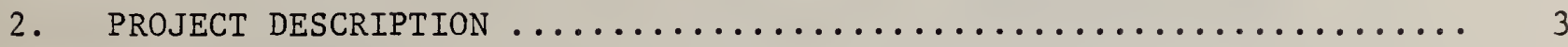

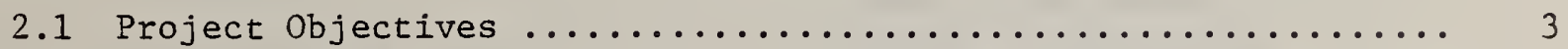

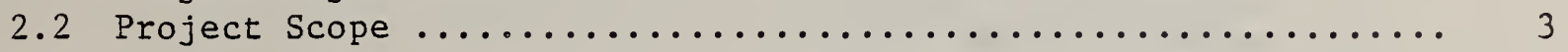

3. CLASSIFICATION OF ONSITE WASTEWATER ELEMENTS AND SYSTEMS $\ldots \ldots \ldots \ldots$

4. DOCURENTATION OF THE ONSITE WASTEWATER SYSTEMS REVIEWED ......... 8

5. ONSITE WASTEWATER SYSTEMS EVALUATION BASIS $\ldots \ldots \ldots \ldots \ldots \ldots \ldots \ldots$

5.1 Performance Criteria ........................... 30

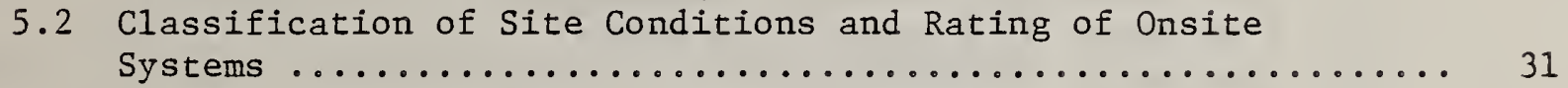

5.3 System Selection Based on Site Conditions ............... 31

6. REQUIREMENTS FOR DEMONSTRATION PROJECTS ................ 40

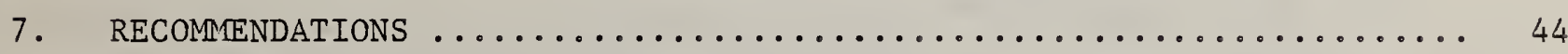

7.1 Recommendation of Wastewater Systems for Demonstration ...... 44

7.2 Recommendation for $\operatorname{Research} \ldots \ldots \ldots \ldots \ldots \ldots \ldots \ldots \ldots \ldots \ldots . \ldots \ldots \ldots$

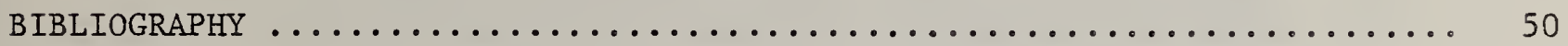

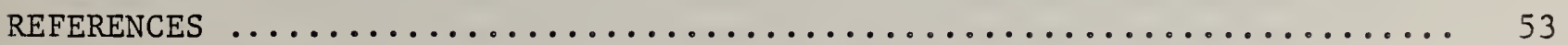




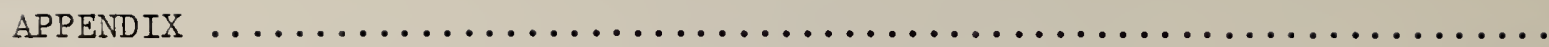

A. COMPILATION OF ONSITE WASTEWATER SYSTEMS $\ldots \ldots \ldots \ldots \ldots \ldots \ldots \ldots \ldots \ldots . . \ldots 6$

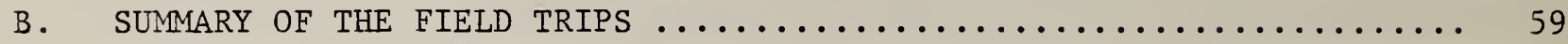

C. DISCUSSION OF WASTEWATER SYSTEMS AS VIEWED FROM THE FIELD TRIPS $\ldots . .70$

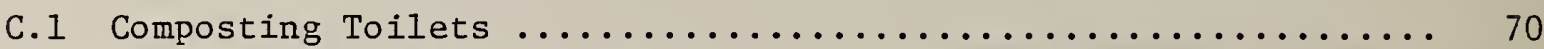

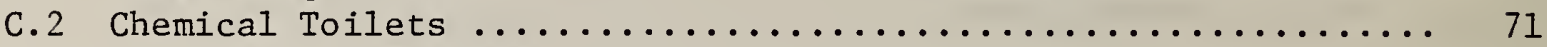

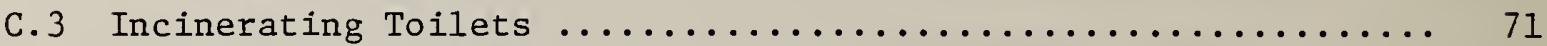

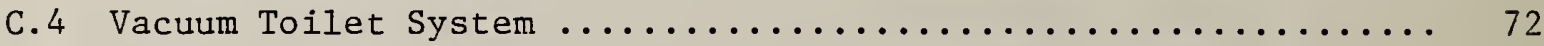

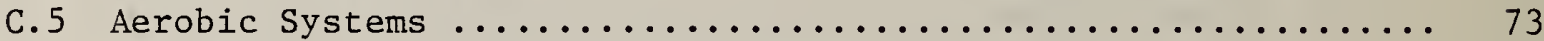

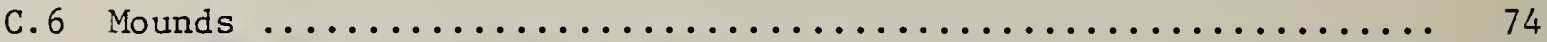

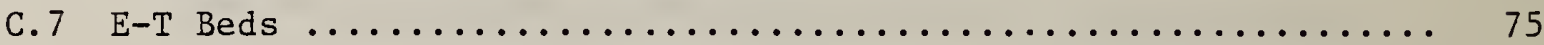

D. ONSITE WASTEWATER DEMONSTRATION PROJECTS $\ldots \ldots \ldots \ldots \ldots \ldots \ldots \ldots \ldots \ldots$

E. SOME ASPECTS OF ONSITE WASTEWATER TOPICS $\ldots \ldots \ldots \ldots \ldots \ldots \ldots \ldots \ldots \ldots$

E.1 The Aspect of the User's Acceptance ................... 84

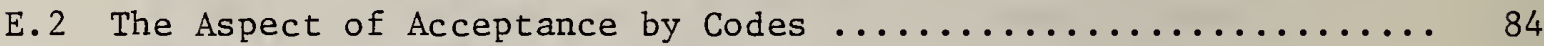

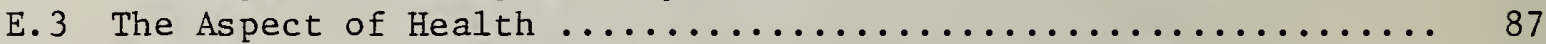

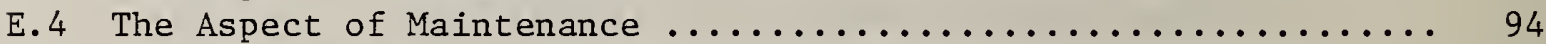

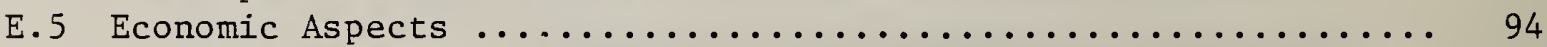

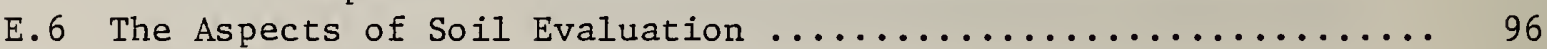

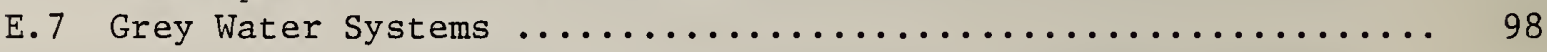

F. ADDITIONAL SOURCES OF INFORMATION ON ONSITE WASTEWATER SYSTEMS .... 101

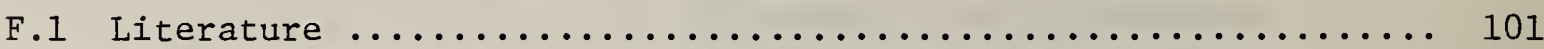

F.2 Conferences Related to Onsite Wastewater Systems .......... 102

F.3 Organizations Dealing With Onsite Wastewater Systems ....... 102

F.4 Manufacturers Marketing Wastewater Package Plants .......... 102 
Table 1. Matrix of Onsite Wastewater System vs. Site Conditions ... 32

Table 2. List of Input Parameters for Onsite Wastewater System

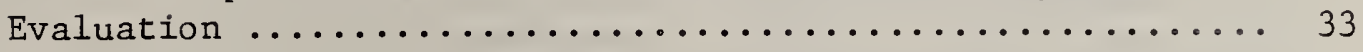

Table 3. Proposed Rating Criteria for Onsite Wastewater Elements ... 34

Table 4. Application of a Rating Scheme for Onsite Wastewater

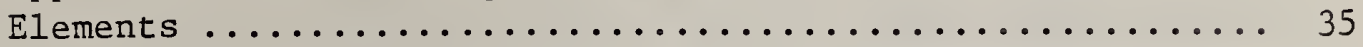

Table 5. Site Conditions Appropriate to the Onsite Wastewater

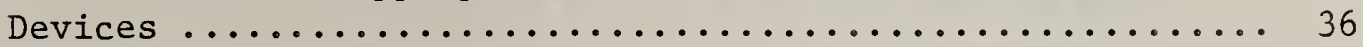

Table 6. Proposed Timetable for Onsite Wastewater Project ....... 43

Table 7. Wastewater Devices Observed or Reviewed in the Project .... 56

Table 8. Absorption Area Requirements for a Single Family Residence Comparison Between Septic Tanks and Aerobic Tanks ....... 74

Table 9. Failure or Malfunction of Systems Reviewed .......... 76

Table 10. Results of the Survey on Attitudes Towards Recycled Wastewater Conducted by "Pure Cycle" ................ 85

Table 11. Public Attitude Ratings Toward Reuse for Various Usages Conducted by the State of California ............... 86

Table 12. Relative Frequencies for Reasons of Nonacceptance of Ful1 Reuse of Reclaimed Water - Conducted by the State of

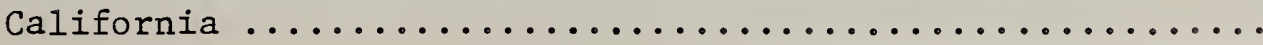

Table 13. Maximum and Minimum Values for Areas of Septic Tank Soil Absorption Systems Required by State Codes ............ 88

Table 14. State Onsite Wastewater Policies .................. 89

Table 15. Wastewater Disease Outbreaks in $1971-1975 \ldots \ldots \ldots \ldots$...... 93

Table 16. Etiology of Waterborne Disease Outbreaks in 1971-1975 .... 93

Table 17. Waterborne Disease Outbreaks by Type of System

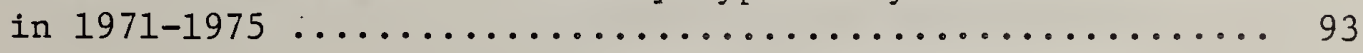

Table 18. Waterborne Disease Outbreaks by Type of Deficiency ...... 93

Table 19. Distribution of Wastewater Loading Between Grey and

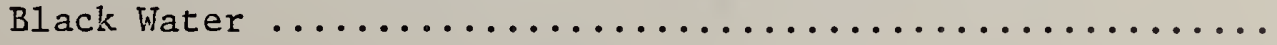


1. Classification of Onsite Wastewater System Elements $\ldots \ldots \ldots \ldots .7$

2. Large Type Compost Toilet $\ldots \ldots \ldots \ldots \ldots \ldots \ldots \ldots \ldots \ldots \ldots, \ldots$

3. Small Type Compost Toilet $\ldots \ldots \ldots \ldots \ldots \ldots \ldots \ldots \ldots \ldots \ldots \ldots, 9$

4. Oil Flush Toilet System $\ldots \ldots \ldots \ldots \ldots \ldots \ldots \ldots \ldots \ldots \ldots \ldots \ldots \ldots \ldots \ldots$

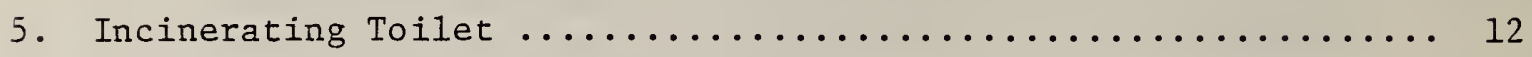

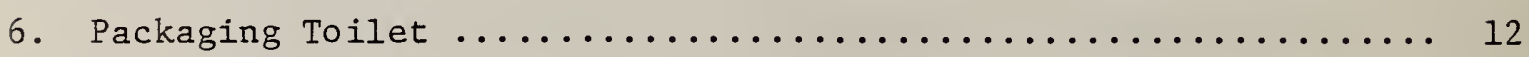

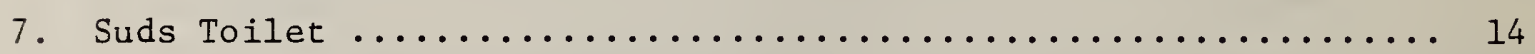

8. Vacuum Drainage and Vacuum Toilet $\ldots \ldots \ldots \ldots \ldots \ldots \ldots \ldots \ldots \ldots \ldots$

9. The Microphor Toilet $\ldots \ldots \ldots \ldots \ldots \ldots \ldots \ldots \ldots \ldots \ldots \ldots \ldots \ldots \ldots \ldots$

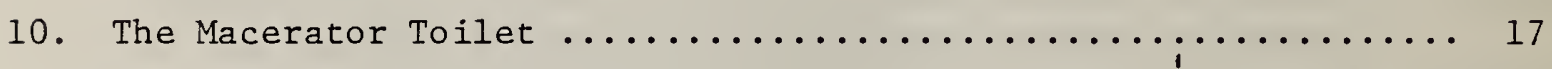

11. European Flush Down Toilet $\ldots \ldots \ldots \ldots \ldots \ldots \ldots \ldots \ldots \ldots \ldots \ldots \ldots \ldots \ldots \ldots$

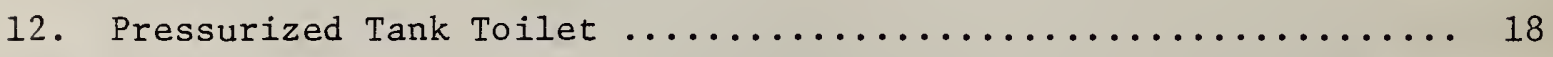

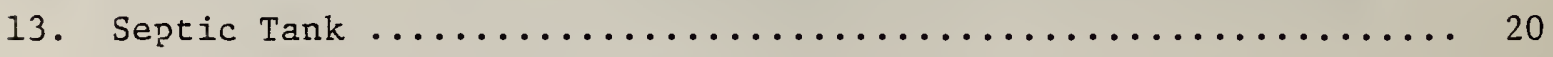

14. Aerobic Tank $\ldots \ldots \ldots \ldots \ldots \ldots \ldots \ldots \ldots \ldots \ldots \ldots \ldots \ldots \ldots \ldots \ldots \ldots \ldots \ldots \ldots, 21$

15. Rotor Disc $\ldots \ldots \ldots \ldots \ldots \ldots \ldots \ldots \ldots \ldots \ldots \ldots \ldots \ldots \ldots \ldots \ldots \ldots \ldots \ldots \ldots \ldots \ldots \ldots, 21$

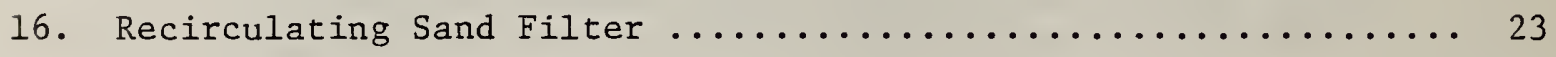

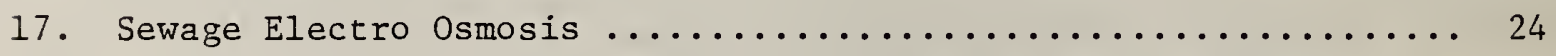

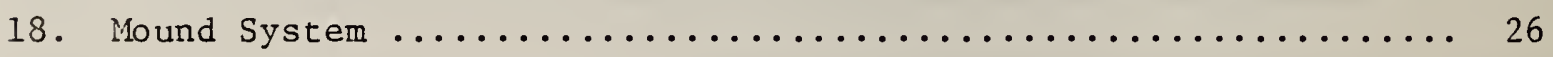

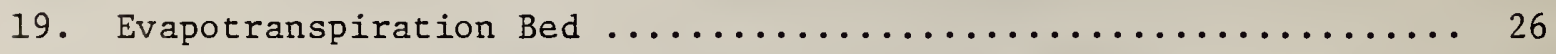

20. Grey Water Recirculation for Toilet Reuse $\ldots \ldots \ldots \ldots \ldots \ldots .29$

21. USDA Soil Textural Classification $\ldots \ldots \ldots \ldots \ldots \ldots \ldots \ldots \ldots \ldots \ldots$

22. Clivus Multrum Grey Water Filter $\ldots \ldots \ldots \ldots \ldots \ldots \ldots \ldots \ldots$

23. University of Wisconsin Grey Water Filter $\ldots \ldots \ldots \ldots \ldots \ldots \ldots$ 
This report is one of a group documenting National Bureau of Standards (NBS) research and analysis efforts in developing water conservation test methods, models for technical and economic analysis, and strategies for implementation and acceptance of practices. This work is sponsored by the Department of Housing and Urban Development, Office of Policy Development and Research, Energy, Building Technology and Standards Division, under Interagency Agreement H-48-78.

Certain trade names and company products are identified in this report. In no case does such identification imply that the products are necessamily the best availabie for the purpose for which they were mentioned. 
A review of onsite wastewater systems and wastewater recirculation/reuse devices based on the literature and field inspections of systems in actual settings and usage is presented. Based upon the observations, an evaluation basis for onsite wastewater systems is proposed. Criteria and requirements for conducting and monitoring demonstration projects is presented. Wastewater systems identified as potentials for demonstration projects are suggested. Topics requiring further study are identified and recommended for specific research.

Key Words: Onsite wastewater systems; wastewater disposal; wastewater recirculation; wastewater reuse; wastewater treatment; water conservation. 


\section{ACKNOWLEDGMENTS}

Appreciation is hereby expressed to the following organizations and persons who devoted their time and provided the investigator with information and material for this report:

- Larry Waldorf from the Appalachian Regional Commission, Washington, D.C.

- David Salisbury from Boyd County, Kentucky

- William Hill from Valley Septic Products, Gettysburg, Pennsylvania

- Lyman Schooley from Montgomery County, Maryland, EPA

o Frank Reeves from R. M. Thornton, Inc., Washington, D.C.

- Curtis Bohlan from the Eastern Environmental Controls, Maryland

- J. Tailor from the Virginia Highway Department

- Bill Johnson and Bill Armstrong from N.C. Highway Department

- Dr. R. Carlile and R. Rubin from North Carolina State University

- Stanley Thompson, Sperryville, Virginia

- Merril B. Glasser from the Department of Health, Maryland

- Gunar and Heather Baldwin, Thornton Gore Enterprises, New Hampshire

- Eugene Moreau from the Department of Human Services, Maine

- William Bullard from Thetford Corporation, Michigan

- Jay Bastion from the Department of Transportation, Michigan

- Jerry Tyler, Bob Siegriest and Dean Cliver from the University of Wisconsin, Madison, Wisconsin

- Mark Palmer and Binx Selbey from Pure Cycle, Boulder, Colorado

- Mike Whitmore from Boulder County Department of Health, Boulder, Colorado

- Dr. Foresti and Mr. Bowl from the Eton Water Cyk, Maryland

- Dick McCulloh from "AQUA SAVER," Maryland 

The needs for innovative onsite wastewater systems and wastewater reuse devices as means for solutions to problems immerging from conventional centralized wastewater systems and septic tanks, has been expressed and documented in numerous publications. The following facts are cited in reports, research papers and surveys related to this topic:

- One third of the population in the United States live in homes with septic tanks for wastewater treatment systems. Failure of these systems result in a nuisance to the homeowners or to the occupants of the adjacent dwellings and/or hazards to the environment by polluting the ground water and other sources of water supply.

- A large portion of the land in the United States has soils of marginal characteristics and is not suitable for septic tanks and wastewater soil absorption systems.

- The high and rising costs of gravity sewers and centralized wastewater systems call for alternatives for the reduction of the overall costs of housing.

- Increase in demand for water and the depletion of potable water resources, in particular, in the Southwest call for water conservation measures.

- A trend of the population to moving to rural areas where centralized systems cannot be reached and onsite wastewater treatment is the only solution to the household wastewater treatment and disposal problems.

- Sewage moratoria in suburban areas hinders the development of such communities and unreasonably escalates the cost of land to which services are available.

The material reviewed, communications with professionals, and field observations revealed the growing needs for innovative onsite wastewater systems in this country. Methods are therefore required to provide an evaluation basis of existing technologies and newly developed devices and equipment for onsite wastewater systems.

Within the past two decades, information and experience has been accumulated for onsite wastewater systems and system elements such as soil absorption systems, aerobic treatment units and low flush toilets, through research, demonstration projects, and actual usage. It appears that the greatest need is to collect and classify the findings into well defined test cases where systems successes and failures can be analyzed and general conclusions drawn for future references.

However, more research is required in several disciplines of onsite wastewater systems to arrive at conclusions and issues that are still debatable and are subject to opinions in the absence of a finalized scientific data base. Further work is required to establish a data base on systems reliability anj limitations, systems suitability to specific site conditions, systems economic feasibility 
and the aspect of health of onsite wastewater systems. This material is essential for the code writing groups so that they have adequate information for incorporating innovative onsite wastewater systems in the building codes, and for the legislative agencies throughout the country so that they have a sufficient degree of confidence for approving innovative onsite wastewater systems. Topics and problem areas, identified in the course of this project are described in Chapter 7. 


\section{PROJECT DESCRIPTION}

\subsection{Project Objectives}

The tasks undertaken in the project had the following objectives:

- Documentation of the state of the art of onsite wastewater systems and water recirculation/reuse devices.

- Develop recommendations to establish a basis for systems evaluation.

- Provide guidelines for HUD in selection of systems for demonstration.

- Identify problem areas in onsite wastewater systems for future investigation.

\subsection{Scope of Activities Carried Out}

- Literature Search

The literature search revealed that a large number of works have been written in the subject of onsite wastewater systems. The material reviewed for this project is cited in the sections of bibliography, references, and Appendix F.1 of this report.

- Conferences and Seminars Attendance (see Appendix F.2)

- Visits to Research Organizations

The visits to research organizations were conducted for the purpose of observing the testing facilities and the ongoing research programs in onsite wastewater systems (see Appendix F.3)

- Visits to Manufacturing Plants (see Appendix F.4)

- Visits to County and State Health Departments

Visits to health departments were for the purpose of studying the personnel's attitude towards innovative wastewater systems, policies regarding the approval of systems, viewing field inspection procedures and observing the performance of wastewater systems under their jurisdiction. 


\subsubsection{Field Trips}

Field trips were conducted to closely observe innovative wastewater systems in actual operation. Information was obtained on the degree and frequency of the required maintenance, repairs and the needs for replacements of parts. Operational problems and failures of onsite systems were experienced. The trips furnished the opportunity for studying the advantages and disadvantages of various installations and their applicability to various site conditions. Conversations with the homeowners and occupants furnished information on the user's attitudes and user's acceptance of innovative wastewater systems. As witnessed, assessment on the performance of the systems can only be attained through extensive field inspections where onsite wastewater systems are observed in "real life" situations.

Field trips were made in states in the East, the Midwest, and the State of Colorado. The field trip findings were documented in 25 field trip reports and their summary is described in Appendix $B$.

This activity has provided the broadest and most significant source of information and illuminated the following aspects in innovative onsite wastewater systems:

a. Problems of operation and maintenance.

Breakdown of moving parts, malfunction of systems controls and unavailability of replacement parts.

b. Problems of users acceptance.

Innovative wastewater systems are not readily accepted primarily because of lack of proper preparation and education.

c. Problems of improper design.

Improper system design yielded inefficient performance, frequent breakdowns and/or prohibitive costs of operation.

d. Problems of proper choice of system to the requirements of the site conditions.

Systems failure because considerations were not given to the particular site conditions and/or systems limitations.

e. Problems in onsite wastewater demonstration projects.

Demonstration projects and their problems as witnessed in the field trips are described in Appendix D. 


\section{CLASSIFICATION OF ONSITE WASTEWATER ELEMENTS AND SYSTEMS}

Onsite wastewater management starts from the water supply to the household and ends with the final disposal of the treated wastewater effluents. The system may incorporate a wastewater package which handles all the undergoing stages of the process, or it may include one or more elements for eliminating the particular problem at the site.

Figure $I$ and the following outline represent a general breakdown of the elements to be considered in onsite wastewater systems.

\section{Water Supply System}

- Comunity (municipality) supply system

- Onsite (well) supply system

- Onsite wastewater recirculation/reuse

- Water conservation appliances and fixtures

II. Generation of Wastewater

Input: from fixtures and appliances

Output: to drains, sewer lines

- Black Water - Wastewater from the water closet (W.C.) and kitchen sink

- Grey Water - All wastewater excluding the wastes from the water closet and kitchen sink

III. Wastewater Treatment

Input: from drain lines, sewers

Output: to treatment unit, i.e., septic tank, aerobic unit, sand filter, disinfection

- Blackwater Treatment

- Greywater Treatment

- Combined Treatment

IV. Wastewater Disposal

Input: from treatment unit

Output: transport lines and disposal systems

- Ground disposal, i.e., soil absorption systems.

- Surface disposal, i.e., creeks, lakes, rivers, oceans.

- Atmospheric disposal, i.e., evapotranspiration systems.

- Elimination, i.e., incineration.

o Transfer, i.e., transfer to centralized locals. 
V. Wastewater Recovery

- Recirculation of effluencts - water reuse for:

- Grey water for gardening

- Grey water for toilet reuse

- Grey water for potable reuse

- Black water for water closet

- Combined water for water closet

- Combined water for gardening

- Recovery of nutrients (compost)

- Recovery of energy (methane) 
Water Supply System

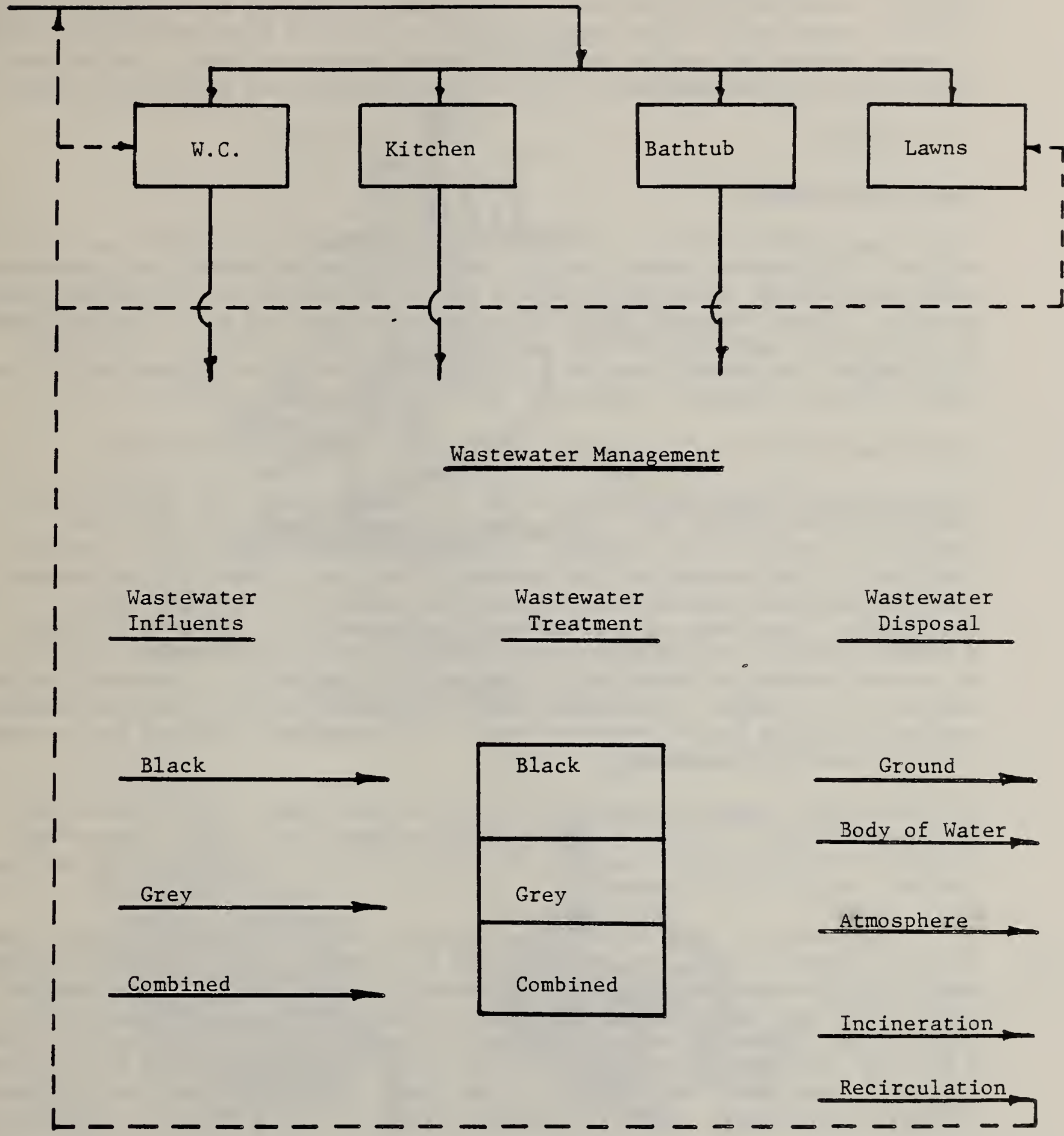

Figure 1. Classification of Onsite Wastewater System Elements. 
A brief description of the systems and their principles of operation is presented. The description of the following systems is based on manufacturers catalogs, technical publications and information obtained by the investigator from his field trips. This study provided a basis for recommendations of some of these systems for onsite wastewater demonstration projects. The inherent advantages and disadvantages of some of these systems are described in Chapter 7 .

\subsection{Toilets}

\section{Composting Toilets}

Composting toilets operate on the principle of biological aerobic decomposition. This process takes place by various species of aerobic microorganisms that thrive in the environment as long as air is present in the organic waste material. These organisms digest the waste materials and in the process break up the organic wastes to deliver a humus-like odorless product. For proper performance, the system requires air circulation, moisture, temperature of at least $35^{\circ} \mathrm{C}$ and a carbon to nitrogen ratio of approximately 30 .

Composting toilets are classified into "large type" and "small type".

The Large Type Composting Toilet (Fig. 2) In the large type system, the wastes from the toilet fall into a tank of approximately 120 cubic feet generally located in the basement. A garbage chute to the tank is normally installed in the kitchen for the disposal of all the organic kitchen wastes. The tank contains air ducts and a vent which extends to the roof for air circulation. Peat moss or saw dust must occasionally be added to the tank for maintaining a satisfactory level of the carbon/nitrogen ratio. The decomposed wastes are occasionally removed from the tank at a frequency which depends on its usage. An ordinary usage of a family of four, may not require emptying the tank for at least one year. The decomposed products may be used as fertilizers for gardening.

The Small Type Composting Toilet (Fig. 3) In the "small type" system, the toilet wastes fall in the container directly under the toilet. The system has approximate overall dimensions of $120 \mathrm{~cm}$ (length) $\times 50 \mathrm{~cm}$ (width) $\times 60 \mathrm{~cm}$ (height) $(40 \times 20 \times 25$ inches $)$.

Air is mechanically supplied by a fan with the vent extended through the roof. The temperature in the tank is controlled by a heating coil of ordinarily 130 watts and a thermostat to maintain a temperature level $\left(35^{\circ} \mathrm{C}\right)$ in the wastes. Some models also have a humidity control device for maintaining the moisture level in the tank. Decomposed material is scrubbed off by a rod and fall into a tray for periodic removal. Due to the relatively small size of the tank the system is less stable as compared to the "large volume" type and requires more frequent maintenance. Improper balance of the air flow, humidity, temperature

(1) This description presents an overview of the systems studied. No attempt was made to evaluate a particular product, but mainly to describe the inherent features and the principles of operation, of the presently available systems. 


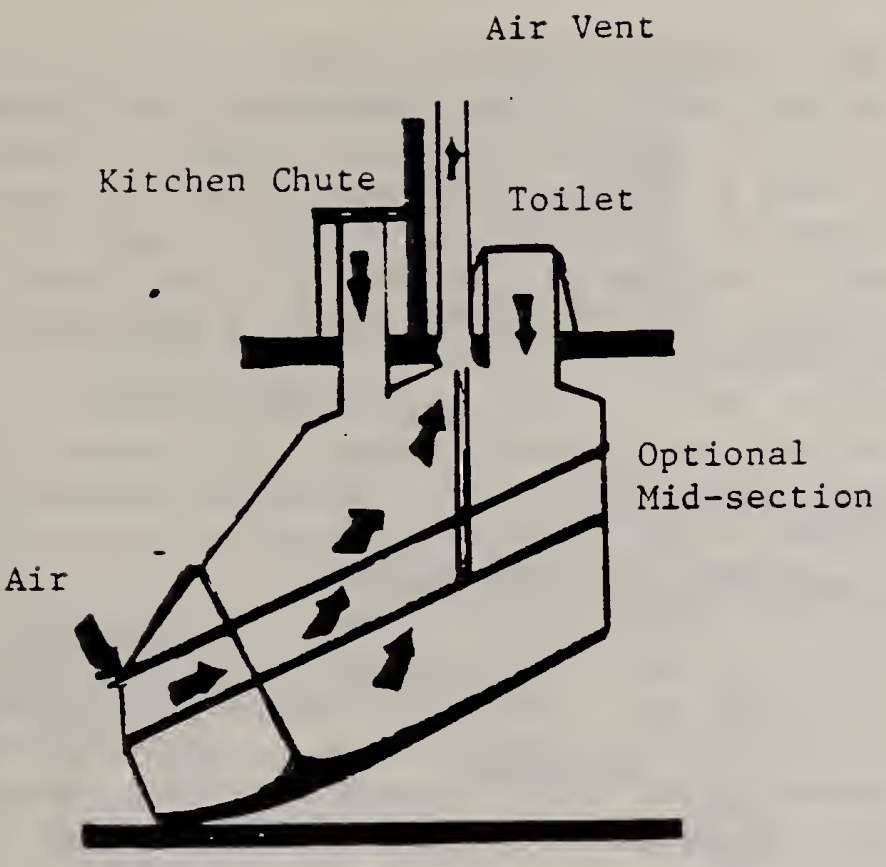

\section{Figure 2}

\section{Large Type Compost Toilet}
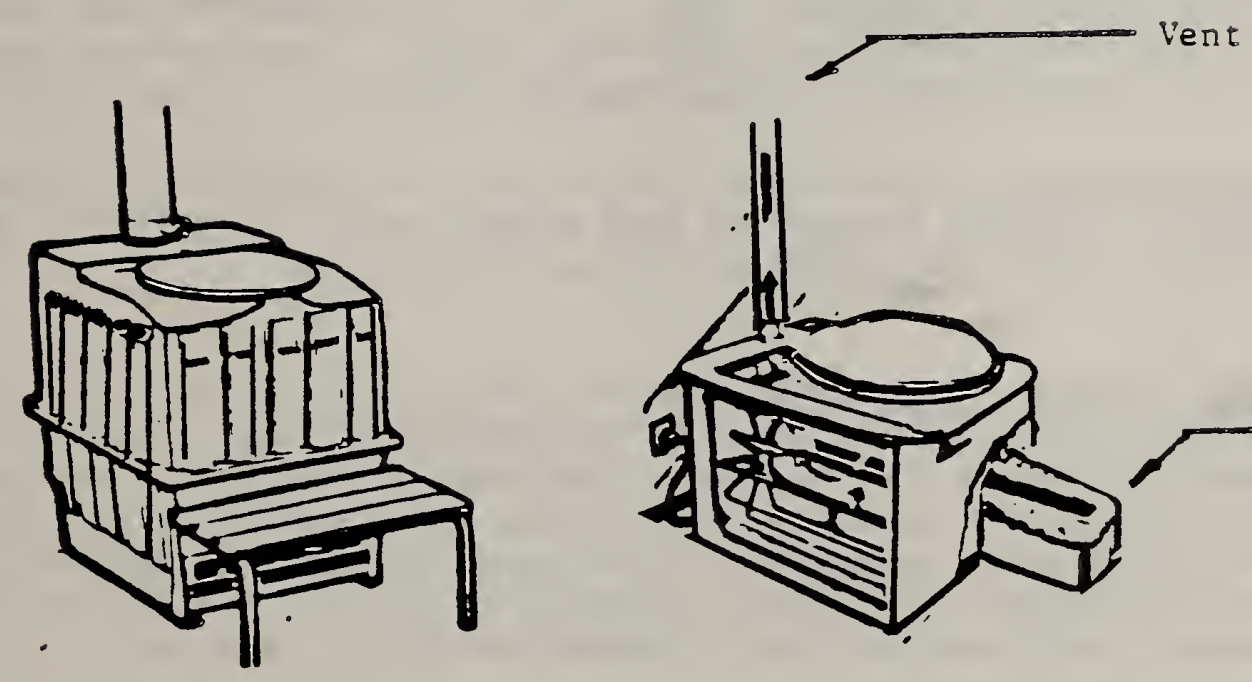

Vent
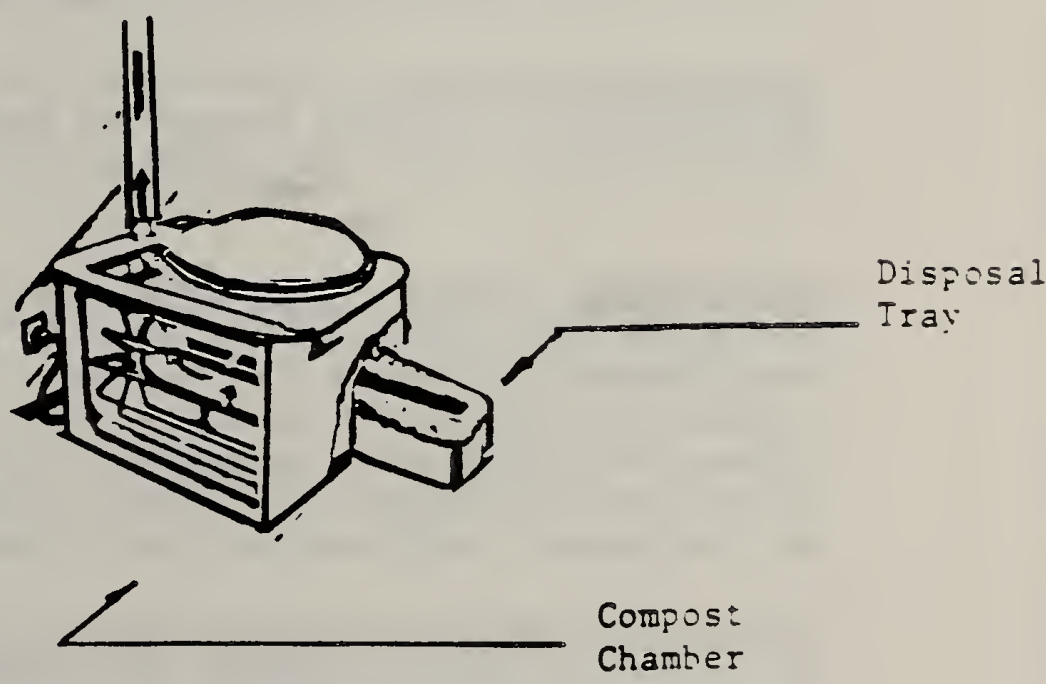

Figure 3

Small Type Compost Tollet

(Source: The Mulbank) 
and organic matter ratio may cause foul odors, flies and rapid accumulation of liquids in the tank. A new model which has recently reached the market operates at higher temperatures and powers a mixing device which loosens up the waste matter in the composting chamber for a more efficient supply of oxygen in the system.

The Carousel Toilet The Carousel toilet is similar to the large type composting toilet since the wastes drop to a holding composting tank located under the toilet. The tank is circular and contains four chambers. Depending on its frequency of usage the tank is periodically rotated so that each chamber collects the incoming wastes separately. A family of four may need to rotate the composting chamber once in six months. According to the manufacturers specifications, the system requires a $150 \mathrm{~mm}$ ( $6 \mathrm{in}$ ) vent, a fan and a 150 watt heater.

Oil Flush Toilets (Fig. 4) This system utilizes mineral oil as a flushing medium which is recirculated in a closed system. The system is composed of an ordinary toilet (one company uses teflon coated toilets for better rinse and scour action) a holding tank, pumps and a series of filters. After flushing the toilet, the wastes settle to the bottom of the tank and the oil is recirculated through the filters back to the W.C. tank. The oil in the system is disinfected by chlorine tablets prior to filtration. The filters must be periodically replaced and a small percentage of oil replenished. The wastes are periodically pumped out, hauled to a processing plant or incinerated on site. Up to the present time, these systems have been limited for use only in public places, such as highway rest areas and park facilities.

Chemical Toilets Chemical toilets are generally designed for recreational areas and vehicles but have also been used to a limited extent in homes. All chemical toilets operate by chemically degrading the incoming waste matter by the insertion of a biodegradable chemical agent to the fixed quantity of water in the bowl. The small portable type can be used for twenty applications after which the decomposed wastes are disposed of. Larger models are recirculating systems utilizing a filter and a recirculating pump where flushing of the bowl takes place after each usage. These systems may be used for 80 flushes before requiring disposal and recharge of a new chemical dose.

Incinerating Toilets Incinerating toilets have had some use in homes. Their applicability is limited because of high energy cost; in addition, foul odors may be produced while the wastes are being incinerated.

Incinerating Toilets - Gas Fired When the seat cover of the toilet is raised the hopper flap opens, permitting the waste matter to fall into the incinerating chamber, at which time, a vent in the rear of the unit opens for air circulation through the system. Upon closing the seat cover, the hopper flap closes, an igniter coil generates a spark igniting the fuel gas which burns up the bowl's contents. The system normally requires a $1 / 4 \mathrm{lb}$. of propane gas per usage. Incinerating time is approximately 10 minutes.

Incinerating Toilets - Electricity Operated (Fig. 5) Incineration involves an electrical heating element which typically draws 2400 watts for ten minutes. Some systems require a longer time for complete incineration (up to 40 minutes) however, the incinerating cycle may be interrupted, and the system used, before 


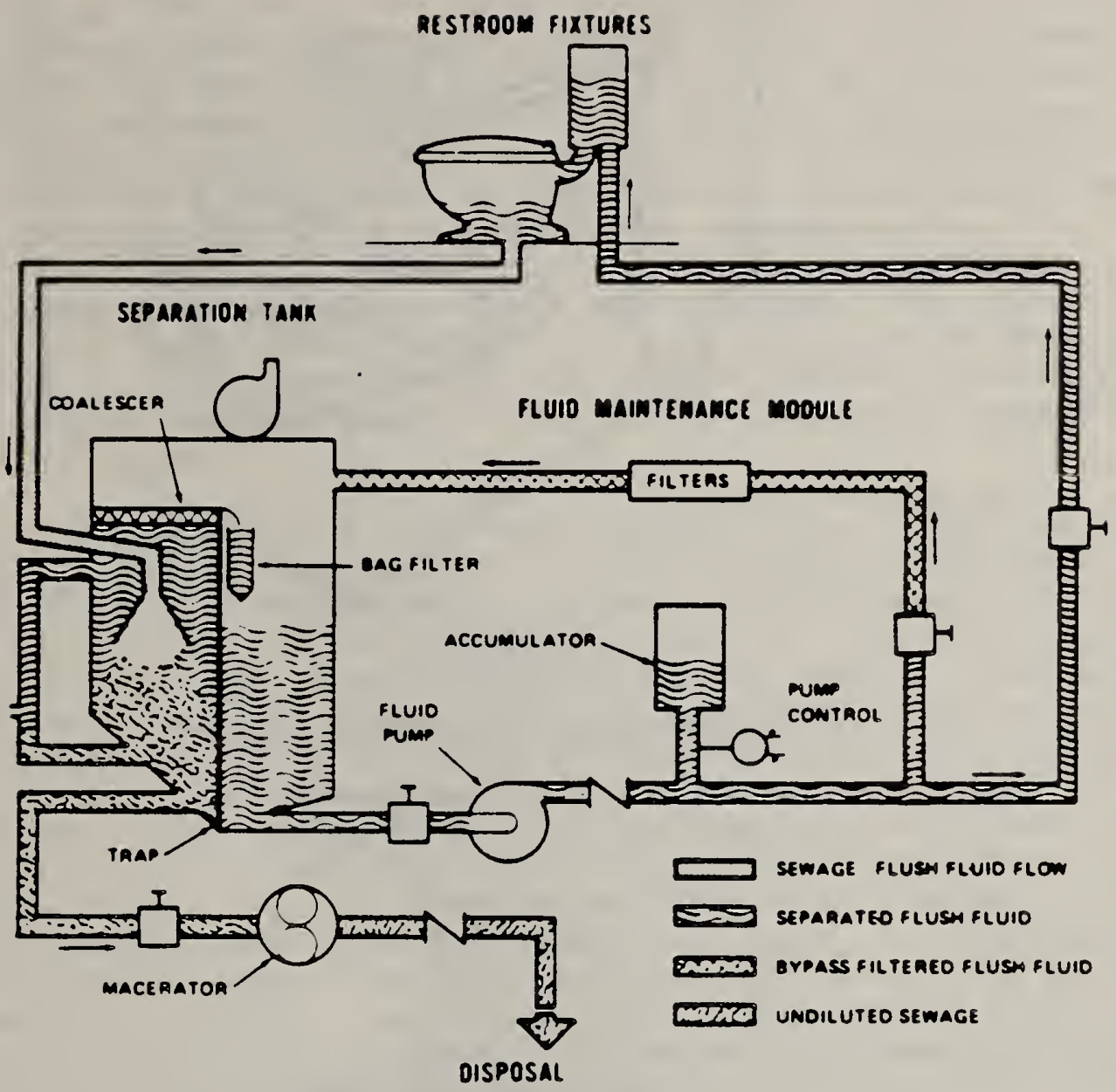

Figure 4

The Oil Flush Toilet System 


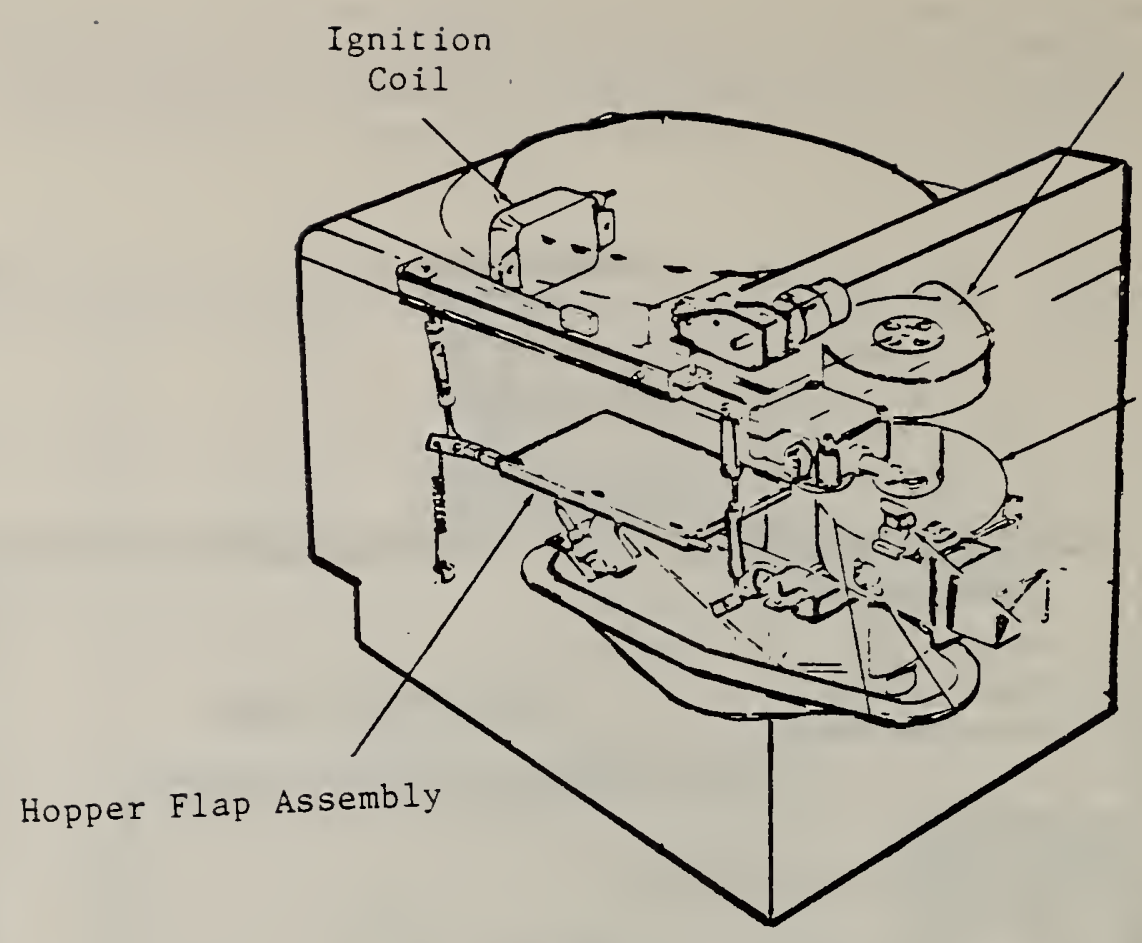

Power Burner

Blower Assembly

Figure 5

Incinerating Toilet (electrical)

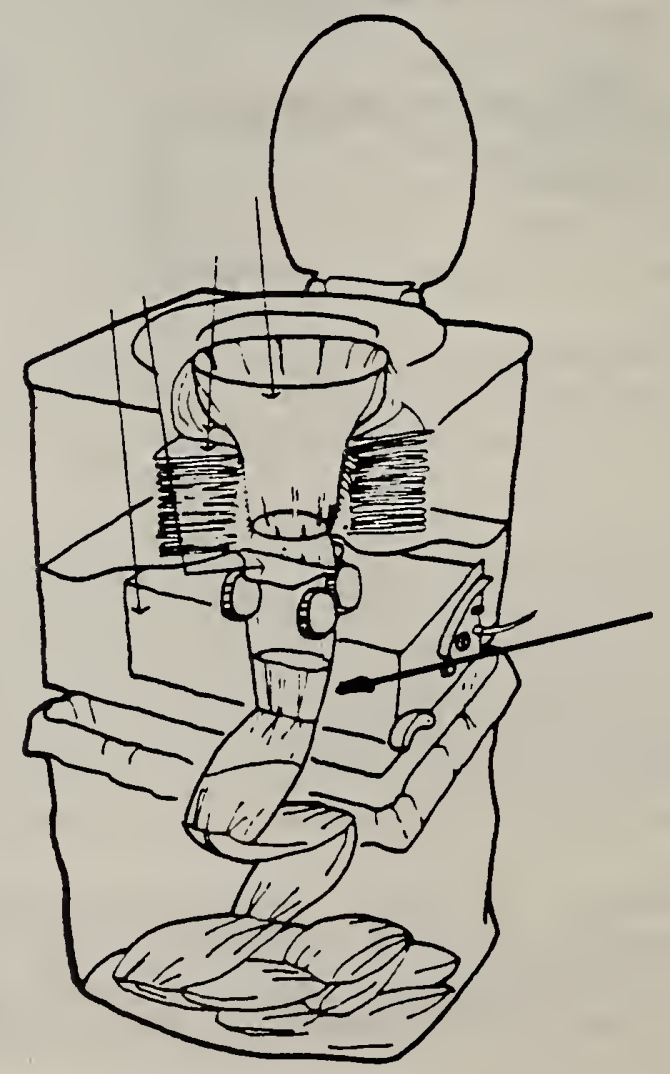

Packaged Wastes

\section{Figure 6}

Packaging Toilet 
termination of the previous incineration occurred. The systems reviewed require a plastic liner which must be placed in the bowl before usage. cost of this plastic liner is approximately 8c-per usage.)

(The

Packaging Toilets (Fig. 6) Packaging toilets are used in Sweden and Norway in recreational areas and summer homes. A long plastic foil is placed in the toilet. The wastes drop into this foil and are sealed by heat to form leakproof sausage-like packages. Fourty usages are available for one continuous foil, after which a new cassette is placed in the toilet. The electrical requirements for the system amount to one kilowatt hourzfor 3400 packaging operations. Provisions must be made for the disposal of the packaged wastes.

Freezing Toilets Freezing toilets are in use in Norway. The toilet contains a 6 gallon bag to store the wastes which are kept frozen and consequently produce no odors. The heat removed as part of the freezing process is transferred to the seat for the user's comfort. Provisions must be made for the disposal of the wastes.

Suds Operated Toilets (Fig. 7) The suds operated toilet, a Japanese invention, operates on a principle of constant release of a foaming surfactant to obtain cleansing of the bowl. This material, claimed to be biodegradable, is stored in a small tank located on the toilet and is used for continuously sudsing the rear section of, the bowl. Flushing takes place upon pushing a button to actuate an electro-magnetic foaming device to completely cover the toilet surface with suds; the "foam" solution continues to flow down the toilet and seals off odor by filling the space around a synthetic rubber flap valve (in lieu of a water filled trap). In its external features this plastic toilet which requires one cup of water per flush, is similar in appearance to a regular water closet. The toilet may be installed in an apartment building requiring no venting since there is no water trap seal. The installation uses a special holding tank which contains a hopper which collects the wastes and all grey water is piped into that holder. When the wastewater in the hopper reaches about two gallons, the hopper is tilted and evacuates the contents into the drain pipe with sufficient water sweeping. This system has been used in Japan successfully according to the manufacturer's claim.

Vacuum Toilets Sewage System (Fig. 8) This system consists of a uniquely designed toilet, drainage system, vacuum pumps, and a vacuum collecting tank. The system is maintained at a partial vacuum of $380 \mathrm{~mm} H$. The toilet contains a mechanism where by flushing takes place with the opening of the drainage line, and drawing water and contents of the bowl by suction to the tank. The toilet requires two quarts per flush. The system has its advantages in its substantial reduction of water and its independency of topography since the transport medium is by vacuum action as compared to the conventional gravity fed sewer system. Its shortcomings are in its dependency on maintaining vacuum, generation of high noise level at the time of the toilet's flush, succeptibility to blockages due to the small diameter of the drainage system and succeptibility to failure of the flush valve due to its complex, intricate mechanism. 


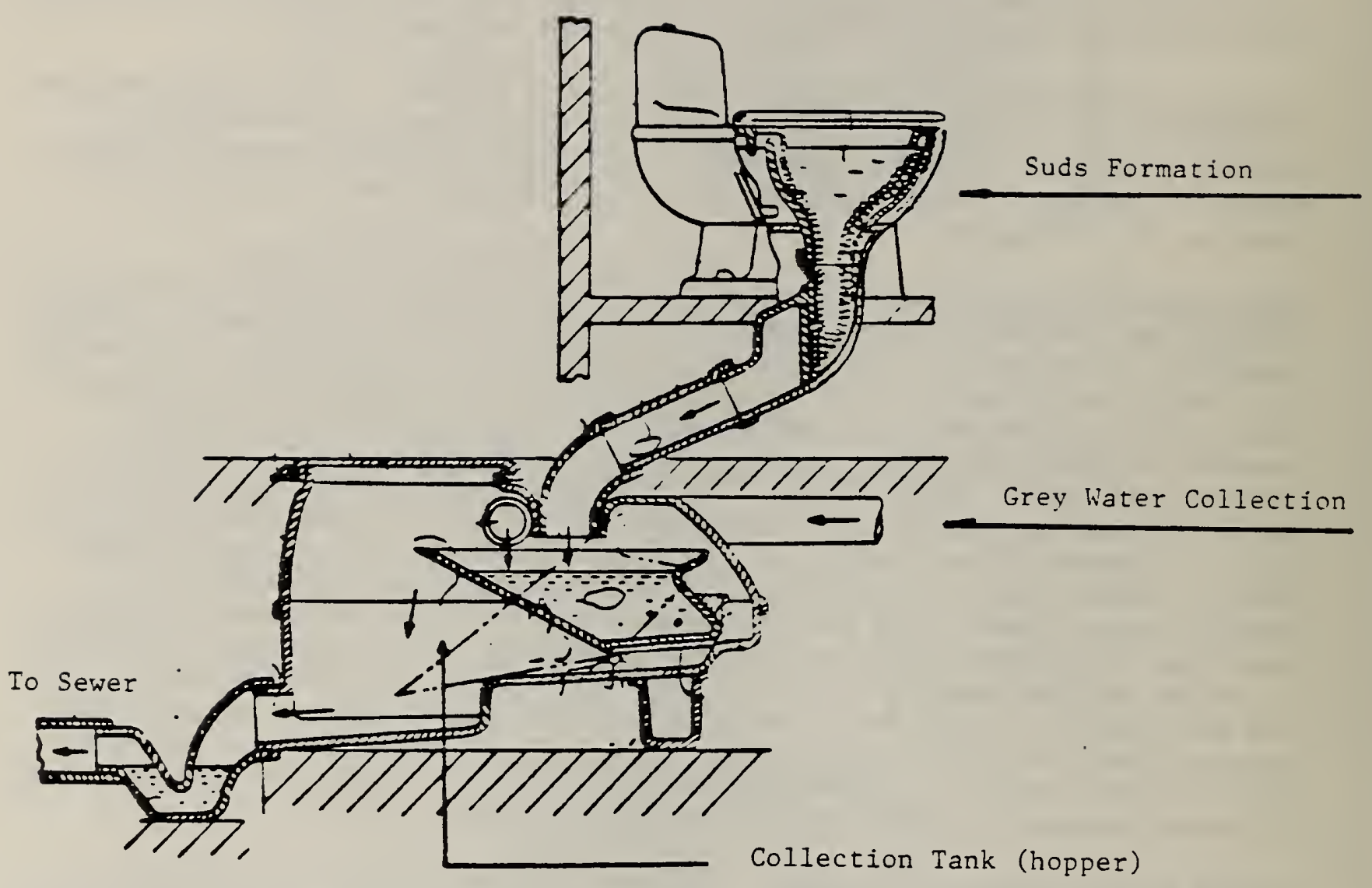

Figure 7

The Suds Water Closet 


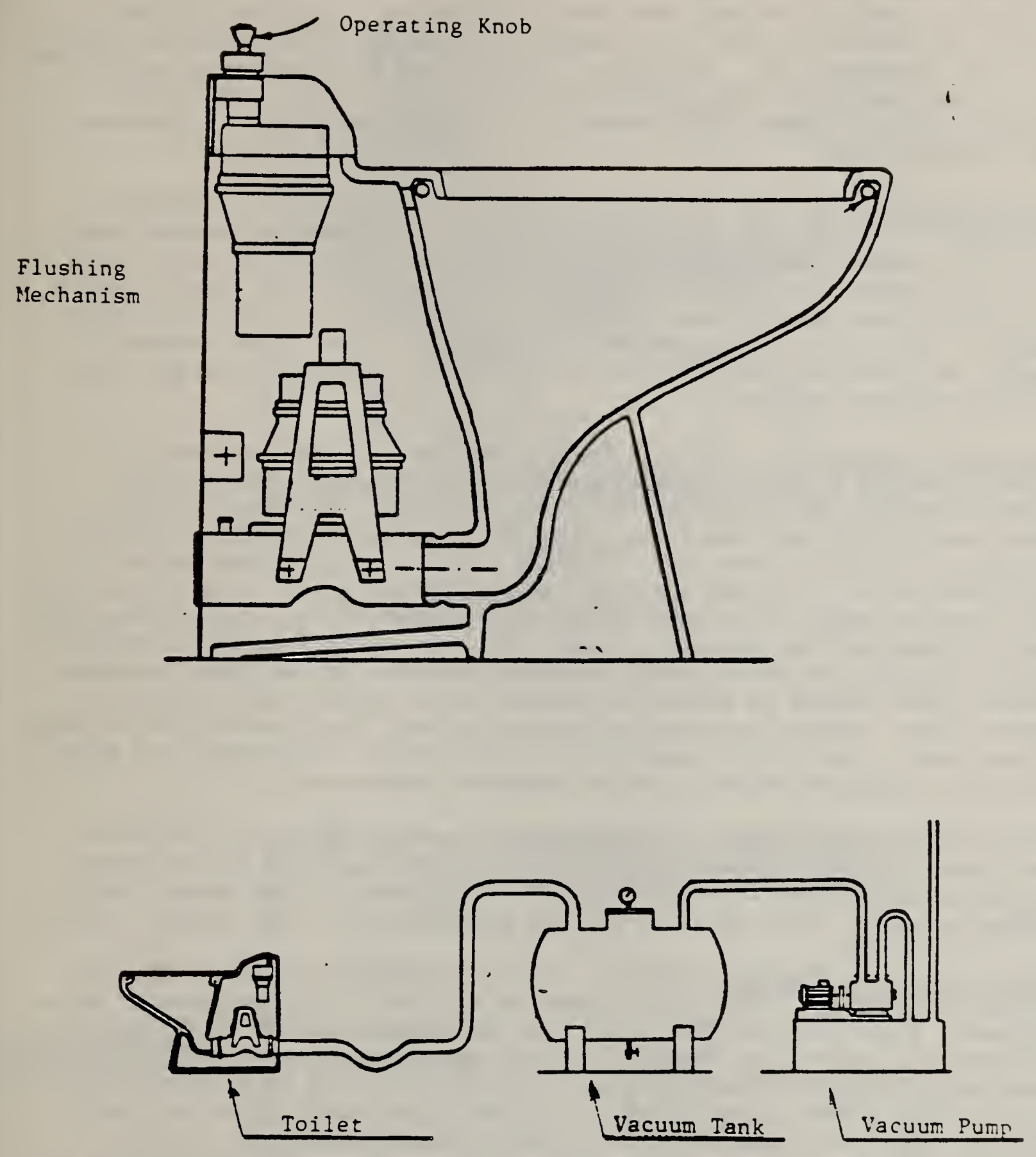

Figure 8

Vacuum Toilet System 
The Microphor Toilet (Fig. 9) This toilet uses two liters (a half gallon) of water per flush, and operates with the following flush cycle: Upon actuating the flush mechanism, a flapper valve in the toilet opens and the wastes with the initial water in the bowl drop into a chamber at a low point in the toilet. The chamber is then air pressurized to 50 psi from a pressure tank and forces the wastes out. The cycle is terminated with the water seal trap refill. The components of the system are: a ceramic toilet similar in appearance to an ordinary water closet, an actuating mechanism, a compressor and a pressure tank.

lacerator Toilet (Fig. 10) The flush cycle is initiated upon depressing a flush button. A pump creates vacuum in the system to draw the wastes into the toilet chamber, where maceration of the solids by a cutting wheel takes place. The slurry is then evacuated through a small one inch pipe through a two inch trap seal down stream. The system requires one and one-half liters of water. The toilet housing resembles a compost toilet in its external features and contains a stainless steel bowl under which the macerator pump and waste trap are situated.

Pressurized Tank Toilet (Fig. 11) Pressurized tank toilets operated by a compressor system or utilize the pressure of the household water supply thereby increasing the available energy for flushing, as compared to the conventional toilet tank where the available potential energy is a function of the head of water in the tank. Several toilet configurations are at present available. A system observed has an ordinary bowl. With the pressurized compressor tank, the toilet requires only eight liters (two gallons) per flush. A Canadian firm markets a plastic toilet. Aside from its tank which is pressurized by the water supply existing pressure, it has other features such as a flush nozzle to direct the wastes to its outlet and a chamber to which the water and wastes enter before evacuation. The chamber also contains the seal trap. This toilet requires only four liters (one gallon) per flush and has been approved by the Canadian Standards Association.

Two Step Flush Water Closet A mechanism is inserted in the conventional water closet tank which enables selective flushing of either all the water contents in the tank or a partial quantity: according to the needs, thus enabling saving of water up to 40 percent as compared to the ordinary toilet.

European Wash Down Toilets (Fig. 12) European Wash Down Toilets are used throughout the world. They usually require 9 liters ( $21 / 2$ gallons) of water per flush. A new type manufactured by Ifo in Sweden requires three liters (less than one gallon) per flush. European toilets operate on the principle of weir action where the water coming from the rim builds up a hydraulic head to create a weir action, contrary to the common American toilets which operate by syphonic action utilizing a large hydraulic head and a more effective flush resulting in a more superior cleansing action as compared to the flush down toilets. Syphonic toilets, however, require a larger quantity of water primarily for the inducement of the syphonic action. They typically require 19 liters ( 5 gallons) and the relatively new Water Saver types require up to 15 liters ( 4 gallons). 


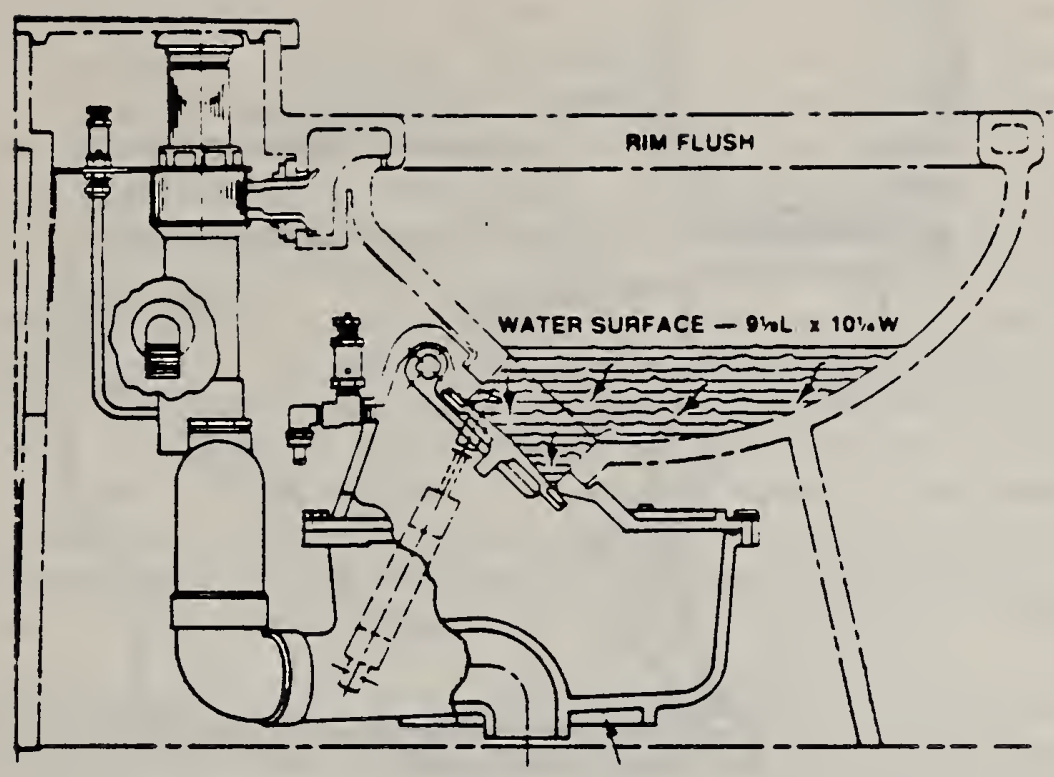

Figure 9

Microphor Toilet

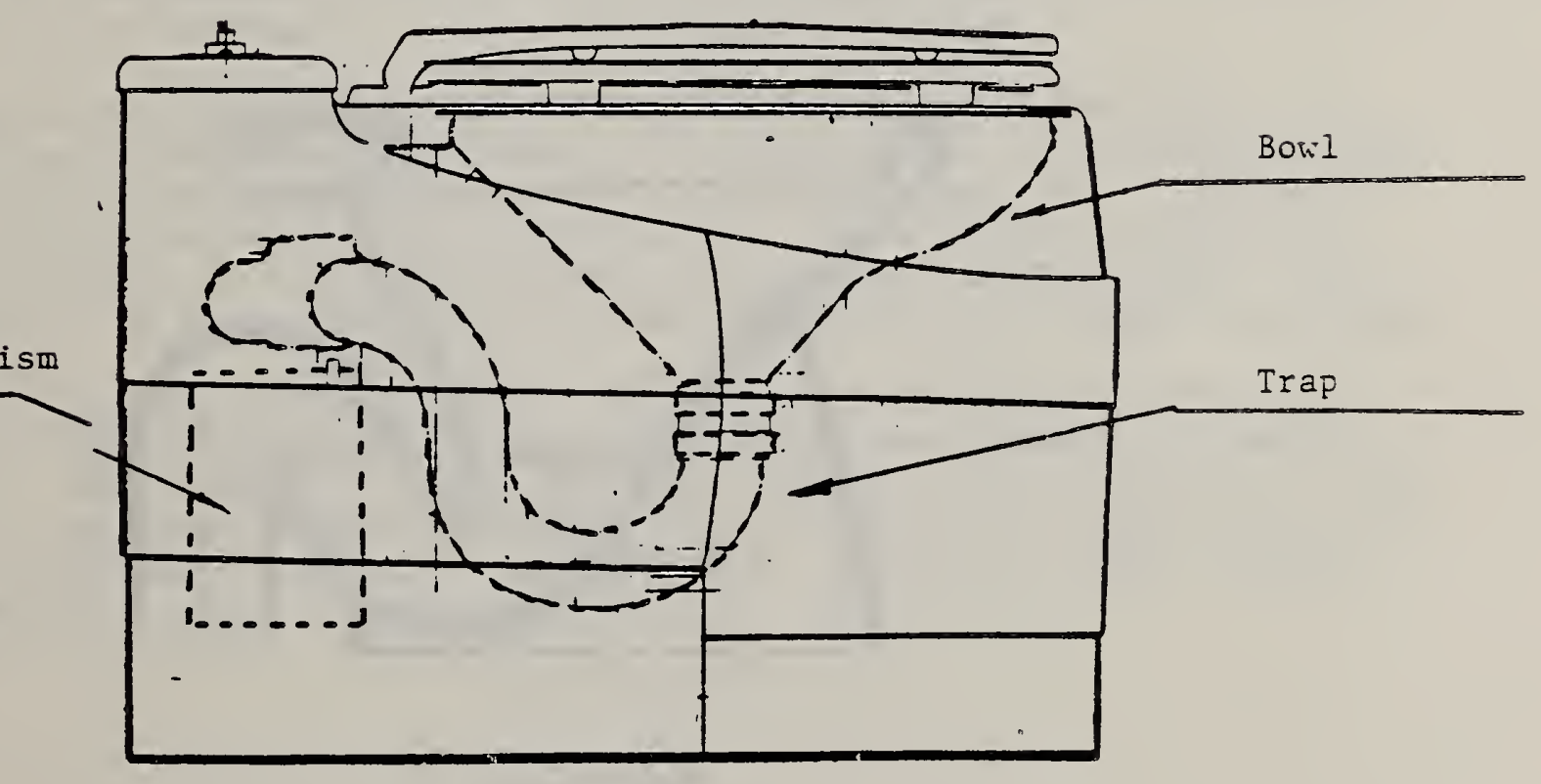

Figure 10

Macerator Toilet 


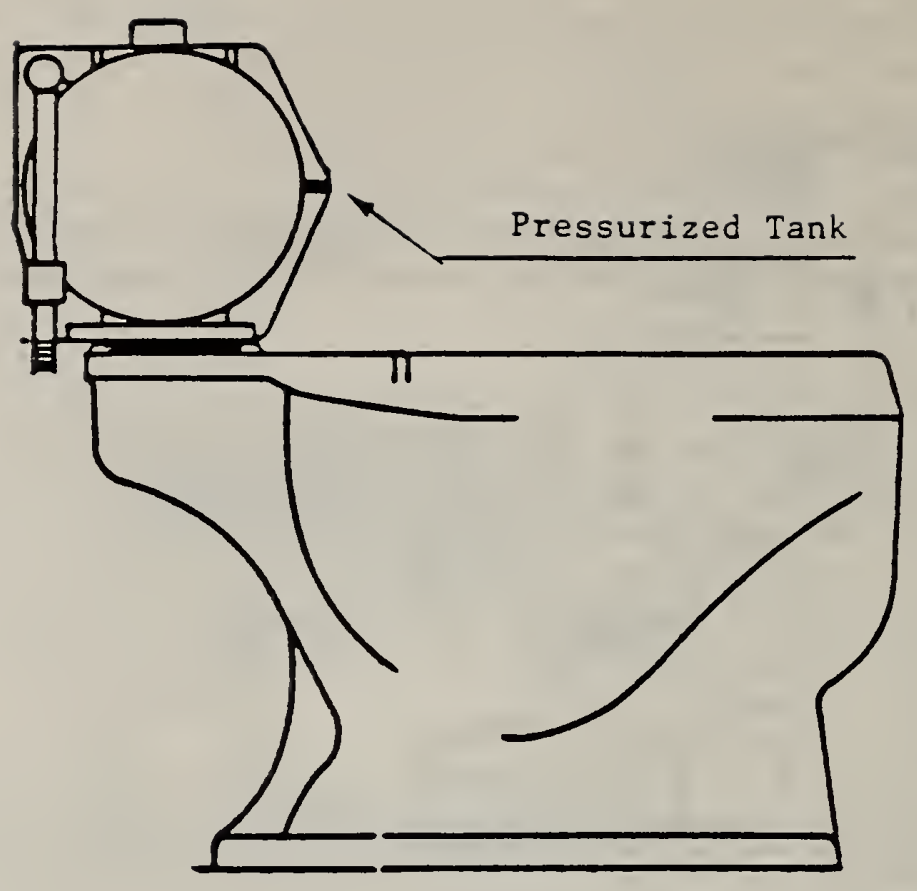

Figure 11

Pressurized Tank Toilet

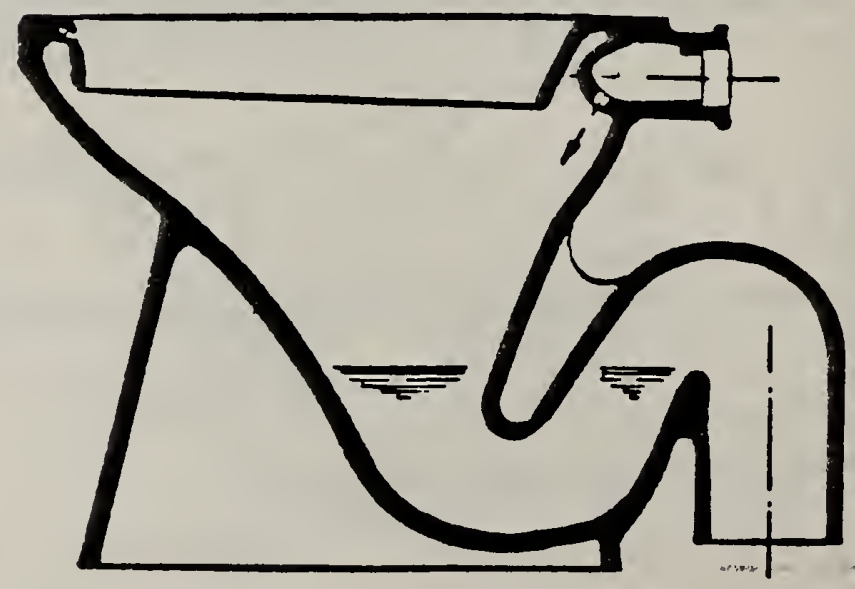

Figure 12

A Typical European Flush Down Toilet 


\subsection{Wastewater Treatment Systems}

Septic Tanks - Anaerobic Treatment System (Fig. 13) Septic tanks are the simplest onsite wastewater treatment systems in their design, installation, and operation. The primary purpose of the septic tank is to protect the soil absorption system from becoming clogged by solids suspended in the raw wastewater. This is accomplished by the design of the tank which provides a chamber for the retention of the settleable and floatable material; and affects the outflow of relatively clear effluents to the soil absorption field. The anaerobic environment in the tank enables the decomposition and partial treatment of the wastewater by the anaerobic organisms which naturally thrive in the wastewater influents. Most tanks have a similiar construction and they vary primarily by their size, which in all codes in the country is determined by the number of the bedrooms in the house. The septic tank is the most economical means of onsite wastewater treatment and functions adequately provided the soil underlying the absorption field has the properties for acting as a wastewater filtration medium and for handling the wastewater hydraulic loading.

Aerobic Treatment Units (Fig. 14) Aerobic wastewater systems decompose the wastewater pollutants by aerobic microorganisms. Aerobic systems of all forms have some mechanical means to maintain a level of dissolved oxygen thereby enabling aerobic organisms to thrive in their natural surroundings, feed on the wastewater nutrients and decompose the sewage. It has been established that among the pertinent parameters evaluated in wastewater systems the reduction in biochemical oxygen demand (B.O.D.), the aerobic process is more efficient as compared to the anaerobic process in septic tanks. It has been claimed and demonstrated that the soil absorption systems are better maintained when subjected to effluents from aerobic systems.

Flow Through Type Aerobic Units This is a simple form of aerobic treatment where air is continuously diffused in the wastewater chamber for maintaining a level of dissolved oxygen (D.O.) in the range of $2-3 \mathrm{ppm}$.

Batch Type Aerobic Units Several system configurations are available. In principle the system contains process control devices for a 24 hour operating cycle which includes aeration, quiescent period and a pump out. This is a more efficient process as compared to the flow through type, in particular, for the prevention of solids carry over resulting in hydraulic surges. Its shortcoming is in its susceptibility to malfunctions of its control mechanisms.

Rotor Disc - Aerobic Units (Fig. 15) The system is composed of a shaft and a series of discs partially submerged in the wastewater which continuously rotates at a slow speed of $3 \mathrm{rpm}$. The discs provide a large contact area for bacteriological growth. Results indicate a high performance efficiency in the removal of wastewater parameters such as B.O.D., suspended solids, nitrogen and phosphates. 


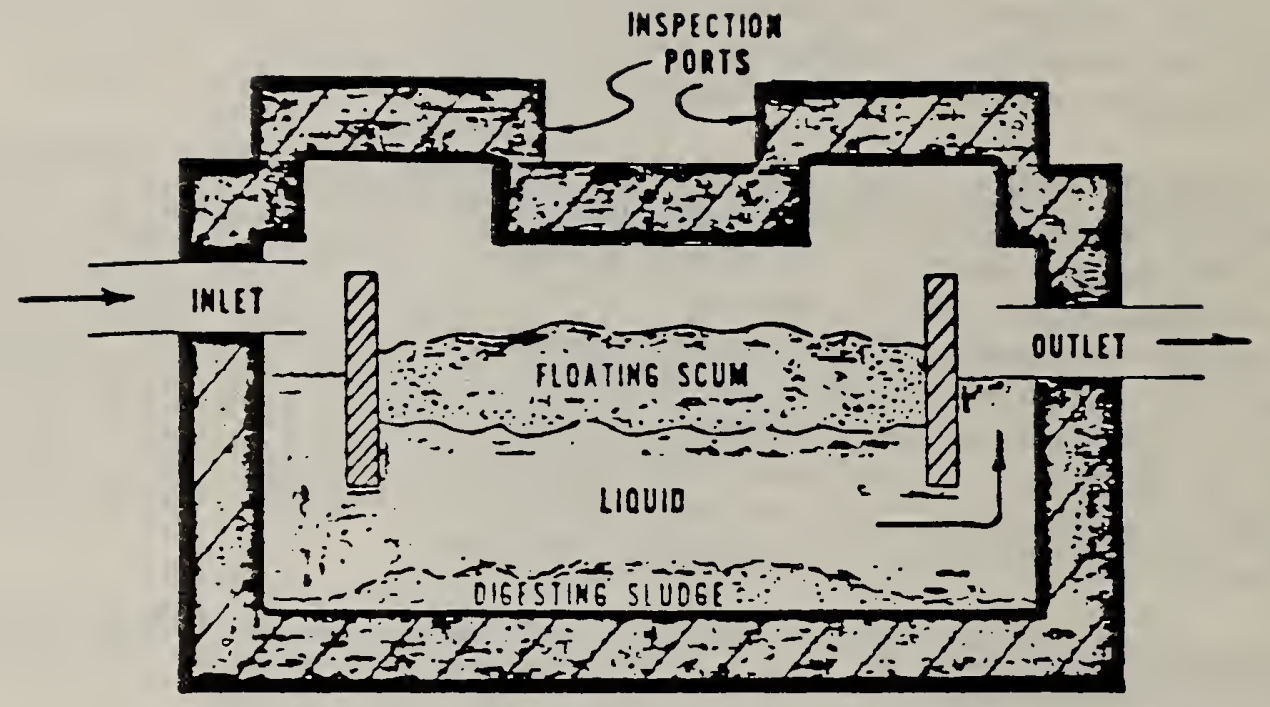

Figure 13

Septic Tank 


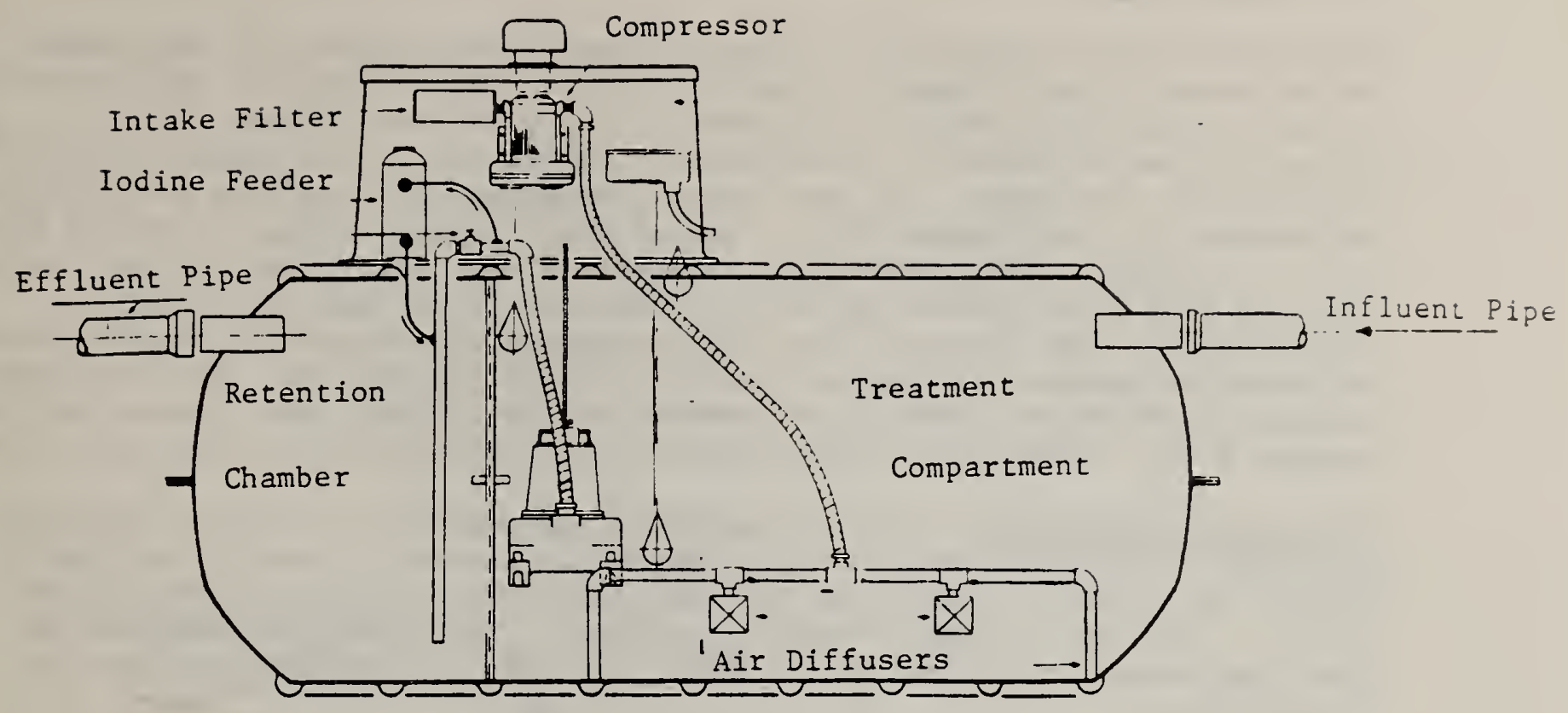

Figure 14

Aerobic Tank (Batch Type)

(Source: Eastern Environmental Controls Inc.)

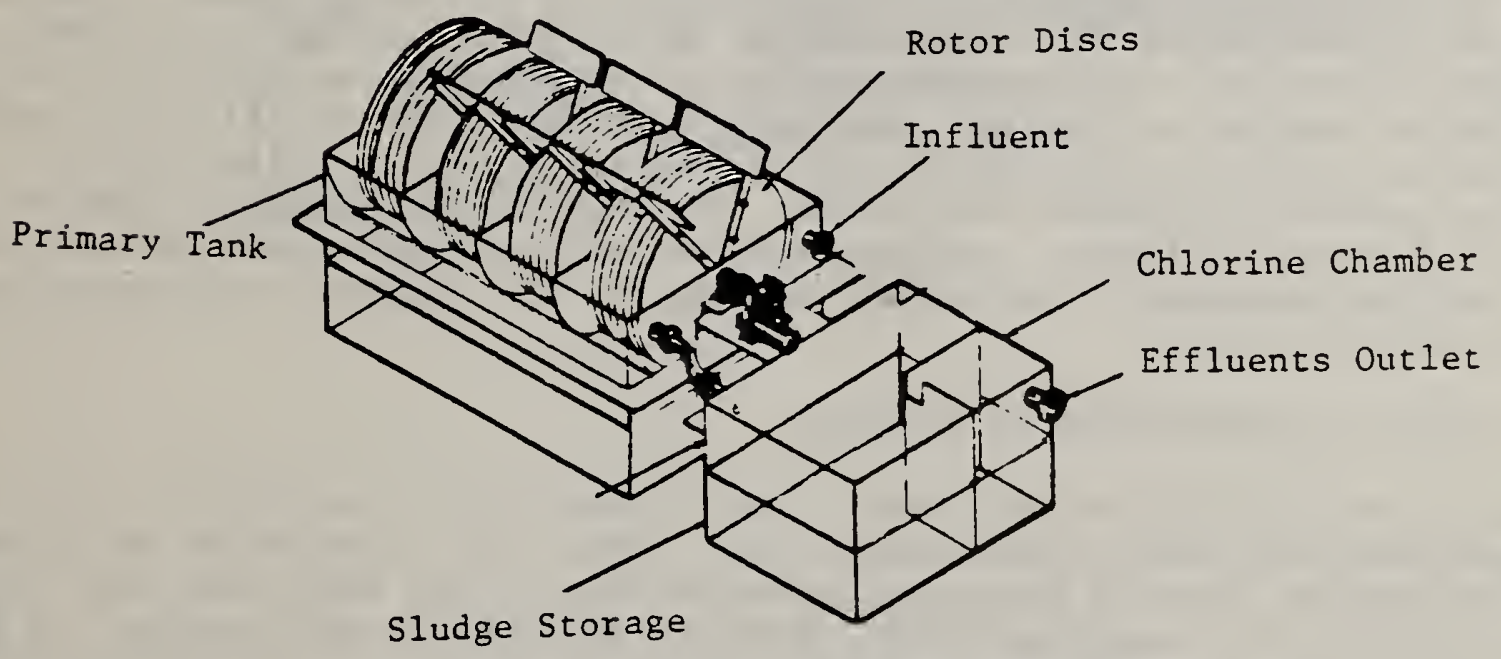

\section{Figure 15}

Rotor Disc Unit

(Source: CMS Rotor Disc) 


\subsection{Sand Filters}

Sand filters have been used as effective wastewater systems, in particular, for achieving a water quality acceptable for surface discharge. The treatment of the incoming wastewater is achieved in the upper sand layers where a biological mat is formed. The effluents leaving the filter undergo disinfection before final discharge. The most common parameter for measuring the filter's performance is the present B.O.D. removal which normally range in values from 75 to 95 percent. The predominant parameter of the filter are the sand grains size and size distribution defined as "effective size" and "uniformity coefficient." The effective size will determine the wastewater loading rates expressed in gallons per day per square foot (gal/day/sq. ft), the frequency of required maintenance, namely, the removal of the clogged upper layers and the present B.O.D. reduction. Several sand filter configurations have been in use.

The Buried Sand Filter $A$ bed is excavated and underlain collector pipes are installed. A layer $30 \mathrm{~cm}$ (1 ft.) of gravel is placed followed by a layer of sand $90 \mathrm{~cm}$ ( $3 \mathrm{ft.}$ ). Drain tile is then placed and covered by gravel $30 \mathrm{~cm}$ ( $1 \mathrm{ft.}$ ). The bed is then covered by top soil. The capacity of systems of that type range from three to six liters ( 0.75 to 1.5 gallons) per day per square foot.

The Recirculating Sand Filter (Fig. 16) The system consists of a septic tank, a sand filter and a recirculating tank. The wastewater from the septic tank flows to the recirculating tank from which it is pumped to the filter and recycled back to the recirculating tank. Thus, every quantity of wastewater makes several passes going from the recirculation tank and back to the filter reducing the level of pollutants in each cycle. It has been claimed, although data was not found in the literature, that the performance of this system as compared to an ordinary sand filter, is more reliable in delivering treated effluents of consistant degree of effluent quality.

\subsection{The Sewage Electro-Osmosis System (Fig. 17) The sewage electro-osmosis} system is constructed for increasing the infiltration rate of septic tank effluents into soils composed of heavy clays which otherwise would fail as wastewater absorption systems. As explained by its inventor [1], the system creates an electric field in the soil and by electrolysis, a dissociation of the water into hydrogen and oxygen. The hydrogen is liberated from the soil and sewage effluent. The oxygen in the soil maintains aerobic conditions for aerobic wastewater digestion in addition to the increase infiltration rate down the soil strada.

The system is constructed as follows:

Adjacent and parallel to the trench line, a hole $120 \times 60 \times 90 \mathrm{~cm}(4 \times 2 \times 3 \mathrm{ft}$.) is prepared and filled with dolomite rock. This rock column makes up the anode of the system. Some 30 feet away, a second hole is dug and filled with carbon and $120 \mathrm{~cm}$ ( $4 \mathrm{ft.}$ ) graphite piles. This column makes up the cathode. In the electrolytic process, the oxygen flows towards the anode to the trench region. The system hardly requires any maintenance and proved to be very effective. Up to the present, these systems were installed only in the western states. 


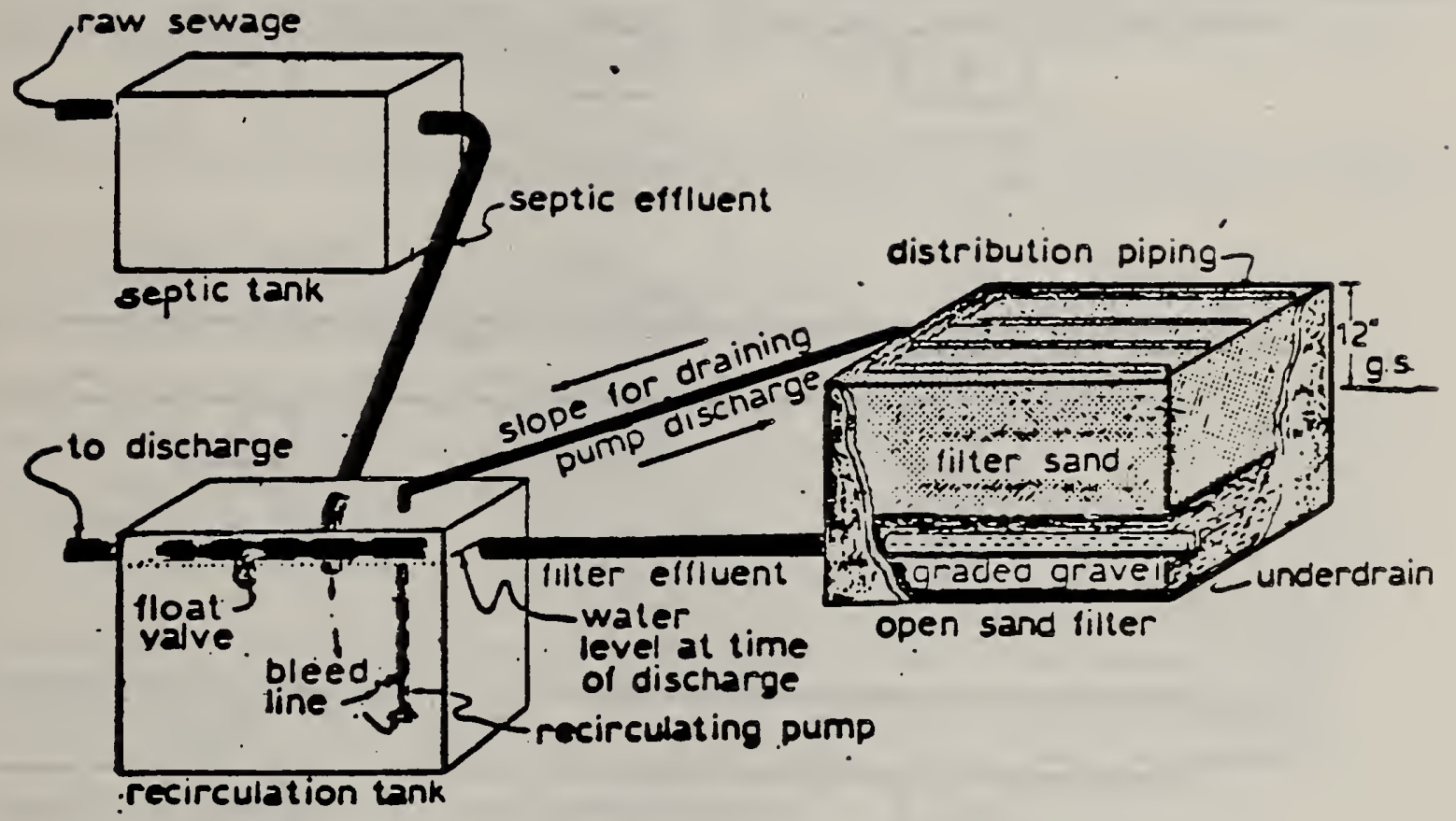

Figure 16

Recirculating Sand Filter 


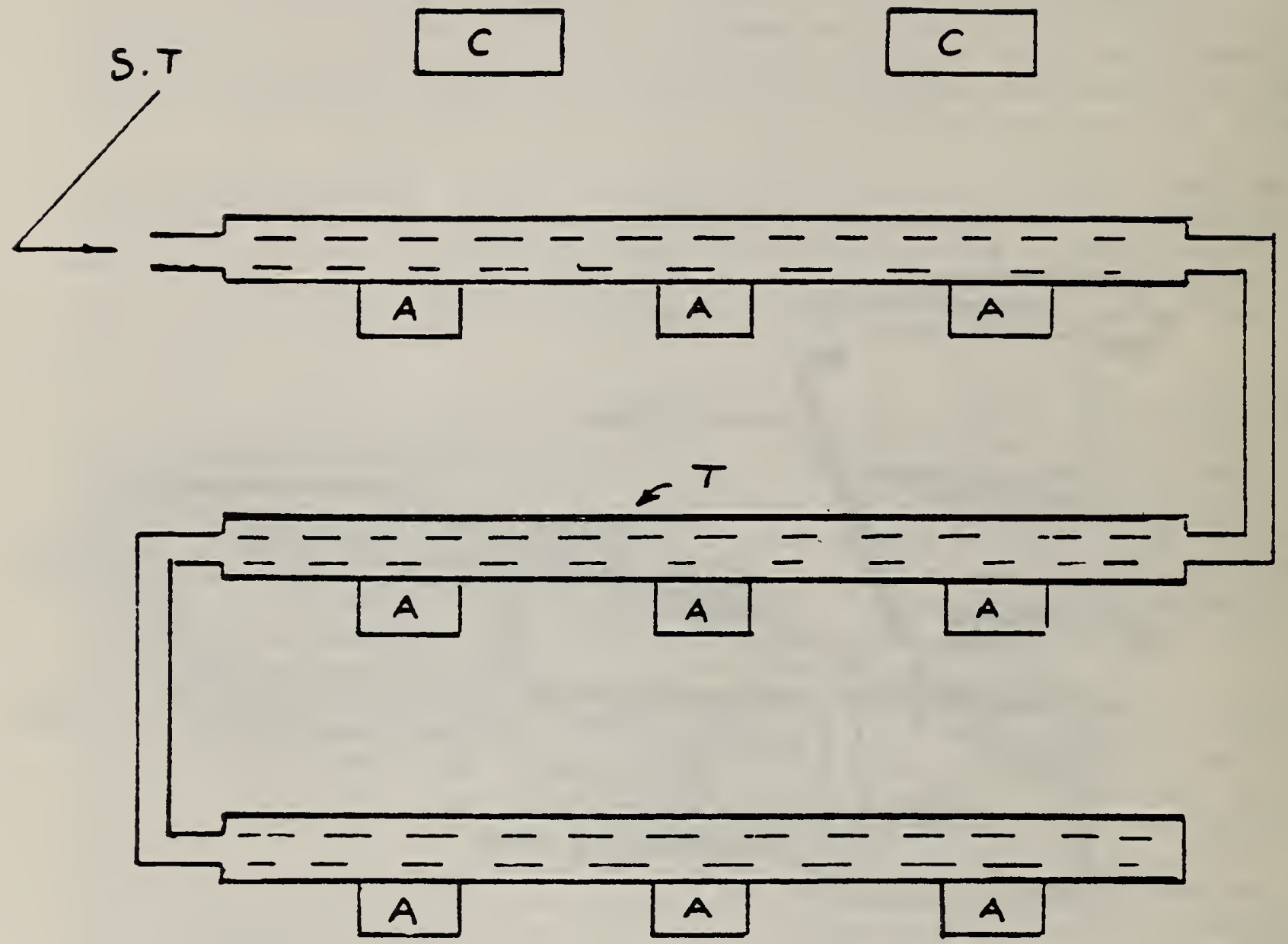

I: Leaching trench

A: Rock filled anode
C: Carbon filled calhode

ST: Effluents from septic tank

Figure 17

Sewage Electro-Osmosis 
Failure of septic tank systems usually manifests itself by seepage of the septic tank effluents to the ground causing the contamination of the ground water or sewage backup in the house plumbing because of soil clogging. System failure is then attributed to the soil absorption system rather than the septic tank itself. Thus, the soil absorption system should have the capability of handling the hydraulic loading in transporting the effluents into the ground and the capability to purify the effluents to some acceptable degree. If the underlying soil meets the above criteria, conventional septic tanks and tile fields work well, otherwise, the following alternatives are at present in use for soil absorption systems.

Multiple Alternating Soil Absorption Fields Soil clogging and crusting result from continuous wastewater loading. "Resting" of the clogged drain fields allows for at least a partial restoration of the soil absorption system to its initial permeability. A design of a multiple alternating fields which diverts the effluent intermittantly by a planned sequential schedule may restore and rejuvenate systems which otherwise would have failed.

The Mound System (Fig. 18) Mound systems have been in use for several years. They are constructed to meet the following problems in the existing soil stratum:

- Slowly permeable soils

- Shallow permeable soils over creviced bed rock

- Permeable soils with high water tables

The mounds are so designed and sized that they can handle the daily wastewater flows without surface outflow and that the basal area, which is the natural soil area beneath the mound will be sufficiently large to conduct the effluent into the underlying top soil. A clean medium size sand is used as the fill material and gravel is used in the trenches in which the perforated pipe network is laid. Top soil covers the upper zone of the mound. Best results are obtained with pressurized mounds where the effluents are pumped and injected under low pressures (2-3 psi). This assures even distribution of effluents throughout the mound.

\subsection{Wastewater Disposal Through The Atmosphere}

Evapotranspiration Beds (Fig. 19) Evapotranspiration (E-T) beds are designed for soils which are composed of very heavy clays where the percolation rates cannot meet the effluent hydraulic loads or in areas where no effluent soil infiltration is allowed. The beds are constructed by excavating an area to approximately two feet deep. The area is enveloped by a plastic sheet and filled with a layer of gravel, sand and top soil on which vegetation is grown. The operation of E-T systems may be critical as it relies totally on the balance between the incoming effluent loads, precipitation and evapotranspiration which consists of transpiration, the movement of water through the plants to the atmosphere and evaporation, the movement of water vapor from the soil to the air.

Mechanical Rotating Discs Evaporation This system is composed of a series of discs partially immersed in the effluents holding tank. The discs which rotate at a low speed provide a large surface area for evaporation. The 


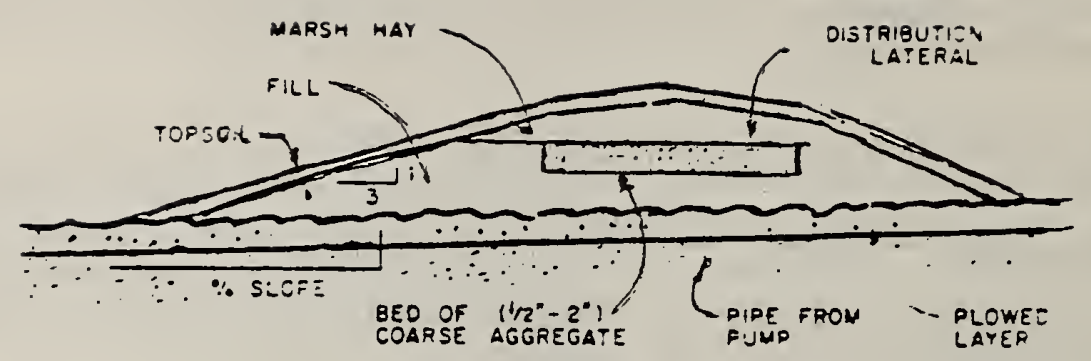

Figure 18

Mound System

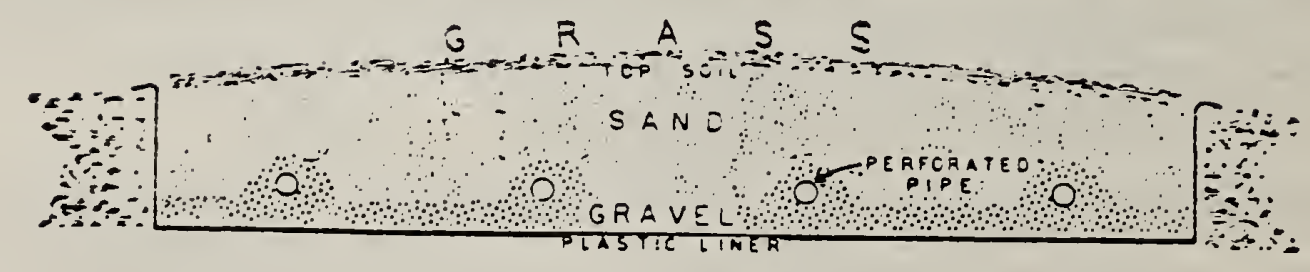

Figure 19

Evapotranspiration Bed (cross-section) 
diameter of the disc typically is six feet and the length of the total unit is 19 feet. As compared to E-T beds, this system requires a smaller area and is less dependent on precipitation. Being a mechanical system, its susceptibility to mechanical failures, in particular, breakage of the disc's shaft is the disadvantage of the system. This system is limited to regions where freezing conditions do not occur.

Surface Discharge-Spray Irrigation Surface irrigation as a means for disposal are used by more than 1300 sewage treatment plants throughout the country and were also observed in individual onsite wastewater systems. The application of this method is also dependent on the infiltration rate of the surface layer, slope and depth of water table. Important consideration must be given to the spread of microorganisms through the air as an aerosol or the deposit on plants and vegetable, therefore, spray irrigation is usually preceded by disinfection. Positive use of irrigation is attained by the utilization of the dissolved nutrients in wastewater for the benefits of the irrigation crops.

\subsection{Lagoons}

Lagoons are used for treating effluents of small communities. Lagoons are classified according to their mode of operation. Oxidation ponds are dependent primarily upon photosynthesis for maintaining an oxygen content in the effluents. Aerated lagoons operate by aeration with mechanical means. Anaerobic lagoons digest the wastewater effluent by anaerobic processes. For onsite systems, aerated lagoons are probably most suitable. Lagoons require maintenance and observation as their ongoing processes are very much dependent on climatic changes which effect their microorganismic ecosystem and consequently, the mode and degree of the wastewater treatment.

\subsection{Wastewater Recycling and Reuse Systems}

\section{Black Water Recycling for Toilet Flush Water Reuse}

Several publications report on self contained recirculation toilets. No prorietary product of relatively simple hardware was found on the market. McGill University has done research on wastewater recirculating toilets where the wastewater decomposition would be accomplished by continuous aeration, however the results were not satisfactory. It is probably difficult to attain a reliable system with that mode of operation unless advanced and expensive hardware is incorporated.

Black and Grey Water Recycling for Toilet Flush Water Reuse Only one wastewater package designed to treat black and grey water to a quality which is appropriate for effluent recirculation was observed in operation. The system entails three basic components to carry out the processes, ultra filtration for the removal of fine suspended particles and a water polishing process for disinfection by a U/V light and carbon treatment for the removal of odor. The system produces a very clear effluent with extremely low turbidity. (See Field Trip No. 16). 
Grey Water Recirculation for Toilet Flush Water Reuse (Fig. 20) Several systems are available. The mode of operation is similar in all the presently available types and involves the collection of all the housenold grey water into a holding tank (except for the kitchen sink wastes) filtration and disinfection by iodine or chlorine. The system includes back flow prevention devices to guard against grey water flowing to the potable water supply, overflow to the drainage system and stand-by provisions from the water supply source, should the recycled grey water be depleted. This type of treatment is probably adequate from a health stand point, however residues of particles remain unfiltered and causes turbidity of visible magnitude, in the recycled water in the water closet bowl which has a greyish appearance (as observed in the field trips).

Total Wastewater Treatment - Recirculation and Reuse for Potable Water Only one system which treats wastewater to the degree rendered to be of potable quality was reviewed and observed in operation. Details on the processes are in Field Trip Report No. 19. At present the company manufactures one model for single family homes only. The system utilized advanced technology including microprocessing for monitoring. The quality of the water produced is high and from the data observed, meets and surpasses the requirement of any known code. The cost of this system is relatively moderate, however, the company will construct this system subject to the condition that at least 150 individual units are built in a radius of 50 miles. In that case a center is formed from which servicing, operation and maintenance are provided. 


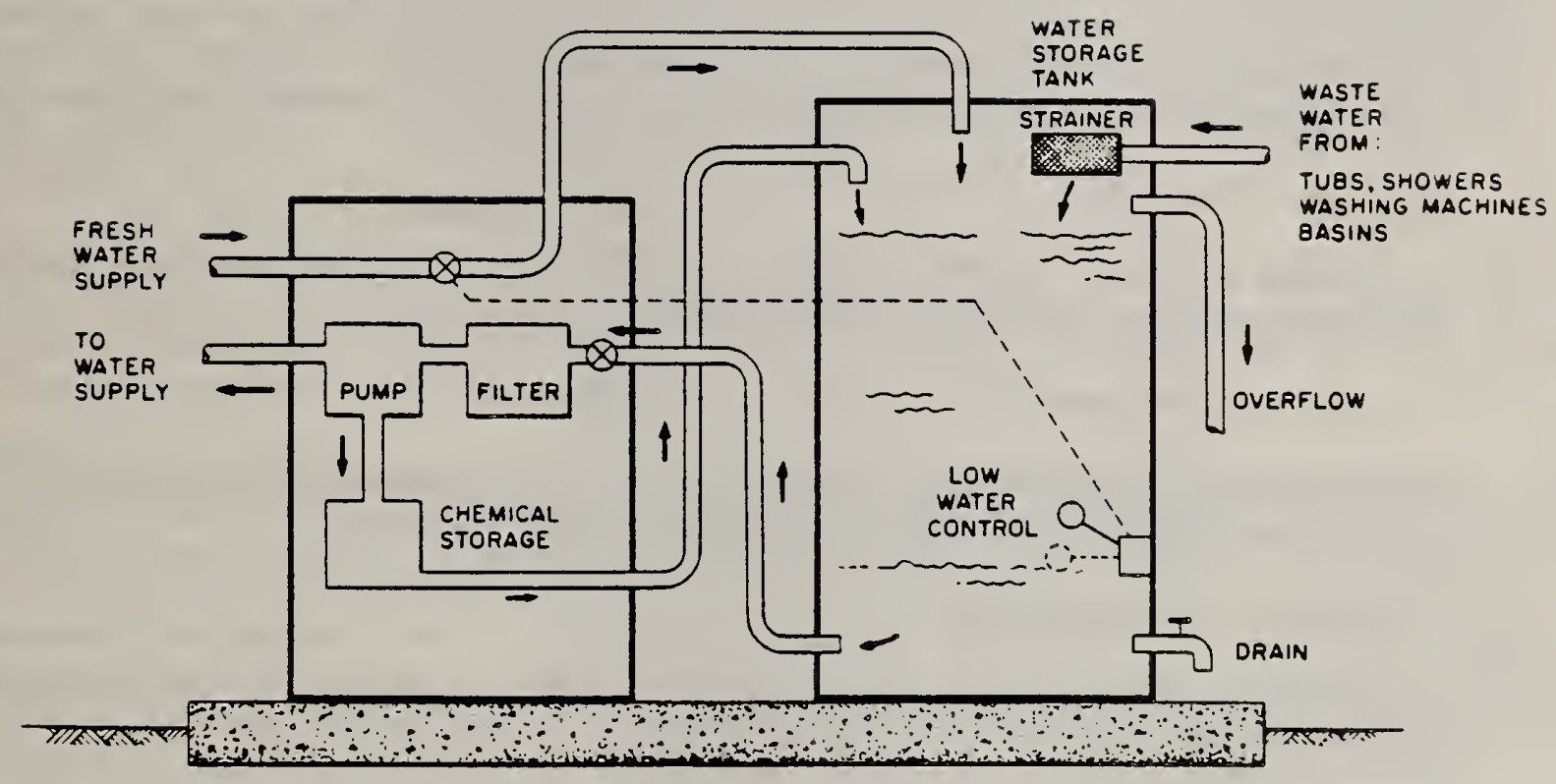

Figure 20

Grey Water Recirculation for Toilet Reuse

(Source: Aqua Saver) 


\subsection{Performance Criteria}

Performance criteria for onsite systems must address the following requirements in order to attain acceptability by the regulatory bodies and the homeowners:

- Adequate Effluent Quality

- System Reliability

- Aesthetic Acceptability

- Simplicity

- Economic Feasibility

Specifications for the above requirements vary from system to system depending on both the intended functional performance of the systems and the local regulatory requirements. Several standards for specific systems exist such as NSF Standard 40 for individual aerobic wastewater treatment plants [2] and NSF Standard 41 for wastewater reuse systems [3]. The need for performance standards for all types of systems exists; however, as systems vary in design, intent of usage and configuration, it is more plausible to require test data from manufacturers on the capability of the system in the following categories:

1. Effluent Quality

Expected effluent quality from the system and range of critical values of the pertinent effluent parameters.

2. System Reliability

Mechanical reliability of the system and its components, susceptibility to stress and shock loading, means of system control.

3. Aesthetic Acceptability

Description of features which require special maintenance and change in user's habits.

4. Simplicity

Simplicity in operation and replacement of parts. Information should be provided whether the system is designed to be maintained by the homeowner, by an ordinary plumber, or requires a maintenance contract with the manufacturer.

5. Economic Feasibility

Cost of the system (i.e., of design, acquisition, construction, energy/ fuel, maintenance, replacement of parts). 
With the above performance information, a decision can be made as to the suitability of the system in meeting specific requirements such as water consumption, B.O.D. loading, turbidity, maximum cost, etc.

\subsection{Classification of Site Conditions and Rating of Onsite Systems}

Two considerations must be anticipated in establishing the basis for systems evaluation: They are

- Given the site conditions, what is the most appropriate system to be selected for the site?

- Given a wastewater system, under what site conditions will it function effectively?

This dual problem may be represented as in Table 1 where the horizontal entries list all the possible site conditions $\left(S_{1}, S_{2} \ldots S_{i}\right)$ and the vertical entries represent the available wastewater systems $\left(0_{1}, \delta_{2} \ldots 0_{j}\right)$ such that the figure $N_{i j}$ represent the rating of system $j$ as applied to site condition $i$. Such an undertaking, however, is too difficult to obtain as it involves too many considerations that cannot be expressed by one unique rating. The following tables are therefore constructed instead:

Table 2 lists the site conditions to be considered for onsite system installation. Table 3 lists the wastewater system's attributes to be considered for system selection. Three rating levels are ranked, for which " $A$ " is considered as "very favorable" and "C" regarded as "not favorable."

In Table 4, the ratings of the wastewater systems reviewed are presented. This scheme is very general. Some attributes such as "water saving" and "reduction in blackwater" can be quantified while most others are subject to judgement and qualitative assessment. In addition, each system must be viewed from its intended use perspective. A system may be too costly for an individual home; however, when applied to a multifamily setting or a cluster of homes it may be regarded as cost effective. For example, the reliability of Evapotranspiration $(E-T)$ beds was rated as " $B$ " in Table 4, E-T systems perform well in arid regions but are susceptible to failure in cold, high precipitation regions. As an illustration, the following information can be drawn from Table 4 on the vacuum toilet system: Relatively expensive, provides for about 50 percent in water saving, nearly 100 percent in black water reduction, poor record of acceptability, requires special construction considerations, and not acceptable by codes.

\subsection{System Selection Based on Site Conditions}

Table 5 lists some of the systems reviewed and identifies site conditions for which these systems are likely to perform adequately. 
$\underline{\text { Table } 1}$

- Matrix of Onsite Wastewater System Selection

vs. Site Conditions

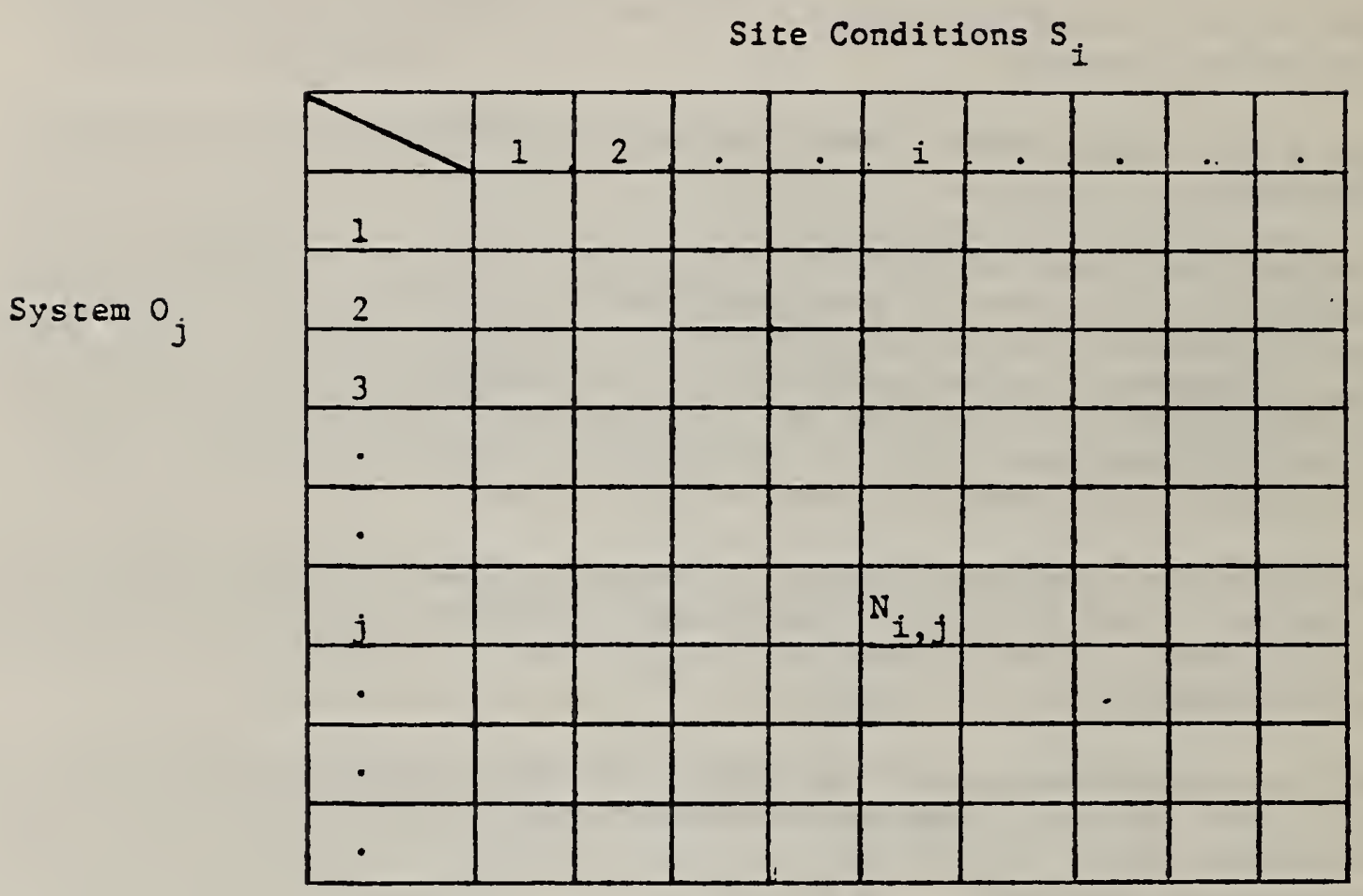


Table 2. List of Input Parameters for Onsite Wastewater System Evaluation

I. Geography - Climate

Cold, moderate, warm

Humid, dry

Precipitation: low, medium, high

II. Home Setting

Rural remote, rural, suburban, urban

III. Means of Wastewater Disposal

1. Degree of Disposal

No disposal, limited means for

disposal, available disposal

2. Point of Discharge

Ground, creek, potable body of water, recreational body of water, ocean, sewer

IV. Availability of Water Resources Water shortage, adequate water supply

V. Home Layout

1. Lot size

2. Lot topography

3. Soil conditions
Sma 11, medium, large

Level ground, moderately slop, steep

Slowly permeable soil, shallow permeable soil over bedrock, permeable soil with high watertable

VI. Demography

1. Population size (number of homes)

2. Family size

3. Population density

4. Population forecast
$1,2-5,6-20,20-100$, over 100 families

$1,2,4,8$

Sparce, moderately dense, dense

Decreasing, stable, increasing

VI. Population Background

1. Population income

Very low, low, medium, high

2. Population education

Low, medium, high

VII. Prospect for construction or

No prospect, connection to a central extension of a central system system in five years 
Table 3

Proposed Rating Criteria for Onsite Wastewater Elements

Parameter to be Rated

Rating Criteria

A

B

C

1. Economic Consideration- Cost Subject to:

- Initial cost, acquisition, shipment and installation

- Maintenance

- Replacement of parts

- Running cost

- Overhaul cost

- Disposal cost

- Energy recovery

Establish basis such as annual cost, from which relative rating is derived.

Low Cost Medium Cost

High Cost

2. Water Saving $100 \%$ $50 \%$ no saving

3. Reduction of Blackwater $100 \%$ $50 \%$ no reduction

4. Reduction of Greywater $100 \%$ $50 \%$ no reduction

5. User's Acceptance subject to: noise, odor, appearance, visitor's reaction

highly Acceptable acceptable reservations

questionable

6. Requirements for routine maintenance and service

Equivalent to

Equivalent

$5 \mathrm{~min} / \mathrm{month}$

to

Equivalent or less $20 \mathrm{~min} / \mathrm{month}$ to $1 \mathrm{hr} /$ month

7. Requirements for periodic system check

requirement once a once a System reliability subject to:

Safety, health hazard, susceptible to shock loads, dependability on specialized personnel, and month week

8. System reliability subject to availability of replacement parts.

9. Special requirements on design (to accommodate system)

$\begin{array}{cc}\text { Highly } & \text { reasonably } \\ \text { reliable } & \text { reliable }\end{array}$

questionable

10. Market Availability (system and parts)

11. Product stage of development

12. Code Acceptance no special requirements

$$
\text { readily }
$$
available

A consumer product

Accepted by most major codes
Some design considerations

Major design consideration

reasonably
available

May require 3 month wait

\section{Well developed} innovative system

Experimental

limited field data

\section{started}

gaining no acceptance 
Application of a Rating Scheme for Onslte Wastewater Elements

ATIRIBLTES

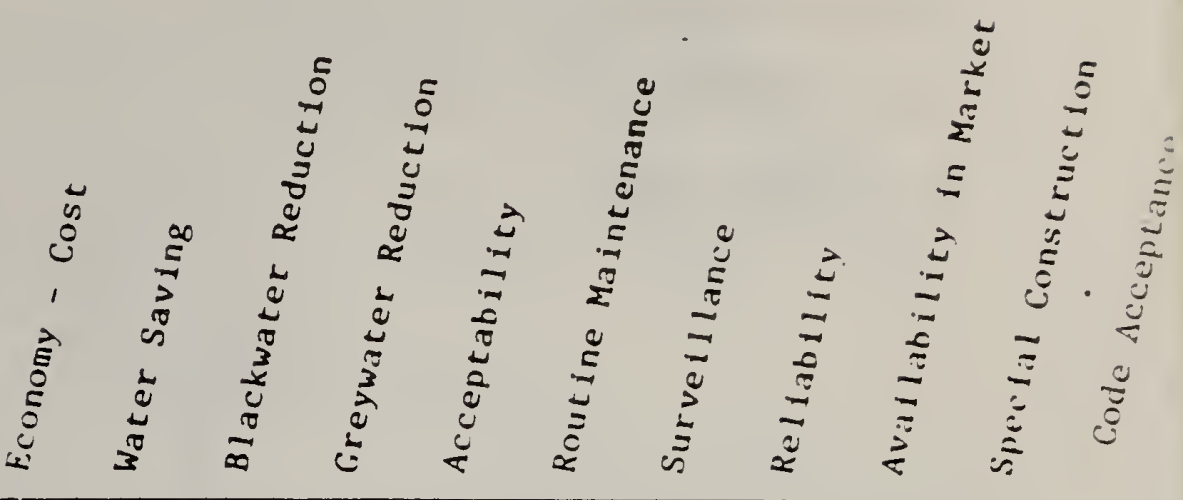

1. Compost Toilet - Large Volume

2. Compost Toilet - Small Volume

3. Oil Flush Toilets

4. Chemical Toilet

5. Microphor Toilets

6. Incinerating Toilet

Electricity Operated

7. Incinerating Toilet

8. Pressurized Tank Toilet

9. Packaging Toilet

10. Freezing Toilet

11. Vacuum Toilet

12. Suds Operated Toilet

13. Macerator Toilet

14. Dual Flush Toilets

15. Wash-Down European Toilet

16. Grey Water System for

Toilet Reuse

17. Total hastewater Systems, Toilet Reuse

18. Total Wastewater Systems, Total Reuse

19. Aerobic Units

20. Evapotranspiration Beds

21. Mounds

22. Spray Irrigation

23. Greywater Disposal by

Sand Filtration

\begin{tabular}{|c|c|c|c|c|c|c|c|c|c|}
\hline$B$ & B & A & - & B & B & $B$ & $A$ & $A$ & $C$ \\
\hline A & B & A & - & B & C & $C$ & B & $A$ & 8 \\
\hline$C$ & B & A & - & $C$ & $C$ & $C$ & $C$ & B & C \\
\hline A & $B$ & A & - & $C$ & B & A & A & $A$ & $A$ \\
\hline A & B & B & - & B & B & B & $A$ & $A$ & B \\
\hline C & B & $A$ & - & $C$ & B & B & $C$ & $B$ & $B$ \\
\hline B & B & A & - & B & B & B & B & B & B \\
\hline A & B & B & - & A & $A$ & A & A & C & B \\
\hline - & - & - & - & - & - & - & - & - & - \\
\hline- & - & - & - & - & - & - & - & - & - \\
\hline C & $B$ & $A$ & - & $C$ & $C$ & B & B & C & C \\
\hline - & B & A & - & - & - & - & - & C & $C$ \\
\hline A & B & A & - & B & $A$ & A & $A$ & B & $A$ \\
\hline A & B & B & - & A & A & A & B & C & B \\
\hline A & B & B & - & $A$ & A & A & $A$ & $A$ & $A$ \\
\hline C & $B$ & C & - & B & A & B & B & C & $A$ \\
\hline$C$ & B & A & - & B & B & B & A & $B$ & B \\
\hline C & A & A & A & B & B & B & B & C & C \\
\hline B & C & $C$ & C & B & B & B & B & $A$ & $A$ \\
\hline B & C & A & A & B & $B$ & B & $B$ & B & C \\
\hline B & C & A & $A$ & B & B & A & $A$ & B & $C$ \\
\hline A & $B$ & A & $A$ & B & B & B & $B$ & B & $A$ \\
\hline A & C & $C$ & A & A & B & B & $A$ & B & $B$ \\
\hline
\end{tabular}




\section{Table 5}

Site Conditions Appropriate to the Onsite Wastewater Devices

\begin{tabular}{|c|c|}
\hline SYSTEM & $\begin{array}{l}\text { SITE CONDITIONS FOR WHICH SYSTEM } \\
\text { MAY BE CONSIDERED APPROPRIATE }\end{array}$ \\
\hline $\begin{array}{l}\text { 1. Compost Toilet - } \\
\text { Large Volume }\end{array}$ & $\begin{array}{l}\text { Climate: moderate, warm (cold may be considered) } \\
\text { Home Setting: rural, rural remote } \\
\text { Means of Wastewater Disposal: no means of } \\
\text { disposal } \\
\text { Availability of water resources: water shortage } \\
\text { Home Layout: } \\
\text { Lot Size: small } \\
\text { Lot Topography: steep terrain } \\
\text { Soil Conditions: impervious, over bedrock } \\
\text { Demography: } \\
\text { Population Size: } 1 \text { family } \\
\text { Family Size: 1-10 } \\
\text { Population Density: sparse } \\
\text { Population Educational Level: high }\end{array}$ \\
\hline $\begin{array}{l}\text { 2. Compost Toilet - } \\
\text { Small Volume }\end{array}$ & $\begin{array}{l}\text { Same conditions as in } 1 \text { except: } \\
\text { System restricted to } 3 \text { users }\end{array}$ \\
\hline 3. Oil Flush Toilet & $\begin{array}{l}\text { Application for Homes: questionable } \\
\text { System is designed for public use (highway } \\
\text { rest areas) }\end{array}$ \\
\hline 4. Chemical Toilets & $\begin{array}{l}\text { Application for Homes: questionable } \\
\text { System is designed for mobile homes, and } \\
\text { public facilities. May be used for a } \\
\text { temporary arrangement to accomodate } 1-4 \\
\text { people. }\end{array}$ \\
\hline 5. Microphor Toilets & $\begin{array}{l}\text { Means of Disposal: limited means of disposal } \\
\text { Availability of Water Resources: water shortage } \\
\text { Soil Conditions: slowly permeable soil }\end{array}$ \\
\hline
\end{tabular}


Table 5 (continued)

\section{SITE CONDITIONS FOR WHICH SYSTEM \\ MAY BE CONSIDERED APPROPRIATE}

SYSTEM

6. Incinerating Toilets Electricity Operated
Home Setting: rural

Means of Disposal: no disposal, ground water only Availability of Water Resources: water shortage

Home Layout:

Lot Size: small

Lot Topography: steep

Population Density: sparse
7. Incinerating Toilets Gas
Same as 6 , and may be preferred as its incinerating efficiency is higher
8. Pressurized Tank Toilet
May be applied anywhere with the potential of water saving of $40 \%$ of toilet use water

May serve an apartment house
9. Packaging Toilet

10. Freezing Toilet

11. Vacuum Toilets
Information on the systems performance was not obtained

The systems serve summer homes in Sweden and Norway

Home Setting: urban

Means of Disposal: limited means of disposal

Availability of Water Resources: Water shortage

Home Layout:

Lot Topography: very steep terrain

Demography:

Population Size: 100-200 families

Population Density: very dense

Population Background:

Note: System may require a high degree of maintenance
12. Suds Operated Toilet

13. Macerator Toilet
Means of Disposal: total disposal Availability of Water Resources: water shortage

Means of Disposal: total disposal Availability of Water Resources: water shortage 
Table 5 (continued)

SITE CONDITIONS FOR WHICH SYSTEM

SYSTEM MAY BE CONSIDERED APPROPRIATE

14. Recirculating

Toilet
Means of Disposal: grey water only

Availability of Water Resources: water shortage

15. Dual Flush Toilet

Potential Water Savings $40 \%$ (black water)

16. Wash Down European Toilet

Potential Water Savings 50\% (black water)

17. Grey Water Systems for Toilet Reuse

18. Total Waste Water System for Toilet Reuse
Means of Disposal: total disposal

Availability of Water Resources: water shortage
19. Total Wastewater System for Total Reuse

20. Septic Tank - Mound System
Means of Disposal: no disposal

Availability of Water Resources: water shortage

Home Layout:

Lot Size: smal1

Lot Topography: steep terrain

Soil Conditions: impervious over bedrock

Demography:

Population Size: 6-20

Population Density: moderately dense to dense
Same site conditions as for 18. May be suitable for very severe water shortage areas.

Home Setting: rural remote to suburban Degree of Disposal: total disposal

Point of Discharge: ground Availability of Water Resources: adequate Home Layout:

Lot Size: moderate

Lot Topography: level to moderately slopy

Soil Conditions: slowly permeable shallow permeable permeable with high water table 
Table 5 (continued)

SITE CONDITIONS FOR WHICH SYSTEM

SYSTEM

MAY BE CONSIDERED APPROPRIATE

21. Aerobic Tank -

Same as system 20. Aerobic system may be more Mound

efficient in delivering effluent to the mound

of higher quality

Comparison between system 20 and 21 needs further study

22. Aerobic Tank -

Geography-Climate: low to moderate precipitation E-T Bed

Means of Disposal: no means of disposal

Availability of Water Resources: moderate

Home Layout:

Lot Size: medium, large

Lot Topography: level ground

Soil Conditions: impervious or when no

Demography:

percolation is mandatory

Population Density: sparse to moderately dense

23. Grey Water Disposal

Used in conjunction with composting toilet

System by Sand systems where the grey water

Filtration and

Disinfection 
The causes of wastewater project shortcomings and failures as discussed in Appendix D are summarized:

- Insufficient data collection and site evaluation prior to the project start.

- Improper choice of system.

- Small size of sample (for conclusion drawing).

- Improper system design.

- Inadequate maintenance program.

- No immediate benefits to the homeowner from the project.

- No concern by the homeowner in the project.

- Insufficient time allocation for the duration of the project.

Based on these observations the following requirements are recommended for demonstration projects of innovative wastewater installations.

1. Establish Specific Objectives to Specific Problems

The demonstration project objectives should be specified in an explicit manner and call for solutions to specific wastewater problems to specific site conditions.

\section{Allocation of Time for the Field Work}

A minimum of three years is recommended for the field study after installation work is completed and occupancy usage begun. The time periods at the site should be divided as follows:

- one year of extensive monitoring maintenance and sampling.

- two years of observation permitting the users to operate the system in a normal unmonitored manner, according to specifications, while visits and sampling are only randomly carried out.

\section{Preliminary Effort - Data Collection}

Data of performance of conventional systems installed in the same location or of location of similar conditions should be collected, if not already available, to enable comparison and final assessment of the project.

\section{System Specifications}

The project demonstration contractor must provide a comprehensive program plan to include the following elements:

\section{A. Test Program}

1. Criteria for testing and data gathering

2. Criteria for evaluating the quality of wastewater effluents 
B. Construction

Supervision of system construction

C. Maintenance, Monitoring, Sampling

1. Present a program for maintenance, monitoring and sampling procedures for the first year of the field demonstration.

2. Present a program for random visits and sampling for the last two years of the program.

5. Size of Test Samples (number of homes involved)

The demonstration project should be composed of a sufficiently large sample size consisting of units of the same type, such that a meaningful statistical inference can be drawn from the final results.

6. Appropriate Choice of Home Dwellers

An alternative waste disposal system is generally constructed to meet the following needs:

From the homeowner's needs: Eliminate nuisance, anguish and expense From the community's needs: Retain the integrity of the environment, maintain health and sanitary requirements.

From the legal aspect: Meet code requirements intended to serve both needs.

It is obvious that the three needs are interrelated; however, the individual homeowner may not have the same perception. An occupant/owner may let a system fail and dump partially treated wastes into a nearby creek as long as the house and its immediate environment are not affected. Depending upon the homeowner's educational background, attitude and personal habits, it will probably be found that all homeowners are concerned to various degrees with the first of the above mentioned aspects; fewer numbers of owners/occupants are concerned with the second aspect; the responsible officials and a very select few are concerned with the last item. As the success of the demonstration project is very much dependent on the homeowners attitude and cooperation, it is desirable to have homeowners or occupants of high concern to keep the system running and guard against any malfunction even when a threat to their immediate surroundings is not likely to happen. Generally, the site localities should be where higher educational backgrounds generate interests and motivation; however, sites with needs for innovative treatments may not always have that level in the population sample. It may be desirable to establish a policy whereby the homeowner will contribute some part in financing the capital cost of the project with later "rewards" as incentives to maintain interests. From the field inspection trips, it was found that systems built at the expense of the homeowners worked adequately, while many of the ones provided at no cost were failing or abandoned. 
Timetable for Wastewater Disposal System Demonstration

Table 6 outlines a possible schedule of tasks for a demonstration project. The first 27 months is the period of testing to establish the theoretical base for the performance of the system, and the last 27 months is the period of observation at which random visits are made. In the second period, the most information comes from the user's feedback, where actual field data is obtained for final evaluation. 


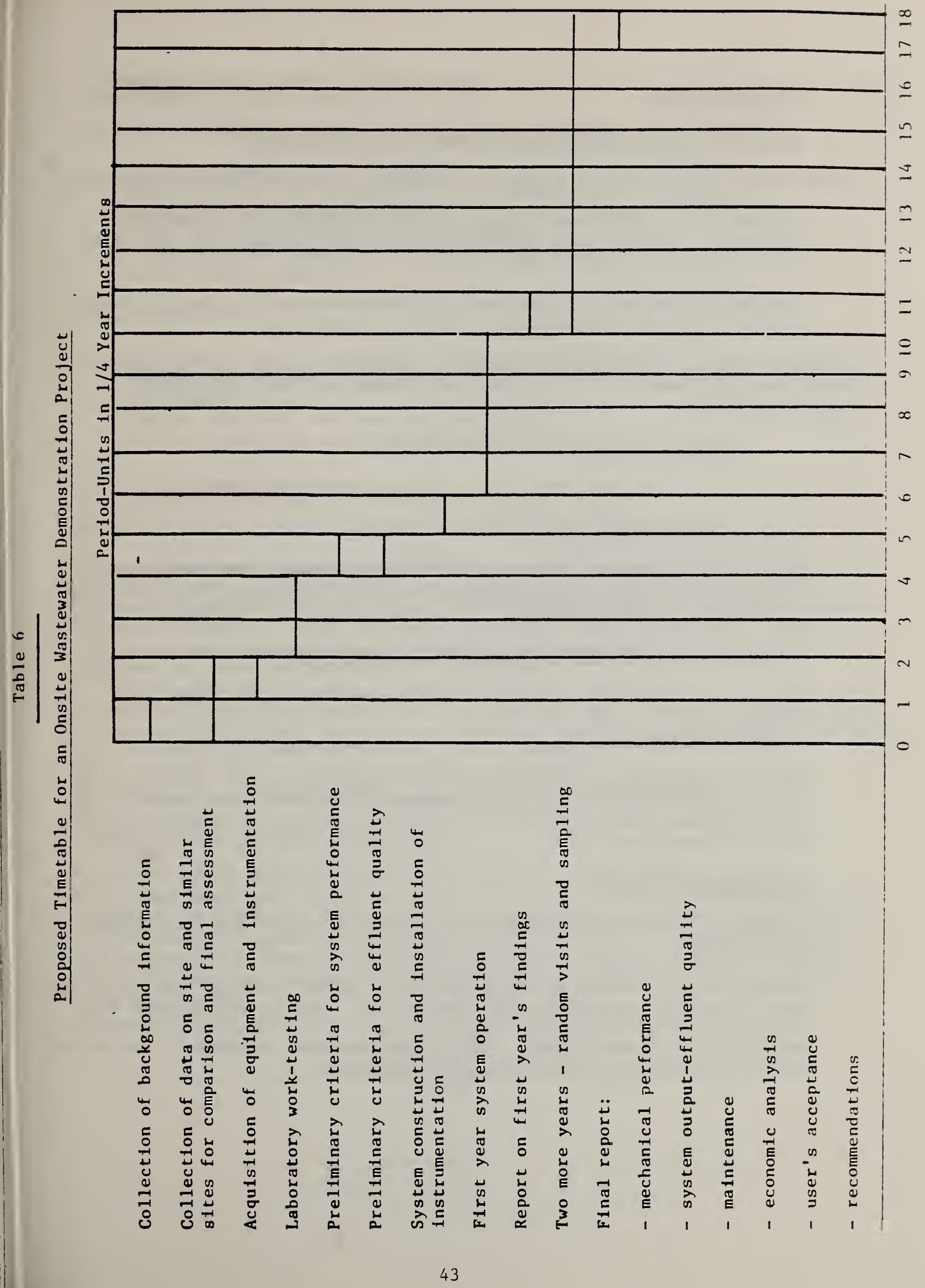




\section{RECOIMENDATIONS}

\subsection{Recommendation of Wastewater Systems for Demonstration}

Demonstration projects will consist of systems from the following categories:

- Systems whose performance adequacy has been proven with reasonable certainty, in which case reaffirmation of their capabilities and worth is the major objective of the project.

- Innovative systems of incomplete field experience where testing their capabilities and limitations is the major objective.

In either case, redundant backup features will be required, and in some cases, provisions for "hook-up" to a conventional system are desirable should failure take place.

7.1.1 Systems Recommended for Demonstration

7.1.1.1 Low Flush Toilets for Water Conservation and Wastewater Reduction

- European Flushdown Toilets

Provides a 40 percent reduction of the total household toilet flush water with no anticipated problems except for a slightly large need for cleaning the toilet surfaces.

- Two-Step Flush Toilet Mechanisms for Ordinary Toilets

Provides a 40 percent reduction of the total household toilet flush water.

- Pressurized Tank Toilets

Several designs are available for water reduction in the range of $50-80$ percent as compared to the water consumption of the "water saver" ( $31 / 2$ gal. syphonic toilet), which provides for a 30 percent saving relative to the five-gallon toilet.

- The Microphor Toilet

Provides a 90 percent reduction as compared to the five gallon toilet water usage.

Limitations: Economic constraints, i.e., capital costs of compressor and parts plus some maintenance and power costs. The toilet operates with moving mechanical components which generally is an undesirable feature in principle for water closets. This toilet has been approved by the major model codes and has started gaining acceptance. 
The Composting Toilet of the Large Type

The system is reasonably well suited for the following home settings:

- Rural to remotely rural settings

- Sparcely populated areas where no advantage can be attained by community type wastewater systems

- Areas of no means of wastewater disposal

- Large families (compost tank can be enlarged)

- Limited water resources

System Limitations:

- Problems of users' acceptance. The users must be informed of the systems workings and given instructions for operation of the systems.

- Maintenance

- Special consideration for the home design

- May be undesirable for installation in cold climate regions

\subsubsection{Wastewater Systems}

\section{Recirculating Grey Water Systems for Toilet Flush Water Reuse}

These systems are very simply constructed, do not require sophisticated components and can be maintained by the homeowner or an ordinary plumber. System acceptance should not pose a problem except for the formation of high levels of turbidity in the recycled grey water in the toilet bowl. The system can be accomodated in any setting where water conservation and/or a reduction in the total wastewater is required.

The system is suitable for serving an individual home. Appreciable reduction in cost may be attained when used in apartment houses to serve several families, with a common treatment and recirculation system.

Recirculation of Total Wastewater for Toilet Flush Water Reuse

The "Cycolet" - Thetford Corporation

At present, this system is primarily designed to meet needs of public

facilities where water shortage exists, and the land is unsuitable for soil absorption systems, or the local real estate cost is high for allocating land for wastewater treatment and disposal. These systems are relatively costly and not suited or designed for individual homes. This system may be appropriate to serve an apartment house of five or more families in an urban and suburban setting. 
This system is suitable for rural and suburban settings in the south western states and any region of dry climate and low precipitation. Its applicability to the eastern states is questionable. Redundant features should include standby beds to be used in case severe climatic conditions such as high precipitation and/or unusually long freezing periods which may cause system loading values to fall outside the design criteria. The beds should be serially designed to constitute several E-T compartments so that the systems downstream are being used only when the upstream systems have been loaded to their full capacity. Such a design will facilitate obtaining data on critical values and minimum area requirements for sizing E-T beds. Water conservation applicances and fixtures such as low flush toilets and low flow shower heads are highly desirable as they may result in an appreciable reduction in the total $E-T$ bed size.

Septic Tank - Mounds Systems

Septic tank - mounds systems are presented with a greater degree of confidencethan E-T systems, as more experience has been gained about them. They are applicable throughout the country and design criteria have been established by experienced organizations such as the University of Wisconsin and the North Carolina State University.

7.1.2 Systems of Limited or Questionable Application

Vacuum Toilet System

Requires a high degree of maintenance. Noisy when flushing takes place. Improper cleaning of the surface of the bowl frequently occurs. With the present design features, the system applicability for homes is questionable. Definitely not cost effective for individual home installation.

Suds Operated Toilet

The information obtained is not sufficient to draw conclusions on its applicability. Information on the Japanese experience is required.

Macerator Toilets

The systems reviewed are designed for recreational areas and vehicles. With modified toilet design macerator toilets may be used in homes.

Small Type Compost Toilet

The systems are designed mainly for summer homes. Systems for year around usage are limited to three users. They may find application for remote rural areas with no means of wastewater disposal. The homeowners must have a positive attitude towards the systems and willing to take the appropriate measures for maintenance and operation. 


\subsubsection{Systems Not Recommended for Demonstration}

The following systems are not recommended for year around application:

$\begin{array}{ll}\text { Packaging Toilets } & \begin{array}{l}\text { Designed for summer homes and recreational } \\ \text { areas only. }\end{array} \\ \text { Freezing Toilets } & \text { Designed for summer homes and recreational areas. } \\ \text { Chemical Toilets } & \begin{array}{l}\text { Designed for summer homes, recreational areas } \\ \text { and vehicles. Limited application for year } \\ \text { around, permanent settings. }\end{array} \\ \text { Incinerator Toilets } & \begin{array}{l}\text { Designed for summer homes. High consumers of } \\ \text { energy. May create odors during the time of }\end{array} \\ & \begin{array}{l}\text { incineration. Limited application for year } \\ \text { around homes. }\end{array} \\ \text { Oil Flush Toilets } & \begin{array}{l}\text { Designed for public usage such as state highway } \\ \text { rest areas. Requires high maintenance and }\end{array} \\ & \text { frequent replacement of parts. Will require } \\ & \text { sludge disposal at relatively frequent time } \\ & \text { intervals. }\end{array}$

\subsection{Recommendation for Research}

As earlier mentioned, a great deal of work has been done in all disciplines related to onsite wastewater systems. The literature, however, has revealed the following: Conflicting conclusions from seemingly similar projects, data outputs confined to isolated test cases with no immediate application for generalization and in turn, information of too general a nature which cannot be applied to specific cases. Apparently, this is part of the learning process in light of the nature of onsite systems which may vary from site to site. A need certainly exists to survey all the innovative systems installed, define their site conditions in terms of soil evaluation, climatic conditions and the characteristics of wastewater loadings together with the evaluation of their performance and economics. This will furnish a broad data base and onsite wastewater systems. The following topics need further investigation:

\section{Effects of aerobics on soil absorption systems}

The effect of aerobic treatment units in comparison to septic tanks has been a topic of quite a few research programs and demonstrations. It appears, however, that final conclusions have not been drawn as yet.

A need remains to establish under what conditions are aerobic systems superior to septic tanks and, in particular when are they economically feasible as applied to tile fields, mounds and E-T beds. 


\section{Evapotranspiration Systems}

Study under what climatic conditions E-T systems are viable, and the frequency of the systems failure by ponding when applied in various climatic conditions. A similar evaluation is required for the relatively new mechanical rotating disc evaporation system.

\section{Mounds}

Similar studies compared to the E-T beds are still required for the mound systems, in particular, what are the critical underlying clay-soil properties for which mounds can be expected to perform adequately.

\section{Effect of Electro-Osmosis on Soil Absorption Systems}

Electro-Osmosis systems were reported to work well in the west. No information was seen on their effectiveness in the east; furthermore, recent findings discredited their merits and effectiveness. Further work is needed for a more reliable data base.

\section{Combined Black and Grey Wastewater}

Comparison of the performance of soil absorption systems of various compositions subject to application of combined wastewater and grey water. This topic has been under study by the University of Wisconsin.

\section{Long-term Effects of Grey Water Recirculation for Toilet Flush Water Reuse}

Several systems are presently available. These systems use very simple means of treatment which includes a relatively coarse filter and disinfection by iodination or chlorination. A study of long-term effects of recirculation is needed to evaluate the accumulation and the possible increase in concentration of hazardous treated effluenty residues. Study the degree of the required disinfection for the prevention of any microbiological hazards from the production of spray and droplets upon toilet flushing.

\section{Water Exchange in Low Flush Toilets}

The revised standard ANSI A 112.19.2-1980 for Vitreous China Plumbing Fixtures has a new "water exchange" performance criterion that a "dilution ratio of at least 100 shall be obtained in each initial flush."

No information is available whether this dilution ratio is necessary or sufficient in terms of disease transmission potentials. It is expected that the "dilution ratio" will be much lower in low flush toilets. A study is therefore required for establishing the "safe dilution ratio" so that low flush, water conserving toilets can be evaluated. 


\section{Wastewater Transport from Low Flush Systems}

As water has been the principal transport medium for moving the solid wastes in the drain lines, low flush toilets may affect the wastewater transport capabilities of the drainage system. Analytical work is-at present conducted at the National Bureau of Standards for investigating this problem. Field work will probably be required for verification of the mathematical modeling performed at the NBS. 


\section{Bibliography}

1. Microbiology, by Michael J. Pelezar, Jr., Roger D. Reid, E.C.S. Chan, McGraw-Hill Book Company, 1968 Fourth Edition.

2. Water Reuse Symposium, Proceedings Vo1. 1, 2, 3, March 25-30, 1979. Co-Sponsored by American Water Works Association Research Foundation, Office of Water Research and Technology (U.S. Department of the Interior), U.S. Army Medical Research and Development Command, U.S. Environmental Protection Agency, National Science Foundation, Water Pollution Control Federation.

3. Management of Small Waste Flows, EPA Publication 600/2-78-173, Grant No. $\mathrm{R}-302874$.

4. Residential Water Re-Use, by Murray Milne, California Water Resources Center, University of California/Davis, Report No. 46, September 1979.

5. Home Sewage Treatment, Proceedings of the Second National Home Sewage Treatment Symposium - 1977, American Society of Agricultural Engineers.

6. Evapotranspiration Method of Wastewater Disposal by Kenneth M. Lomex and Paul N. Winn, Horn Point Environmental Laboratories, Center for Environmental and Estuarine Studies, University of Maryland.

7. Manual of Grey Water Treatment Practice, by John H. Timothy Winneberger, Published by Ann Arbor Science Publishers, Inc., 1974.

8. Segregation and Separate Treatment of Black and Grey Household Wastewaters to Facilitate Onsite Surface Disposal, by Robert Sregrist, Small Scale Waste Management Project, University of Wisconsin.

9. A Study of Methods of Preventing Failure of Septic Tank Percolation Systems, by P. H. McGauhey and J. H. Winneberger, Sanitary Engineering Research Laboratory, College of Engineering and School of Public Health, University of California, Berkeley, October 31, 1965, Serial Report No. 65-17.

10. A Study of the Biological Aspects of Failure of Septic Tank Percolation Fields, by P. H. McGauhey, G. T. Orlob, J. H. Winnenberger, Sanitary Engineering Research Laboratory, University of California, Berkeley.

11. Alternatives to Septic System Home Wastewater Disposal in Northwest Arkansas, by Chery1 L. Peterson, Arkansas Water Resources Center, Thesis and Dissirtation Series, Report No. 7, University of Arkansas, 1977. 
12. A Study of Flow Reduction and Treatment of Waste Water From Households, by James R. Baily, Richard J. Benoit, John L. Dodson, James M. Mobb, Herold Wallman, Prepared for Federal Water Quality Administration, Department of the Interior, Program 非1050 FKE, December 1969.

13. Individual Onsite Wastewater Systems, Proceedings of NSF National Conferences, 1974-1978, Edited by Nina McClelland, Ann Arbor Science, Ann Arbor, Michigan.

14. The Effect of Aerobic and Anaerobic Household Sewage Pre-treatment on Seepage Beds, by R. Laak, 1966, University of Toronto, Department of Civil Engineering.

15. Standard Methods for the Examination of Water and Wastewater, 1975, 14th Edition. Published by American Public Health Association, Washington, D.C.

16. Study of Water Recovery and Solid Waste Processing for Aerospace and Domestic Applications, Prepared under Contract NAS9-12503, National Aeronautics and Space Administration, Houston, Texas. Grumman Aerospace Corporation, Bethpage, New York, Dec. 1972.

17. Clogging and Unclogging of Septic Systems Seepage Beds, by J. M. Harkin, M.D. Jawson, Soil Sciences Department, University of Wisconsin.

18. Use of Physical ifethods to Expand Soil Survey Interpretations of Soil Drainage Conditions by J. Bauman, Soil Science Society of America, Volume 37, No. 3, May-June 1973.

19. The Economics of Urban Sewage Disposal by Paul B. Downing, Fredrick A. Praeger, Publishers, New York - Washington - London.

20. Sewage Disposal by Evaporation - Transpiration by Edwin R. Bennet, et a1, Colorado University, Boulder, September 1978, EPA/600/2-78/163.

21. Pilot Plant Study Nitrogen Removal in a Modified Residential Subsurface Sewage Disposal System, Suffolk County Department of Health Services and William F. Cosolich Associates, P. C. Hauppauge, New York, Oct. 1977.

22. Sewer Moratoria Causes Effects Alternatives. The Department of Housing and Urban Development - July 1977.

23. Treatment and Disposal Alternatives for Domestic Sewage Management. The Department of Housing and Urban Development - Apri1 1977. 
24. Household Wastewater Composition and Properties by: Lars Karlgren, Krister Ijungstom, Eskil Olsson, Viktor Tullander Bulletin $177: 16 \mathrm{E}$, The National Swedish Institute for Building Research, 1979.

25. Recycled - Water Sanitary Waste Disposal System by: William Joseph Shoupp. Dissertation submitted to the Graduate School of West Virginia University, Morgantown, West Virginia, 1978.

26. Household Energy Conservation Study. Final Report, April 1978. G.E. Report No. 78SDS 4219. General Electric, Valley Forge Space Center. P.O. Box 8555, Philadelphia, Pennsylvania 19101.

27. Appropriate Sanitation Alternatives - A Field Manual, Energy, Water and Telecommunications Department. The World Bank, October 1978.

28. Demonstration of Non-Aqueous Sewage Disposal System, Environmental Protection Agency Series EPA-670/2-73-088, Dec. 1973.

29. Final Environmental Impact Statement (EIS) on Mound System for Private Waste Disposal, October 1979, The State of Wisconsin. 


\section{References}

1. Electro-osmosis, A Proven Soil Absorption Sewage System, Environmental Consulting Associates, 5522 Atlas Street, Los Angeles, California.

2. NSF - National Sanitation Foundation, STANDARD 40, Individual Aerobic Wastewater Treatment Plants.

3. NSF - National Sanitation Foundation, STANDARD 41, Wastewater Recycle/ Reuse and Water Conservation Systems.

4. Dindal, Daniel L., Soil Organisms and Stabilizing Wastes, SUNY College of Environmental Science and Forestry, Composting and Recycling Conference, July/August 1978.

5. Nichols, H. Wayne, Analysis of Bacterial Population in the Final Product of the Clivus Multrum, Center for the Biology of Natural Systems, Washington University, St. Louis, Missouri.

6. Ilberg, H. and Zanker, K. J., Water Conservation Measures in Plumbing Vacuum Sewage System - Israeli Experience, the Standards Institution of Israel, Sponsored by the U.S. National Bureau of Standards, Contract No. NBS (G)-100-IS-ST-TBT, December 1973.

7. Report on the Preliminary Economic Study of Vacuum Sewage Scheme at Yellow Elder Gardens and Big Pond Nassau, Bahamas, December 1978. By D. Tilakaratue, Water \& Sewerage Corporation.

8. Bernhart, Alfred P., Treatment and Disposal of Waste Water from Homes by Soil Infiltration and Evapotranspiration. University of Toronto Press, 1973.

9. Tanner, C.B. and Bouma, J., Influence of Climate on Subsurface Disposal of Sewage Effluent, College of Agriculture and Life Sciences, University of Wisconsin, Madison, Wisconsin.

10. Hoover, M.T., G.W. Peterson and D. D. Fritton, Utilization of Mound Systems for Sewage Disposal in Pennsylvania Department of Agronomy, The Pennsylvania State University.

11. Pasrew, Lee, Evapotranspiration as an Alternative to Septic Systems in Rural Metropolitan Washington, Division of Planning, Office of Community Development, Montgomery County, Maryland, March 1979.

12. Waldorf, Larry, Rural Sanitation, The Appalachian Regional Commission, Washington, D.C.

13. Glasser, Merril B., Garrett County Home Aeration Wastewater Treatment Project, 1973-74, Environmental Health Administration, Bureau of Sanitary Engineering, Maryland State Department of Health and Mental Hygiene.

14. Rex, Connie C., Consumer Acceptance of Water Recycling, Marketing Research Department, Pure Cycle Corporation, Boulder, Colorado, September 1977. 
15. Stone, Ralph and Company, Inc., Wastewater Reclamation, Socio-Economic, Technology and Public Acceptance, Distributed by NTIS, U.S. Department of Commerce, May 1974.

16. On-Site Wastewater Treatment Alternatives (Notes for a 2-day seminar from Jan. 15, 1980) by Applied Science Through Research and Engineering, Charlottesville, Virginia.

17. State of Maine - Plumbing Code, Subsurface Wastewater Disposal Regulations, Department of Human Services, Division of Health Engineering.

18. Rural Wastewacer Disposal Alternatives, State Water Resources Control Board, State of California Office of Planning and Research, Interagency Agreement W6-028-40, September 1977.

19. Evaluation of Microbiology Standards for Drinking Water, EPA/570/9-78-00c, 1978.

20. Wellings, Flora Mae; Lewis, Arthur L.; Mountain, Carrol W.; and Pierce, Virginia, Demonstration of Virus in Groundwater After Effluent Discharge into Soil, Epidemology Research Center, Tampa, Florida.

21. Gerba, Charles P.; Wallis, Craig; and Melnick, Joseph L., Microbiological Hazards of Household Toilets: Droplet Production and the Fate of Residual Organisms, Department of Virology and Epidemology, Baylor College of Medicine, Houston, Texas. American Society for Microbiology - Applied Microbiology Journal, March 1975.

22. Cliver, Dean 0., Infection with Minimal Quantities of Pathogens from Wastewater Aerosols, Proceedings of Symposium on Wastewater Aerosols and Diseases, September 19-21, 1979, EPA Sponsorship.

23. Fancy, John, Individual Aerobic Plant Operation and Maintenance, P.O Box F, Waldboro, Maine.

24. Siegrist, Robert L., Segregation and Separate Treatment of Black and Grey Household Wastewaters to Facilitate Onsite Surface Disposal, Smal1 Scale Waste Management Project, University of Wisconsin - Madison, College of Agriculture and Life Sciences.

25. Siegrist, Robert L., Management of Grey Water (See Ref. 24).

26. Hinter, Fred, "Field Trip Reports" from the Project "Sewerless Devices Evaluation Basis", the National Bureau of Standards. Letter Report to the Department of Housing and Urban Development, Division of Energy, Building Technology and Standards, June 20, 1980. 
APPENDIX 
A. Compilation of Onsite Wastewater Elements and Systems Reviewed

Table 7 contains the list of the systems reviewed, their manufacturers name and reference to the field trips for which these systems were visited.

\section{TABLE 7}

Wastewater Devices Observed or Reviewed in the Project

\begin{tabular}{|c|c|c|c|c|}
\hline Item & System & Manufacturer & $\begin{array}{l}\text { Observed } \\
\text { (number) }\end{array}$ & $\begin{array}{l}\text { Reference } \\
\text { to Trip No. }\end{array}$ \\
\hline & Waterless Toilets & & & \\
\hline \multirow[t]{2}{*}{1} & $\begin{array}{l}\text { Composting Toilets } \\
\text { Large Volume Type }\end{array}$ & $\begin{array}{l}\text { Clivus Multrum } \\
\text { Toa Throne }\end{array}$ & over 5 & $\begin{array}{l}5,11,12 \\
15,20\end{array}$ \\
\hline & & Carousel & $*$ & \\
\hline \multirow[t]{2}{*}{2} & Composting Toilets & Mulbank & over 5 & $13,14,15$ \\
\hline & & Humus & 1 & 24 \\
\hline 3 & Oil Flush Toilets & Monogram Industries & 2 & 9,15 \\
\hline \multirow[t]{3}{*}{4} & $\begin{array}{l}\text { Chemical Toilets } \\
\text { (nearly waterless) }\end{array}$ & Western Field & 1 & 13 \\
\hline & & Jensen & & \\
\hline & & Monogram Industries & 1 & 20 \\
\hline 5 & $\begin{array}{l}\text { Incinerator Toilets } \\
\text { Gas Fired }\end{array}$ & Incinolet & 2 & 15 \\
\hline 6 & Incinerator Toilets & Incinomod & 2 & 15 \\
\hline 7 & Packaging Toilets & Factosm, Sweden & & \\
\hline 8 & Freezing Toilets & Osby, Norway & & v \\
\hline 9 & $\begin{array}{l}\text { Suds Toilets } \\
\text { (nearly waterless) }\end{array}$ & Nepon, Japan & * & \\
\hline
\end{tabular}


Table 7 , continued

\section{Low Flush Toilets}

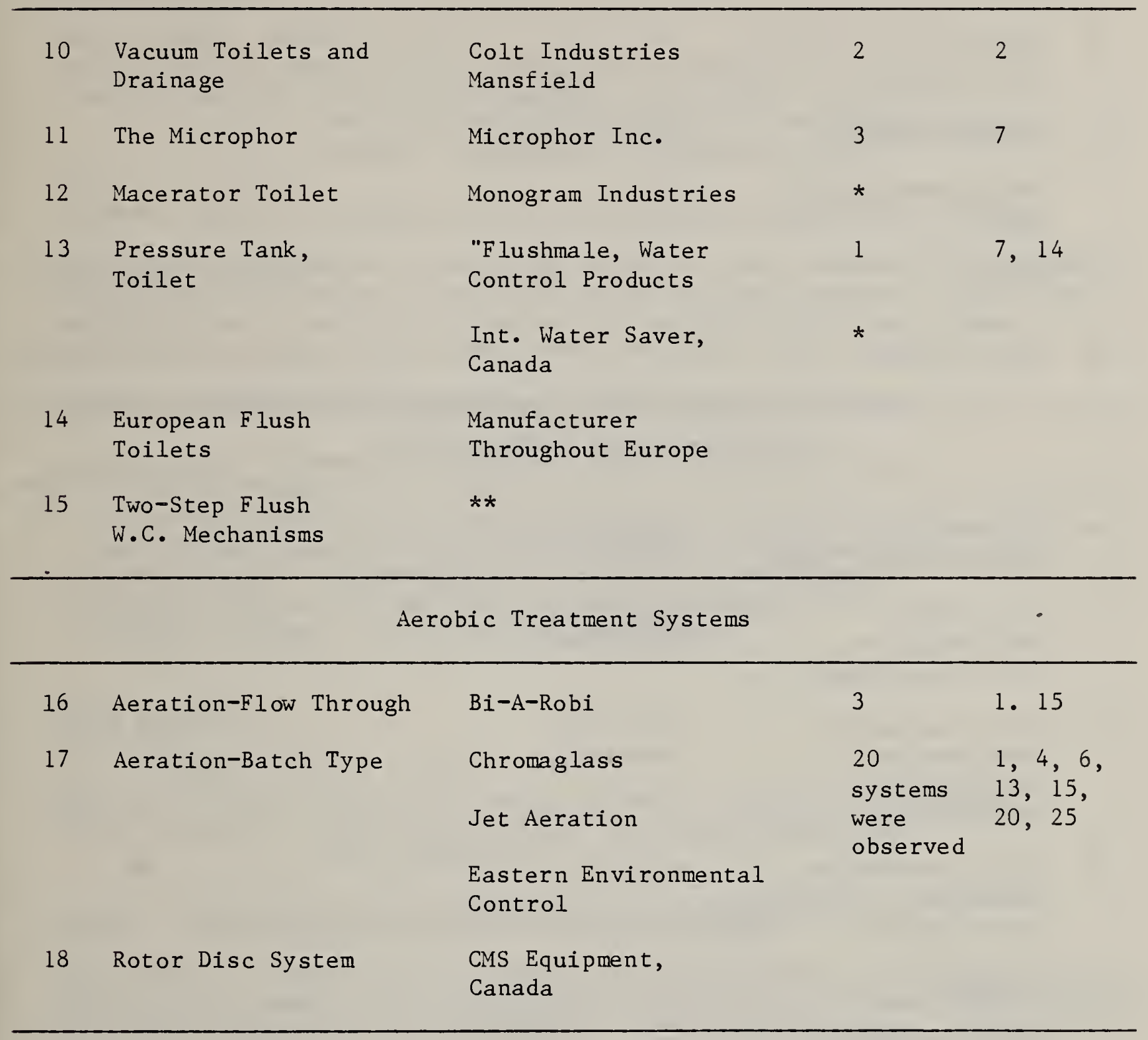

* Systems seen in exhibits.

* Two-step flush mechanisms are at present tested and evaluated at the National Bureau of Standards. 
Table 7, continued

Soil Absorption Systems

19 Multiple Alternating

Leach Field

20 Electro Osmosis

21 Evapotranspiration --

Beds

22 Mounds

$-$

23 Sand Filters

$--$

over $51,6,9$,

20,25

over $54,10,20$,

24,25

over $510,13,15$

Wastewater Reuse Package Plants

24 Blackwater -

Recirculating Toilet

25 Grey Water

Recirculation

for Toilet Reuse

26 Total Wastewater

Treatment and

Recirculation for

Toilet Reuse

27 Total Wastewater

Treatment to Potable

Water Quality

28 Lagoons

29 Spray Irrigation

30 Rotating Discs -

Evaporation
Ecol-Sanitary,

Canada

Water Cyk

Aqua Saver

1

22

1

23

Pure Cycle

16

Corporation

1

Pure Cycle

1

19

2

17,20

1

10 


\section{B. Summary of the Field Trips Conducted}

The following are summaries of the twenty five field trip reports written of trips to onsite conducted in the course of this study. (See Reference 26).

Field Trip No. 1

Date of Visit: March 5, 1979

Location Sites: Catlellsburg, Boyd County, Kentucky

Persons Contacted: Mr. David Salisbury - FIVCO (606) 739-5191

Referred by Mr. Larry Waldorf from the Appalacian

Regional Commission in Washington, D.C.

Systems: Aerobic Wastewater Units - Boyd County Demonstration Project

This setting encompasses 36 dwelling units in a rural community. The waste disposal systems include aerobic units from six manufacturers with various configurations of wastewater disposal such as E-T bed, direct stream discharge and recirculation, and reuse for toilet flush water.

Systems Performance as Observed and as Described by the Users

The individual systems are rated from satisfactory to failure:

- Wastewater recirculation system: The system operates well and solves the problem of water shortage experienced by the homeowner.

- Aerobic Units: Malfunctioning of the aerobic unit pumps.

- E-T bed: Failure of the bed resulting in flooding.

General problem: Lack of systems maintenance.

Field Trip No. 2

Date of Visit: March 9, 1979

Location of Site: White Flint Shopping Center, Rockville, Maryland

Person Contacted: Mr. George Pontias, Maintenance Supervisor

(301) $881-1780$

System: Black Water Waste Disposal Vacuum Drainage

The system is connected to 150 toilets via two and four inch PVC pipe 1 ines. The wastewater goes to two 2,000 gallon storage tanks. Vacuum pumps keeps the vacuum in a range of $18^{\prime \prime} \mathrm{Hg}$ (shutoff) to 10" (restart) vacuum. Wastes are evacuated directly to a sewer line with no prior treatment.

Water consumption per flush: 1 liter (quart)

Manufacturer: Colt Industries 
- Pipe lines get clogged but only with the use of paper towels, handy-wipes and similar heavy paper material.

- Some problems in loss of vacuum (but not significant).

- Some problems in flushing mechanisms - needle valve has to be reset to obtain the 1 pint flush.

Normally, these problems are manageable and the system works well except for inherent problems with the present system design resulting in a high noise level upon flushing the toilet and occasional incomplete cleansing of the toilet bowl.

\section{Field Trip No. 3}

Date of Visit: March 13, 1979

Location Site: Montgomery County, Maryland

Person Contacted: Mr. Wallace from Montgomery County

Department of Environmental Protection

Construction of Wells \& Septic Tanks - (301) 468-4192

Purpose of Visit: Study soil evaluation procedures for the

approval of construction of septic tanks.

Soil evaluation in the county is performed by the "soil percolation test."

Soil Percolation Test Criterion: A minimum of 1 inch per 30 minutes.

Limitations of the validity and reliability of this test were realized. As observed, "perc test" results in one property varied from $1 / 8$ " to 7 " per 30 minutes.

Field Trip No. 4

Date of Visit: March 16, 1979

Location of Sites: Montgomery County

Person Contacted: Mr. Lyman Schooley from Montgomery County EPA (301) $468-4126$

\section{Systems: Aerobic Units and Mounds}

The three systems visited are composed of aerobic units of the "batch type" and mounds. The units worked adequately, with the aerators diffusing air into the effluents. From the three mounds observed, one was not working properly, as seen by the soggy ground around it.

Apparent reasons for its failure: Improper construction practices and lack of proper maintenance of the mound crown. 
Field Trip No. 5

Date of Visit: March 21, 1979

Location Site: Industrial Building in Washington, D.C.

Person Contacted: Mr. Frank Reeves, R. M. Thornton, Inc.

(301) 350-5000

System: Large Volume Composting Toilet and Grey Water System

The systems have been in operation for 20 months and serve the office staff. The grey water system is composed of a roughing pea gravel filter and the treated grey water are used for gardening. No complaints were expressed by the users.

Field Trip No. 6

Date of Visit: April 4, 1979

Location Sites: Montgomery \& Fairfax Counties

Person Contacted: Mr. Curtis Bohlan from the Eastern Environmental Controls (301) 778-0967

\section{Systems: Aerobic Units and E-T Beds}

Three systems were observed. The units are of the batch type and worked well. A minor malfunction occurred in one unit. A five hour power failure caused a five hour time $1 \mathrm{ag}$ in the aerator's operating cycle. The cycle control was reset and the system was restored to normal operating conditions. The beds were dry and seem to function well.

\section{Field Trip No. 7}

Date of Visit: April 11, 1979

Location Site: Kent Island, Queen Ann County, Pier No. 1 Motel

Person Contacted: Mr. Morris, Motel owner (301) 643-5011

Systems: Pressurized Tank Toilets and the Microphor Toilet

Twenty-two toilets are installed in the motel bathrooms. The toilets operate on a pressure of 40-55 psi and require 2 gallons per flush. No complaints were expressed from the motel owner. One Microphor toilet is installed for observation only and is very rarely used. Some malfunction was observed in this toilet performance which manifested itself by water splashing out because of improper watertightness of the flapper valve. 
Field Trip No. 8

Date of Visit: April 20, 1979

Location Sites: Rest Areas on US 64 in the vicinity of Charlottesville, Virginia

Person Contacted: Mr. J. Tailor from the Virginia Highway Department (804) 786-2859

Systems: Oil Flush Toilet System

Extended Aeration with Water Reuse for Toilet Flushing

The oil flush toilet system serves fifteen toilets in the rest area. The system has been in operation for three months. Complaints were expressed by the rest area attendants regarding leakage of mineral oil. An appreciable amount of oil is drained with the wastes during disposal and in the time of the replacement of the filter. Complaints were expressed on poor performance of the incinerator resulting in incomplete incineration and in its excessive energy consumption of fuel oil.

The extended aeration system has been successful, trouble-free and cost effective, delivering a high degree of effluent quality and retrieving most of the wastewater ( 95 percent) for toilet flush water reuse.

Field Trip No. 9

Date of Visit: May 21, 1979

Place of Visit: State Highway 70 in Craven County, North Carolina Wastewater System in a rest area.

Persons Contacted: Mr. Bill Johnson and Jim Armstrong from the Highway Department (919) 733-2920

System: Oil Flush Toilet System and Grey Water E-T System

The oil flush toilet system serves nine toilets and three urinals. The system has been recently constructed and no working experience has been obtained. A recent inquiry indicated that in the first year of usage of the system, mechanical problems occurred causing offensive odors from the toilets. 
Field Trip No. 10

Date of Visit: May 22, 23, 1979

Place of Visit: North Carolina State University and Waste Disposal Systems in the vicinity of Raleigh, North Carolina

Person Contacted: Robert Rubin, from the Biological \& Agricultural Engineering (919) 737-2675

Purpose of Visit: To learn about the activities of North Carolina State University in onsite waste disposal systems and take part in a field tour.

Systems Observed:

Sand filters, recirculating sand filter, spray irrigation system, pressurized mounds and aerobic unit. The aerobic system seemed to be failing. The aeration pump was not in operation and the dark untreated sewage was observed in the aerator tank.

Field Trip No. 11

Date of Visit: June 27, 1979

Location: Sperryville, Virginia

Person Contacted: Mr. Stanley Thompson (703) 987-8714

System: Large Volume Composting Toilet

The system serves a family of three. The compost tank is connected to two toilets placed in two levels in the house. The system has been used for eighteen months to the full satisfaction of the homeowner.

Field Trip No. 12

Date of Visit: July 2, 1979

Location: Office building in Washington, D.C.

Person Contacted: Mr. Fox, Institute of Local Self Reliance - 232-4108

System: Large Volume Compost Toilet

The system was installed for demonstrating the feasibility of waterless toilets, and has been in operation for two and one-half years. The office has a staff of 15 but only 10 persons use the compost toilet (the rest prefer to use the conventional facilities). The system has been working well. 
Date of Visit: July 18, 1979

Location Sites: Garrett County, Maryland

Persons Contacted: Merril B. Glasser - Environmental Health Administration, State of Maryland (301) 334-3965

Edgar Harman - Oakland Department of Health (301) 334-8111

Systems: Aerobic Units, Sand Filter Beds, Chemical Toilet, Small Type Compost Toilets

Aerobic Units: The systems were installed as part of a demonstration project in 1973 and were under observation for a one-year period. Of the three sites visited, two systems were abandoned, one of which delivers raw effluent to a nearby ditch. The third was not in operation at the time of the visit (apparently for saving of electricity) but was reactivated to proceed normal operation.

Sand Filter Beds: The beds serve private homes and were designed by the county. The clear odorless effluent flows to a nearby creek. The beds function adequately.

- Chemical Toilet: Used by a single person in a home having no plumbing facilities and provided a solution of water conservation and wastewater disposal.

Small Type Compost Toilets: Two homes were visited. In one home, the toilet serves two persons and works well. In the other, the toilet has been failing: creating offensive odors, accumulating liquids and attracting flies. Reasons for failure: Improper vent design, possible system overloading from the family of four and incorrect seeding of organic material into the wastes, for maintaining the proper carbon to nitrogen ratio.

Field Trip No. 14

Date of Visit: July 24, 1979

Location of Site: New Hampshire

Person Contacted: Mr. Gunnar Baldwin, Thorton Gore Enterprises, Inc. (603) 726-3295

Systems: Small Type Compost Toilets, The Microphor

Small Type Compost Toilets: The toilets were observed in three homes. The homeowners expressed satisfaction with them. Some problems occur in time of large social gatherings as these systems are designed for, at most, three persons.

Microphor Toilets: The toilets were observed in a private home and in a restaurant. The system performed adequately. 
Field Trip No. 15

Date of Visit: July 25 and 26,1979

Location of Site: Augusta, Maine and Vicinity

Person Contacted: Mr. Eugene Moreau, Dept. of Human Services, Augusta, Maine (207) 289-3826

Systems: Composting Toilets - Large and Small Type, Oil Flush Toilets, Incinerator Toilets - Gas and Electric, Grey Water Disposal Systems, Aerobic Systems, Sand Filters

Compost Toilets of the Large Type: Several systems were observed in year around settings, summer homes, restaurants and schools. All worked well except for the one in the school which failed apparently because of excessive usage and lack of adequate maintenance.

Compost Toilets of the Small Type: Observed in summer homes and a high school dormitory. The toilets installed in the dormitory for the male students were failing, manifested by a high accumulation of solid wastes in the toilets and liquids in the disposal trays.

Oil Flush Toilets: Observed in a state highway rest area. The toilets are manufactured by Monogram Industries. No serious problems were reported by the facility attendants.

Incinerator Toilets - Gas Operated: Observed in two homes. No complaints were expressed by the owners.

Incinerator Toilets - Electricity Operated: Observed in two public places. The one installed in a court house had been abandoned because of offensive odors to the neighbors in the time of incineration. The other, installed in a library, has limited usage to the library staff only.

Grey Water Disposal System: Used in homes where compost toilets handle the black water wastes. The grey water is filtered, disinfected by U/V or chlorination and then discharged to the ocean.

Aerobic Systems: Observed in several installations. No problems reported. Sand Filters: Observed in several installations. Some serve large systems, such as restaurants in the waterfront. No problems reported.

Field Trip No. 16

Location: Ann Arbor, Michigan

Date of Visit: November 1, 1979

Person Contacted: William Bullard - Thetford Corporation

(313) 769-6000 
System: "Cycolet" Wastewater Package

This package contains hardware for wastewater recirculation and reuse for toilet flush water. The trip included a visit to the company's manufacturing facilities and observation of a system in normal usage.

\section{Field Trip No. 17}

Location: Michigan, Monroe County and Vicinity

Date of Visit: November 2, 1979

Person Contacted: Jay Bastion from the Department of Transportation

Systems: Oil Flush Toilets, Septic Tank Lagoon System

These systems serve state highway rest areas.

Oil Flush Toilets: The following problems were reported by the station's attendants: Dirty surfaces remain after flushing, malfunction of the macerator pump, corrosion of copper tubes and malfunction of the controls in the holding tank.

Field Trip No. 18

Location: The University of Wisconsin, Madison, Wisconsin

Dates of Visit: November 5 and 6, 1979

Person Contacted: Jerry Tyler (608) 263-3137

The purpose of this trip was to see the ongoing research programs of the university in onsite systems. The University has been very active in this in particular, in the topics of grey water studies and soil absorption wastewater systems, with emphasis in finding optimal solutions for wastewater dosage into the soil absorption beds.

Field Trip No. 19

Location: "Pure Cycle," Boulder, Colorado Date of Visit: November 7, 1979

Person Contacted: Robert 0. Menkes (303) 449-6530

System: "Pure Cycle" Wastewater Package

"Pure Cycle" is a package for wastewater recirculation and reuse for drinking. The trip included a visit to the manufacturing facilities and to a home where one system is being used (no information was obtained from the users). 
Field Trip No. 20

Location: Boulder County, Colorado

Date of Visit: November 8, 1979

Person Contacted: Mike Whitemore from Boulder County Department of Health (608) 441-3530

Systems: Compost Toilets - Large Type, Chemical Toilet, Septic Tank - Mound System, Septic Tank - E-T Bed, Aeration Unit Lagoon System

Compost Toilets: The problems experienced with the toilet observed were the hardening of the waste pile in the compost tank and excessive accumulation of liquids. The reasons to this failure were attributed to improper venting of the system.

Recirculating Chemical Toilets: Situated in a small diner which also was used as a home. The owners experienced unpleasant odors and breakage of parts, apparently because of excessive usage.

Septic tank - E-T Beds: Several systems were observed. All perform well. Aeration Unit - Lagoon System: One system was visited. The system worked adequately.

Field Trip No. 21

Date of Visit: November 30, 1979

Location of Site: Upper Occoquan - Northern Virginia

Person Contacted: Mr. Ehalt - (703) 830-2200

System: 15 MGD Advanced Wastewater Plant

The purpose of the trip was to review the elements of an advanced large wastewater system. This plant serves a population of 70,000 in Northern Virginia. The system was designed to meet the problem of increased discharges of conventionally treated effluents to the Occoquan Watershed in Virginia. The system delivers a very high quality effluent, of nearly potable water quality to the watershed. The solid wastes products are being handled by composting.

Field Trip No. 22

Date of Visit: December 19, 1979

Location of Site: Washington, D.C.

Person Contacted: Mr. Bowl, Eaton Water Cyk (301) 821-8892 
System: Grey Water Recycle System for Toilet Flush Water Reuse

The system is installed in a house and is under study by Dr. Foresti from the Catholic University. The installation is composed of a grey water collection network, holding tank, and filters. Prior to recirculation, the effluents are disinfected by iodination. The system appears to function well except for noticeable turbidity of the water in the toilet bowl.

Field Trip No. 23

Date of Visit: January 16,1980

Location of Site: Queen Ann County, Maryland

Person Contacted: Dick McCulloh, "Aqua Saver" - (301) 644-9550

System: Grey Water Recycle for Toilet Flush Water Reuse

This installation is similar to the one described in Field Trip No. 22, except that disinfection of the recirculated wastewater is done by chlorination. The system was installed in a home after approval was granted by the county and constructed to reduce the total wastewater flow to the septic tank. The homeowner experienced no problems during its three months of operation and the turbidity appearing in the bow1 is not troublesome for him.

Field Trip No. 24

Date of Visit: January 23, 1980

Location of Sites: Gettysburg, Pennsylvania and Vicinity

Person Contacted: Wr. William Hill from V.S.P., Valley Septic Products (717) $334-9135$

Systems: Sma11 Community Wastewater Systems, Compost Toilet - Small Type

Smal1 Community Wastewater System: The system serves nine families and is composed of two large capacity batch type aerobic units and a large mound. At the time of the visit, the aerators were not operating due to malfunctions of the relays and dark scum showed in the tanks. (The system is fairly new and does not work to its full capacity as yet).

Compost Toilet: The system is installed in a grocery store and serves three people, generally with no problems. In the past, the fan broke which created a very unpleasant odor. The fan was immediately replaced and the odor was eliminated. 
Field Trip No. 25

Date of Visit: March 17, 1980

Location of Sites: Montgomery County

Person Contacted: Lyman Schooley from Montgomery County EPA

Systems: Mounds and E-T Beds - Montgomery County Demonstration Project

Five systems with combinations of septic tanks, aerobic units and E-T beds were installed in 1977 and monitored for a one year period. At the time of the visit, all the systems exhibited some form of failure from ponding of a clear effluent to flooding of dark raw sevage with unpleasant odor. Of the mounds visited in this trip, some worked well and some exhibited surface ponding around their base. 


\section{Discussion of Wastewater Systems as Viewed from the Field Trips}

As mentioned earlier, the activity of the field trips illuminated the aspects involved in onsite innovative wastewater systems, in spite of the small sample size inspected and reviewed. The conclusions drawn on the systems performance are based upon visual inspection, information from the home occupants, and discussions with the engineers, manufacturers and State Iealth representatives who accompanied the investigator on the trips. Table 9 lists systems failures or malfunctioning as observed on the trips. The following discussion is based on the field trip observations and the 1iterature.

\section{C.1 Composting Toilets}

Composting toilets have been a topic of controversy for quite some time because of their unique mode of operation and various problems involved. Theoretically, compost toilets form a well balanced, naturally managed ecosystem composed of communities of microorganisms which inhabit the wastes, creating a food web where one colony thrives on the other and finally transform the wastes into a stabilized odorless organic matter and soil humus [4]. Also, test results [5] from laboratories indicate that the end product is harmless and consists of soil borne organisms which are found in any ordinary soil. Compost toilets require certain conditions such as proper air, and temperature, moisture and a fixed carbon to nitrogen ratio, otherwise, they may fail. Needless to say, failure of a composting toilet is a very unpleasant experience. Another inherent limitation-is the fact that one cannot take the system for granted with no maintenance and as one user expressed it "you have to build your house around them." Since people's life-style and personal habits vary, the composition of the waste products vary from household to household and consequently uniform maintenance policies cannot be prescribed.

Each individual has to experiment with the system and discover from his experience, the optimal procedures for running the compost toilet. The toilets certainly have an "odd shape" similar to an outhouse toilet and to some people their appearance may not be appealing. Some systems had a "slightly musty odor," which was, however, bearable and caused no alarm.

The breaking in period is another aspect to take into consideration. It generally takes one year for the system to reach normal operating conditions. In that period, one may experience accumulation of liquids in the tank, odor and flies.

Of course, the problem of acceptance is the most critical aspect. Of interest was an installation in Washington, D.C. The "large type" compost toilet is installed in the Institute of Local Self Reliance. This organization is in the energy conservation business. One may expect the employees of such an organization to welcome the system and use it with no reservations. However, out of fifteen staff personnel, six preferred to use conventional facilites. 
In the course of the trips, successes and failures were witnessed. The failures are described in Table 9. Due to their large composting chamber, the "large volume" type composting toilets are more stable, less susceptible to variations in wastes loadings and the mode of failure less critical as compared to the small systems. Failure of composting toilets is manifested by intolerable odors, flies and accumulation of liquids in the tray compartment at the bottom. The reasons for failure were attributed to improper venting and overloading. This system cannot accommodate more than three persons. Of interest was a phenomenon observed in year-round dormitory for boys and girls of high school age. There were two small type composting toilets in the girl's bathroom which worked reasonably well while in the boy's bathroom failures took place. This also repeated itself when the facility usage was switched, namely, the girl's had no problem and the boy's toilets failed. The differences in toilet habits between the sexes, in particular, the differences in use of toilet paper probably accounted for the difference of performance, as the additional paper normally used by the female students sustained a more appropriate carbon to nitrogen ratio.

Composting toilets may work well provided the proper operating conditions are met with proper attention given to them. They may be suitable for individual homes in rural settings, and in areas of limited water resources.

Their merits: They are completely waterless, have very little operating expenses, and can be maintained by the homeowner.

Their disadvantages: May require a change in life-style and acceptance; susceptible to failure if proper maintenance is not carried out.

\section{C.2 Chemical Toilets}

Chemical toilets are designed for recreation vehicles and situations of occasional use. They are generally not intended to be used in houses on a year-round basis. Chemical toilets were seen in remote low income areas used by single individuals. Attempt to use chemical toilets in a small restaurant in a rural region in Colorado resulted in failure apparently due to system overloading. Obviously the owner of this establishment was ill advised as this system should not have been installed in the first place.

\section{3 Incinerating Toilets}

Incinerating toilets have their merits since they leave hardly any residue requiring disposal; however, with the rising costs of fuel, their operation costs limit their advantages, and therefore, their application to home installation is questionable. Gas fired incinerating toilets were observed in summer homes in remote rural areas. The toilets were very favorably accepted in spite of their high operation costs. Electric incinerating toilets were observed in public facilities. One system visited was abandoned because it emmitted offensive odors through its vent during the incinerating cycle, and caused discomfort to the neighbors in the adjacent homes. The other toilet was observed in a public library. Its use was limited to the 
library staff. The problem of offensive odor was witnessed in this system also. It was noted that the incinerating time cycle is rather long ( 30 minutes). Incineration may be interrupted prior to complete incineration for another usage, however, this inherent feature of the long incinerating cycle is undesirable. In comparison to the compost toilets, incinerating toilets are probably more aesthetically acceptable, also, the problem of offensive odors can be overcome by proper venting installation. However, the high running cost of operation is inherent in the systems and probably discounts its application for homes.

\section{4 Vacuum Toilets and Drainage Systems}

Vacuum sewage drainage is used as an efficient medium for wastewater transpcrt. Its advantages are; the independency of the site on the topography of its terrain and the usage of smaller conduits sizes as compared to the conventional gravity fed systems. Vacuum toilets, incorporated in the system, require only one to two quarts of water per flush. The following three case studies are briefly described:

1. White Flint Shopping Center in Rockville, Maryland. The system has been in operation for three years and serves 150 toilets. The system was visited in March 1979. The plumbing attendant expressed satisfaction with the system, however, the following problems occur:

- Pipe lines get clogged when excessive paper towels and "handy wipes" are used.

- Problems with the flushing mechanisms.

- Loss of vacuum in the drain lines.

- Excessive noise upon flushing

- Incomplete cleansing of the toilet's surfaces.

2. Vacuum Sewage System in Carmiel, Israel [6]. The system was constructed in 1967 and served two hundred families most of whom lived in apartment houses. The following problems occurred frequently:

- Loss of vacuum in the drain lines.

- Clogging of the drain lines because of flushing bulky materials and because of formation of calcium deposits in the lines.

- Failure of the toilets intricate flushing mechanism.

- Excessively high noise upon flushing the toilet. A fact which aggrevated the system had been its design, which was in a series configuration such that any failure incapicitated all the homes downstream. The investigator had spent a day at that site in 1973. On that day a maintenance crew had been trying an acid dose treatment for clearing the deposit formation in the drain lines. Fortunately, a redundant conventional sewage system was constructed with the vacuum drainage. As the problems increased in frequency and severity, a time was reached that it was more economical to abandon the system and replace it with a conventional standby system. 
3. Vacuum System in Nassau, Bahamas [7]. The vacuum sewage toilet system has been used in Nassau for over ten years. Some 1000 units have been reported in 1977 which serve private apartments, a large hotel and public housing projects. A report issued [24] indicates similiar problems as described for the system in Israel. The economic analysis in that report indicates that from the costeffectiveness view point it would be desirable to abandon the system and construct a new conventional system instead.

It is apparent that the vacuum drainage-toilet system needs major improvements, in particular, in the design of the toilet, to make it feasable and more reliable for residential application.

\section{5 Aerobic Wastewater Treatment}

Aerobic systems have been in use for the last two decades and are approved by some states plumbing code such as Maine and Pennsylvania. The following statements appear in the brochure of an aerobic system manufacturer:

"By changing the existing septic tank from anaerobic state to aerobic, not only will the efficiency of biological decomposition increase from 15-30 percent to 80-95 percent, but it will reconvert the seepage fields and the soil around them back to their natural aerobic condition" ... Since the wastewater effluents then have a high dissolved oxygen (DO) content, it develops an attractive environment for air breathing microbes ...to rejuvenate the soil by controlling the propagation of bacteria, thus keeping soil pores open."

These positive statements on the performance of aerobic processes are backed up by several researchers such as Dr. A. Bernhart from the University of Toronto who states that [8]:

"A seepage bed area of about $700 \mathrm{sq}$. ft. using soil infiltration and evapotranspiration is sufficient in clay-loam soil under aerobic conditions while $14,000 \mathrm{sq}$. ft. are required if conditions are anaerobic."

These findings are highly favorable; however, no other known researcher was able to duplicate or come close to such results. It has been claimed that the energy generated in the form of heat in aerobic processes also contributes to increased evaporation at the soil absorption beds. Theoretical calculation of this heat production indicates that the heat contribution to evaporation by aerobic decomposition amounts to less than one percent [9]. Most of the research findings indicate a marked reduction of the BOD effluent of the aerobic systems as compared to the reduction in septic tanks but no appreciable differences on the reduction of the total suspended solids in the secondary treatment effluents. In septic tanks, reasonably representative figures will be a reduction in $B O D$ from $200 \mathrm{mg} / \mathrm{I}$ to $160 \mathrm{mg} / \mathrm{I}$ as compared to aerobic systems where the reduction is from 200 to $40 \mathrm{mg} / 1$. It has been recommended to apply these facts in sizing of waste disposal fields with the use of the following equation [8]:

$$
A e=A s \sqrt[3]{\frac{B O D+S S}{250}}
$$


Where: "As" is the required area with use of a septic tank and "Ae" is the adjusted area when an aerobic unit is used. "BOD" and "SS" are the values in $\mathrm{mg} / \mathrm{l}$, the biochemical oxygen demand and the suspended solids of the effluents from the secondary treatment system.

An inspection of this equation shows that even for very favorable conditions an aerobic system will yield only a 20 percent reduction in field sizing. Some states allow for a reduction in the absorption field when aerobic units are used. Table 8 and the following statements are taken from the code of the State of Pennsylvania.

\section{TABLE 8}

\section{Absorption Area Requirements for Single Family Residences}

\section{Comparison Between Septic Tanks and Aerobic Tanks}

(a) "The following figures shall show absorption area requirements for the effluents of single family residences, including allowances for garbage grinders and automatic sequence washing machines":

Average Percolation Rates $Z \quad \begin{gathered}\text { Septic Tanks } \\ \text { (Sq. ft./bedroom) }\end{gathered}$

$0-5 \mathrm{~min} /$ inch

6-15 $\mathrm{min} /$ inch

16-30 $\mathrm{min} /$ inch

31-45 min/inch

46-60 $\mathrm{min} /$ inch

61 or more min/inch unsuitable

175

250

300

330

unsuitable
Aerobic Tanks

(Sq. ft./bedroom)

\author{
unsuitable \\ 120 \\ 170 \\ 200 \\ 220 \\ unsuitable
}

It is noted that the effectiveness of aerobic systems is still subject to opinions by various professionals in the field. Then a comparison is made between the performance of septic tanks and aerobic units, the viability of the aerobic systems is questionable. The aerobics require a smaller size of soil absorption systems, however, their higher capital costs, power and maintenance cost probably overshadow their benefits. The field inspection of 30 aerobic systems seen indicated that one third of the installations had some form of failure such as pump breakdowns, improper functioning of the air diffusers and malfunction of the control systems. Some systems were not properly maintained and some were entirely abandoned because of lack of replacement parts and/or excessively frequent failures.

Therefore it has been the tendency of various researchers to retain the septic tanks which require very little maintenance and direct the efforts towards the improving the performance of soil absorption systems.

\section{6 Mounds}

Twenty mound system installations were observed in the field trips. Most systems performed adequately, retaining a dry surface in their immediate surroundings. Failing systems were observed in Montgomery County, Maryland. 
The ground around these mounds was soggy, which indicated that the underlying soil was of very marginal properties and could not absorb the effluents coming from the mound. Reasons for failure may be attributed to poor construction practices such as soil smearing or soil compaction at the time of the system installation, which upset the natural permeable properties of the soil and caused an early failure of the systems. A large amount of mound failures were also reported in the state of Pennsylvania [10]. The reasons for failure were because the underlying soil was of extremely heavy clay; also, the systems constructed were gravity fed mound and not pressured, which may have resulted in uneven effluent distribution in the mound.

When properly designed and constructed, a mound is an appropriate alternative to conventional soil absorption systems. Mounds may be constructed to properly blend with the home and its surrounding landscape.

Mounds receive the wastewater effluents from either conventional septic tanks or from aerobic treatment tanks. As mentioned earlier, it is claimed by some professionals that the performance of the mound is more effective with aerobic wastewater effluents as compared to the septic tank effluents. This argument needs further study and verification.

\section{7 Evapotranspiration (E-T) Beds}

As mentioned earlier, the performance of $E-T$ beds is more sensitive in comparison to mounds systems as they form a closed system and do not depend on the soil surroundings. They are also dependent on climatic conditions. $E-T$ beds were observed to work very well in the state of Colorado and probably work well in any region of relatively dry climate and low precipitation. The adequacy of their performance in areas of high precipitation is marginal. Systems observed in the east were not entirely successful. A system observed in Kentucky was a total failure. The E-T bed was soggy with puddles of water in some areas causing inconvenience to the homeowner. A similar mode of E-T beds failures were observed in Montgomery County, Maryland.

Evapotranspiration beds are designed according to the following equation [11]:

$$
(V / A)=E T-P
$$

where: $\quad V=$ total volume of effluents to ${ }_{2}$ the bed in meter ${ }^{3}$

$A=$ area of the $E-T$ bed in meter

$\mathrm{ET}$ = evapotranspiration in a water column in the bed in meters

$P=$ precipitation in meters

$\mathrm{V} / \mathrm{A}=$ the water column in the bed in meters

This expression represents the balance between wastewater loading, evapotranspiration and precipitation required at all periods and obviously the period with lowest "ET" and highest "P" values are the critical ones. If disposal is entirely dependent upon the bed, the value for (ET-P) should be positive at all times, namely, evapotranspiration should exceed precipitation. This situation rarely exists in most regions east of the Mississippi River where at least one of the following climatic factors are prevalent: high precipitation, low temperature, high humidity and snow. Thus, the feasibility of E-T systems in such areas is questionable, as indeed witnessed in the systems observed in the East. 
$\underline{\text { TABLE } 9}$

Failures or Malfunction of Onsite Wastewater Systems Reviewed

\begin{tabular}{|c|c|c|}
\hline System & Mode of Failure & ible Cause of Failure \\
\hline $\begin{array}{l}\text { Composting Toilets } \\
\text { Large Volume Type }\end{array}$ & $\begin{array}{l}\text { Strong odor from toilet } \\
\text { Accumulation of liquids } \\
\text { in tank }\end{array}$ & $\begin{array}{l}\text { System overloaded } \\
\text { Vent pipe clogged }\end{array}$ \\
\hline $\begin{array}{l}\text { Composting Toilets } \\
\text { Small Volume Type }\end{array}$ & $\begin{array}{l}\text { Unbearable smell } \\
\text { Flies hovering all around } \\
\text { No decomposition of wastes } \\
\text { High accumulation of } \\
\text { liquids }\end{array}$ & $\begin{array}{l}\text { Too many users ( } 4 \text { ) } \\
\text { Improper venting } \\
\text { Improper dosing of } \\
\text { composting agents } \\
\text { (observed in several } \\
\text { cases) }\end{array}$ \\
\hline $\begin{array}{l}\text { Incinerating Toilets } \\
\text { Electricity Operated }\end{array}$ & $\begin{array}{l}\text { Strong odor from vents } \\
\text { Long time of incineration }\end{array}$ & $\begin{array}{l}\text { Improper vent design } \\
\text { (observed in two cases) }\end{array}$ \\
\hline Chemical Toilet & Strong odor from toilet & $\begin{array}{l}\text { Malfunction of } \\
\text { recirculating pump } \\
\text { Over usage } \\
\text { Improper choice of } \\
\text { system for its } \\
\text { purpose of usage }\end{array}$ \\
\hline Oil Flush Toilets & $\begin{array}{l}\text { System observed in a } \\
\text { state highway rest area } \\
\text { Dirty surfaces in the } \\
\text { toilet's well }\end{array}$ & $\begin{array}{l}\text { Note: This improper } \\
\text { functioning was } \\
\text { observed in one oil* } \\
\text { flush system. Another } \\
\text { manufacturer coats the } \\
\text { toilets with tephlon } \\
\text { which apparently } \\
\text { provides for better } \\
\text { cleansing of the } \\
\text { toilet in which case } \\
\text { no foul surfaces were } \\
\text { detected. }\end{array}$ \\
\hline
\end{tabular}


Table 9. continued

One system observed incorporated an incinerator for the disposal of the waste. The system encountered operating problems resulting in incomplete incineration of the wastes with exhorbitant costs of oil fuel.

Microphor Toilet

Water splashed out of the fixture during flush.
The flapper valve did not seal the bottom chamber when pressure was applied.

Note: This was noticed in one toilet only and may not be a prevalent problem.
Vacuum Toilets

Relatively high noise
level upon flushing
Improper cleansing of
the bowls
Blockages (not frequent)
of the drain lines
Another system observed
in Israel (1971)
encountered the
following problems:
- Blockage in lines
- Failure of the flushing
mechanism
- Loss of vacuum (leakage)
- Blockages of the traps
and the PvC drainage pipes
- High noise level

Relatively high noise

Noise is inherent with the present design

Water does not reach all the bowl surfaces

Use of paper towels and diapers

Most problems we re attributed to improper design and improper maintenance. Noise level is inherent in the system's operation.
Aerobic Tanks

\section{No aeration}

Sewage has a dark grey color, formation of scum with unpleasant odors.
Failures were observed in $30 \%$ of systems seen:

- Aerator pump breaks

- Malfunction of the controls such as freezing of the relays and timers.

- No provisions for system's restoration after electric power failure

- No maintenance 


\section{Table 9, continued}

\begin{tabular}{|c|c|c|}
\hline System & Mode of Failure & Possible Cause of Failure \\
\hline$E-T$ Beds & $\begin{array}{l}\text { Flooding of the bed } \\
\text { Bed is soaked with with } \\
\text { waste effluents }\end{array}$ & $\begin{array}{l}\text { Improper sizing of the bed } \\
\text { Area subject to high precipitation } \\
\text { Bed located in low ground receiving } \\
\text { water from the surroundings in } \\
\text { addition to the waste effluents }\end{array}$ \\
\hline Mounds & $\begin{array}{l}\text { The slopes on the mound } \\
\text { and its surroundings } \\
\text { are soggy and muddy }\end{array}$ & $\begin{array}{l}\text { - Mounds base is located on very } \\
\text { heavy clay soil } \\
\text { - The mound was constructed with } \\
\text { improper soil material } \\
\text { - The aerobic unit has not been in } \\
\text { operation for quite some time } \\
\text { - Generally very poor maintenance } \\
\text { of the system (as readily } \\
\text { observed by the wild growth of } \\
\text { grass and vegetation on the } \\
\text { mound) }\end{array}$ \\
\hline
\end{tabular}




\section{Onsite Wastewater Demonstration Projects}

Any onsite wastewater demonstration project entails the introduction of an advanced wastewater technology for presenting feasible solutions to one or more of the following problems which exist in the selected site:

1. Conventional systems - very costly. (i.e., problems of small communities, in particular, in rural sparcely populated areas).

2. Failure of existing conventional wastewater systems. The systems do not meet the wastewater effluent quality criteria and may be an environmental hazard and/or a nuisance to the community.

3. Conventional wastewater systems consume too much water in a region of limited water resource and wastewater reuse devices are needed.

4. Conventional systems cannot be accomodated in the site because of space, topography and geological constraints.

5. Conventional systems are not permitted by regulation. Sewer moratoria on existing centralized wastewater systems restrict further housing development or septic tank construction permit was not granted after a failure of the onsite soil evaluation test.

The measure of success of any demonstration project is the realization that the selected wastewater handling/treatment system provided an adequate solution as indicated by the inspection, monitoring and laboratory sampling program, and from the feedback furnished by the homeowners while the systems were under observation. Beyond the project demonstration period, the same maintenance should continue as the project, in effect, still goes on. The system may be considered to have accomplished its goal even if the system failed provided that clear and sound conclusions were drawn from it for future alterations and improvements.

An overview of demonstration projects observed on the sites visited and studied from the literature is presented to point out successes and failures resulted from improper system planning, design, construction and/or maintenance.

Section 6, "Requirements for Demonstration" outlines the minimal essential requisites for a demonstration or any project of innovative nature. In the following reviewed cases those criteria were not fully met.

Vacuum Sewage System in Carmiel, Israel [6]

The town of Carmiel is situated on a rocky steep terrain and has had limited water resources. Thus, water shortage and wastewater transport problems necessitated an alternative wastewater system. The vacuum sewage system seemed to be a viable wastewater alternative as it provides a solution to both problems. The system was installed in 1967. The problems, which were described earlier in this report were increasing in frequency until finally the system was abandoned in 1973. 
The following reasons for failure of the system can be partly attributed to improper planning and partly due to unanticipated problems which may occur with innovative projects:

- Improper design of the drainage system. The wastewater transport system which was constructed in a series arrangement certainly aggrevated the situation, as localized problems propagated downstream and upset a large size of the plumbing network.

- There was no planned maintenance program and no periodic inspection.

- The problem of system rejection by the users because of the toilets noise upon flushing has been a serious one and could possibly be avoided by preliminary testing; in which case the system probably would not have been installed. One may note, however, that in similiar installations in the Bahamas no complaints of that nature were expressed by the occupants of the dwellings.

The significant positive feature in this project was the construction of a redundant conventional system which was successfully taken advantage of, almost as soon as it was decided to abandon the vacuum system.

\section{Boyd County Experience [12]}

Boyd County Demonstration is a project initiated by the Appalachian Regional Commission which funded 100 percent of the equipment and maintenance for the first year. The project is situated in the State of Kentucky in the heart of Appalacia, a rural sparcely populated region of very low to middle income families. Conventional centralized sanitation facilities would have been too costly and septic tank systems not reliable since the local soils cannot provide adequate percolation. The project objectives were to demonstrate the feasibility of innovative onsite individual wastewater systems. The project employed a "system approach" where the community's individual wastewater systems were managed by a County Sanitation District. This public body took responsibility for supervision and maintenance of the systems. As a start, the project entailed 36 homes which incorporated wastewater systems of various configurations as follows:

- Aerobic units from six manufacturers

- Disposal systems such as E-T beds, sand filters with stream discharge and leach fields

- Wastewater recirculation for toilet flush reuse

Continuous test data $(1976,77)$ indicated reasonably careful monitoring and data collection program of the pertinent wastewater parameters.

A one day trip in the winter of 1979 , observation of some of the installations in the homes, and a talk to some of the homeowners indicated various aspects of the systems, both positive and negative: 
The system is composed of a holding tank which collects the aerated effluent. The treated wastewater is then disinfected and recirculated for toilet flush water reuse. The unit provided a significant improvement to the homeowner who expressed entire satisfaction with the system. Prior to its installation, he had acute water shortage as his well did not deliver sufficient water to the household.

- Aerobic Units

Malfunction of the unit electrical control mechanisms. Breakdown of the unit aerator pump.

System overloading.

\section{- Evapotranspiration Bed}

Apparent improper design of the E-T bed resulted in flooding of the front yard and caused a serious inconvenience to the homeowner.

The general impression was that except for the person receiving the recycling device, the other homeowners were not concerned nor did they express appreciation for obtaining these systems which probably did not add to their quality of life appreciably. As it turned out, the systems were not maintained for quite some time, apparently, for lack of man-power. Based on the general state of the systems as observed at the time of the visit, the following criticisms may be stated:

- Sustained satisfactory performance was not experienced as the maintenance was not carried out throughout the period up to the day of the investigator's visit.

- The benefits of the innovative systems of the project cannot be fully assessed because the systems have not been appreciated by the homeowners.

\section{Garrett County Home Aeration Wastewater Treatment Project [13]}

This project was conducted by the Environmental Health Administration of the Maryland State Department of Health and Mental Hygiene. The project objectives were the evaluation of aerobic wastewater systems subjected to actual working conditions and testing aspects such as wastewater stress loading and detergent foaming problems. The system was installed in Garrett County, Maryland, in homes which "had experienced some degree of septic tank system failure." [13] Five aerobic units manufactured by five different manufacturers were installed. An extensive program of maintenance and sampling of the treated wastewater effluents was conducted for a period of one year (1973, 74). This project may be regarded as successful in as much as the outlined objectives within the period were achieved. Also, the conclusions drawn from this project were useful and provided material for future applications. However, a visit to the site in the summer of 1979 revealed the following: 
Out of three systems observed, two were entirely abandoned and one was not in operation at the time of the visit. (The users would occasionally shut the system down, apparently to conserve electrical energy). Of the two abandoned systems, the owners claimed that they had continuous pump failures but they had no one to turn to for maintenance and repair. In one case, the owner expressed dissatisfaction with the system since black partially treated effluent comes from his soil absorption system and flows by gravity to a ditch alongside his house. In the second case the aerator pump broke. The aerobic unit has been functioning as an ordinary septic tank. The anaerobic effluents flow from the tank, by gravity, to some form of a soil absorption system located alongside Deep Creek Lake. The pump failure caused no concern to the owner, as it did not create any noticable problems. It is apparent that in the latter two cases the failure of the systems did not affect the owner terribly, since otherwise they would find some way to ameliorate their situation. This fact poses the question whether these sites were a proper choice for demonstration. It is probable that prior to that project the degree of failure of the existing wastewater disposal systems was not very severe so that the effect of the innovative system cannot be assessed and evaluated.

\section{Montgomery County (Maryland) E-T Systems Demonstration [11]}

This project for evapotranspiration systems was initiated by the office of Community Development (OCD) in the county and funded by the Metropolitan Washington Council of Governments (COG). The project objectives were:

1. To determine the feasibility of Evapotranspiration in the Washington Metropolitan Area.

2. If $E-T$ beds are found to be feasible, present recommendations of $E-T$ systems, regarding design, construction, and operation.

Five E-T systems were installed in the county in the summer of 1977 with the following variables and configurations:

- Geometry: bed, trench, mound.

- Treatment Type: septic tank, aerobic tank.

- Base Lining: no base lining, with plastic lining.

The systems were under observation for one year during which the parameters related to weather, flows, chemical and biological conditions were sampled and measured on a weekly basis.

In their final report the researchers concluded "that the test system did in fact accommodate the flow pattern generated." Their finding, though, indicated that two of the sites did exhibit problems of overflowing and ponding.

A recent visit to four of the five sites revealed the following:

- Ponding of effluents in all the sites, two of which had dark liquid with foul odor surfacing. In the two systems containing 
the aerobic treatment tank, one was in operation and the other seemed to be abandoned. The project may be criticized in thefollowing areas:

1. Lack of continued maintenance resulted in obscuring the outcome of the project as conclusions cannot be drawn regarding the feasibility and effectiveness of the system.

2. Conclusions reflected in the final report were perhaps premature, as the system was under observation for only 12 months whichis not a sufficient period for conclusions and final assessments for systems which are strongly dependent upon climatic conditions.

3. The demonstration was conducted on a small scale with a small sample size, and too many variations of systems configurations. A better approach would have been to reduce the number of variables under study and concentrate on one or at most two parameters, so that more meaningful and conclusive information could have been drawn for the monitored period and beyond.

\section{Shortcomings and Limitations of Demonstration Programs}

It appears that demonstration programs may have the following shortcomings:

1. Insufficient collection of data on the sites prior to the project start. If this information is not complete, full assessment of the demonstrated innovative system cannot be obtained.

2. Insufficient funds or manpower for providing adequate maintenance and observation. In this case, the system may fail and the project will be self-defeating with erroneous conclusions drawn from it.

3. A small sample size for the demonstration. A small sample size will furnish results with little statistical significance. The size of the project depends on the available funds allocated for the project; however, if funds are not available for a sufficiently large project, the usefulness in starting the project is questionable.

4. Insufficient time for system observation. Sufficient time must be allocated to ascertain that a steady mode of operation was achieved so that the system will continue to operate in the same mode after the demonstration project had officially ended.

5. User's acceptance, cooperation and participation. The success of a demonstration project depends to a very large extent on the users' acceptance, and the project's importance in solving the immediate wastewater problems. It would probably be advantageous if the homeowners participate in some of the equipment cost. As seen, free systems given to the homeowners were not always appreciated and consequently not maintained.

In the above described demonstration projects, at least one of the categories was not met. 


\section{E. Aspects of Onsite Wastewater Systems}

\section{E.1. The Aspect of User's Acceptance}

The problem of user's acceptance has its impact to various degrees in most innovative wastewater systems. Contrary to conventional, centralized systems, which are taken for granted, innovative systems require considerations which range from periodic system check to an overall radical change of the homeowner's personal habits and life style. Any required awareness from the users has a nuisance demerit and affects his general attitude. The vacuum toilets produce a high sound upon flushing and may be disqualified for that reason alone. The composting toilets require a radical change in habits and attitude, from the standpoint of daily usage and maintenance. Their external shape may be appalling and, as mentioned earlier, a considerable percentage of people are reluctant to use these devices.

The problem of acceptance is a concern and a subject for numerous surveys conducted on attitudes towards the usage of reclaimed water. Table 10 indicates the results of the survey conducted by "Pure Cycle" [14] on consumers attitude in drinking recycled wastewater. These results may be encouraging to Pure Cycle as only 24 percent are crossed off their list of prospective customers of wastewater package system. However, from the community view such results are discouraging if one considers a large community recycling system which may be imposed on the community as a whole. A more detailed survey was conducted in the State of California [15] and included ten communities with a sample of 100 per community. This survey examined several parameters involving the attitude towards various usages of recycled wastewater such as garden irrigation, fishing, bathing and drinking. Table 11 indicates the degree of acceptability for these usages. In addition, these surveys indicated that acceptance is a function of the user's educational level, a well known fact which has been established in other studies too. Table 12 lists the relative frequencies for reasons of nonacceptance of full reuse of reclaimed wastewater. It is noted that the psychological reason is the most dominant factor. Apparently, people who expressed resentment did not know the fact cited by EPA that 50 percent of the population of the U.S. drink recycled water of some form or another. Therefore, the major effort for the promotion of innovative systems has to be through public education by various dissemination programs and the news media.

\section{E.2 The Aspect of Codes Acceptance}

Codes and regulatory agencies may be viewed as agents which block the promotion of innovative wastewater technology or as buffers against the introduction of devices which may be a threat to public health due to water borne diseases or a nuisance to the homeowner because of problems such as mechanical failures and excessive maintenance. Almost all innovative systems have the inherent problem of lack of experience, incomplete data base for evaluation and some probability of failure. Therefore, the incorporation of innovative systems into codes is a long process and the following two questions are raised by legislative personnel and manufacturers: 
TABLE 10

Results of the Survey on Attitudes Towards Recycled Wastewater Conducted by "Pure Cycle"

Does the idea of drinking recycled water bother you?

$\begin{array}{lr}\text { Yes } & 28 \% \\ \text { No } & 67 \% \\ \text { Don't know } & 5 \%\end{array}$

Water recycling is the reuse of sewage and waste water after it has been purified. If the quality of the recycled water is as good or better than municipal water, would you drink recycled water?

$\begin{array}{lr}\text { Yes } & 76 \% \\ \text { No } & 18 \% \\ \text { Don't know } & 6 \%\end{array}$

Do you think ways of recycling household sewage and waste water should be studied and made available to the homeowner?

$\begin{array}{lr}\text { Yes } & 94 \% \\ \text { No } & 1 \% \\ \text { Don't know } & 5 \%\end{array}$

If a water recycling system is completely fail/safe, would you favor or oppose the use of such a system?

$\begin{array}{lr}\text { Favor } & 81 \% \\ \text { Oppose } & 11 \% \\ \text { Don't know } & 8 \%\end{array}$


TABLE 11

Public Attitude Ratings Towards Reuse for Various Usages Conducted by the State of California

\begin{tabular}{llll}
\hline \multicolumn{1}{c}{ Use } & $\begin{array}{c}\% \text { of } \\
\text { acc. }^{\text {a }}\end{array}$ & Rank & Acceptability category \\
\hline Garden irrigation & 88.4 & 4 & \\
Toilet & 88.3 & 3 & \\
Park/golf course & 87.7 & 1 & \\
Factory & 87.6 & 2 & Most acceptable \\
Farm irrigation & 83.6 & 6 & \\
Scenic lakes & 82.9 & 5 & \\
& & & \\
Boating/fishing & 72.4 & 7 & Moderately acceptable \\
Laundry & 67.3 & 9 & \\
Beaches & 65.9 & 8 & \\
Bathing & 61.4 & 10 & \\
& 49.5 & 11 & Least acceptable \\
Food canning & 48.1 & 12 & \\
Cooking & 39.1 & 13 & \\
Drinking & & & \\
\hline
\end{tabular}

TABLE 12

Relative Frequencies for Reasons of Nonacceptance of Full Reuse of Reclaimed Wastewater Conducted by the State of California

1. Psychological

2. Lack of purity

43.7

3. Can cause disease

16.4

4. Lack of experience

10.3

5. Danger through improper plant operation

9.2

6. Undesirable chemicals added

7.2

7. Prefer other sources/methods

5.6

8. Taste/odor problems

3.1

9. Body contact undesirable

2.1

10. Unreasonable treatment cost

1.8

0.7 
If data and field experience is not available, how could the system be approved?

If the system is not approved, how is it possible to obtain sufficient field data?

Review of plumbing codes make one realize the large variations in procedures and requirements. Table 13 presents minimum and maximum values for conventional septic tank soil absorption systems as specified in the State Codes.

These variations are for systems that have been in use for several decades. These differences cannot be explained and are not related to any scientific findings nor can they be attributed to climatic or other specific requirements among the states. If such variations exist for conventional systems, one may expect larger variations in innovative wastewater systems. Table 14 is a compilation of the onsite wastewater policies [16] as administered by all the states in the country.

Policies vary from state to state and also between counties of the same states as described in Table 14. One may even find special regulations in townships. The tendency is generally to stay on the conservative side and approve innovative systems in special conditions such as replacements of failing systems. The State of Wisconsin still does not approve the construction of mounds in spite of the experience and know-how gained in the state through the University of Wisconsin. This state will approve only 3 percent of mound construction requests throughout the state and a maximum of 5 percent for an individual county. Boulder County in Colorado will let ten innovative systems be constructed for observation. The State of Maine [17] may be noted as having a plumbing code which includes progressive approaches and regulatory provisions. This code specifies requirements for experimental systems, allows for the reduction of soil absorption fields when water saving devices are used and approves waterless toilets such as chemical toilets, compost toilets and incinerator toilets.

It may be noted that the national plumbing model codes do not specify requirements for innovative systems. Requirements for onsite wastewater systems are specified only for septic tanks and conventional tile fields.

\section{E. 3 The Aspect of Health in Onsite Wastewater Systems}

The problem of health and safety of wastewater systems has been very much debated and various views have been expressed. This problem was very well addressed and defined in [18] as follows:

"From the public health point of view, there are two basic criteria for the safety of an onsite system:

- Is the system safe in terms of disease transmission in theory?

- Is the system safe in terms of disease transmission in practice? 
TABLE 13

Maximum and Minimum Values for Areas Septic Tank Soil Absorption Systems Required by State Codes

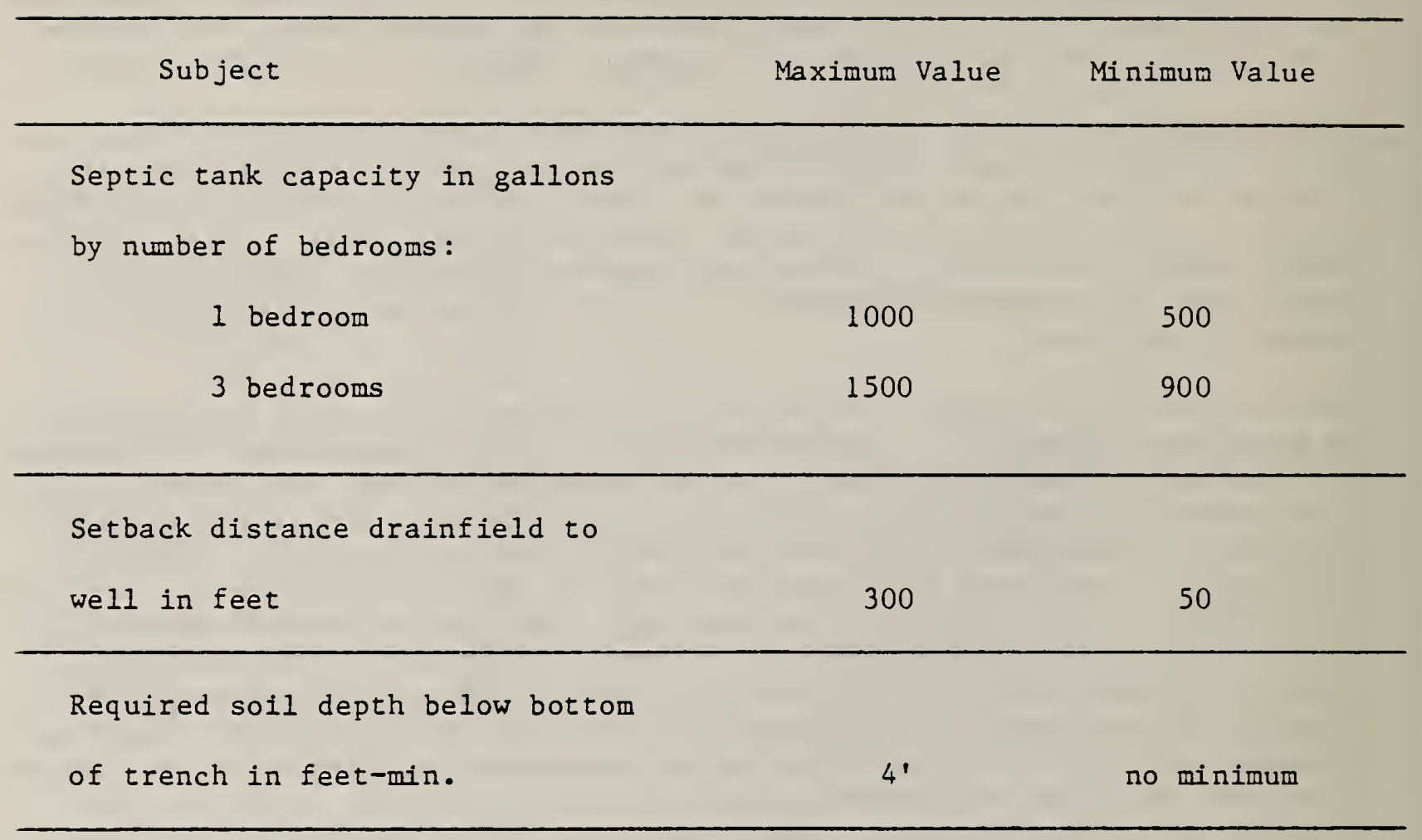




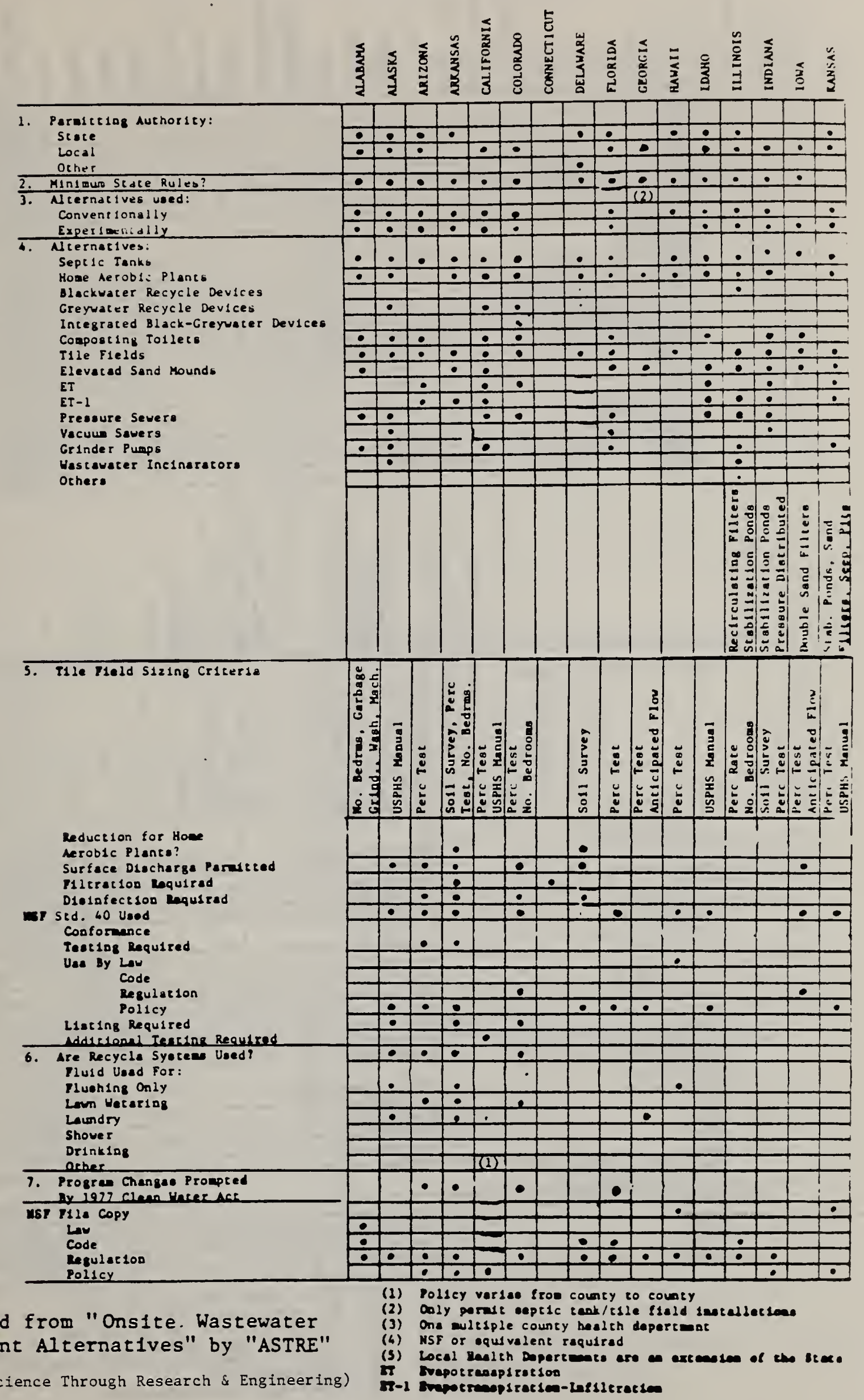


1. Peralte1ng Authority:

seace

Locel

Oether

2. Minlmum Scace Rules?

3. Nicernacives ueed:

Conventsunally

Experimentally

4. Niternacives

Sept1c Tanke

Hose Aerobic Plante

- blackuater Recycle Devices

Greyuater Recycle Devices

Integrated Black-Greyucter Devica.

Compoting tollete

Tile Fields

Eleveted Sand Mounds

ET

ET-1

Presoure Sever:

Vecuum Severs

Grinder Pumps

Hesteverer lacinerecore

Othere

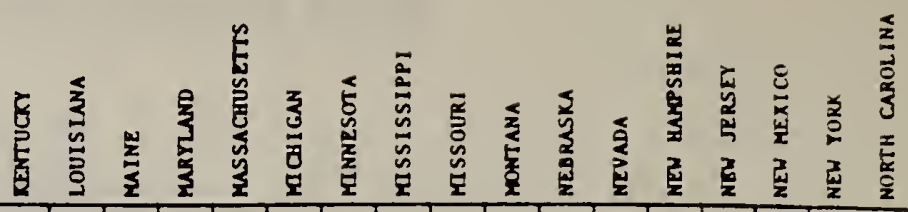




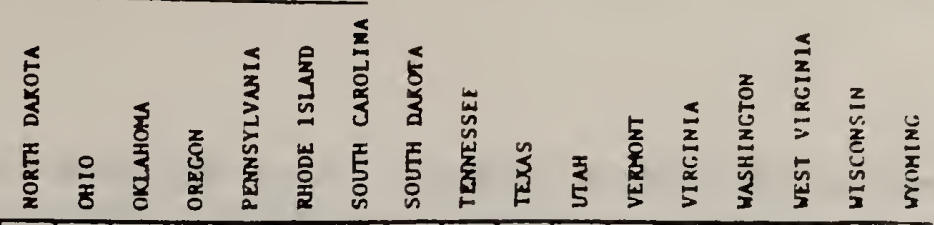

\begin{tabular}{|c|c|}
\hline 1. & $\begin{array}{l}\text { Peradeling Authority: } \\
\text { Stote } \\
\text { Local } \\
\text { Weher }\end{array}$ \\
\hline 2. & Minloum State Rules? \\
\hline 3. & $\begin{array}{l}\text { Alernetivas uead: } \\
\text { Convent lonelly } \\
\text { Expertancally } \\
\end{array}$ \\
\hline 6. & 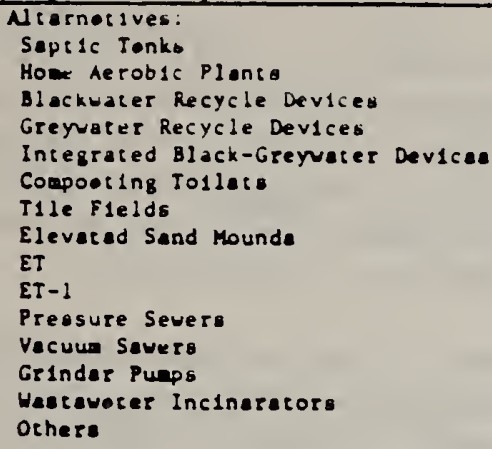 \\
\hline
\end{tabular}
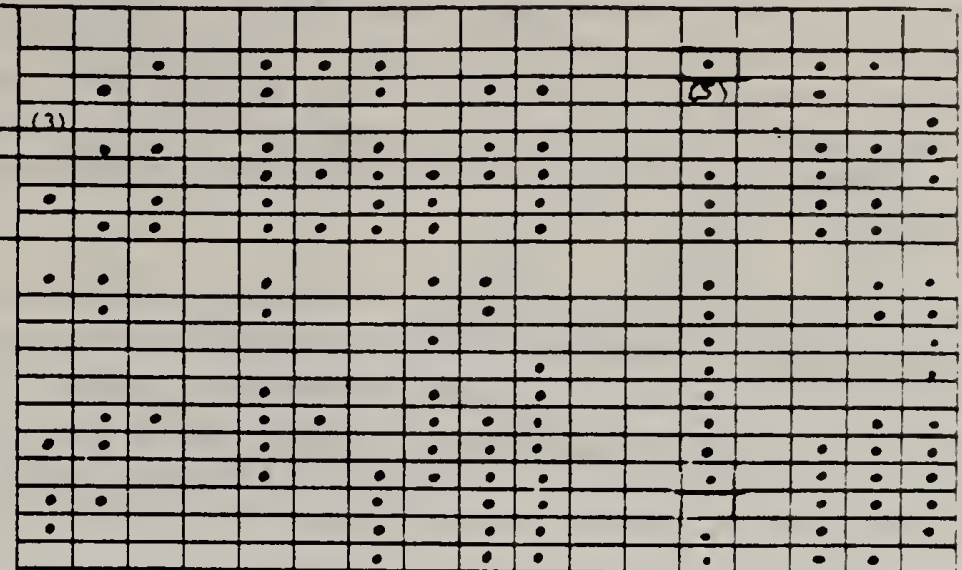

3. N1e Plald Sisins Critario

ieduction for Hone

Nerob1c Planta?

Surfece Diecherge Parnteted

Pileration Iequired

Dieinfection Required

WSF Std. 40 Uaad

Cosformance

Testing Required

Use By Lau

Code

Reguletion

Pollcy

Liating Raqulred

Addiclomi Teestare Requirad

6. Ara Racycla Syaceo Uaed?

Fluld Unad For:

Pluating only

Lewn Hacering

Leundry

Shover

Drinkine

Other

7. Progran Changes Propted

Dy 1977 Clean Wacer Act

isf Pile copy

Lav

Code

teguletion

Pol1cy
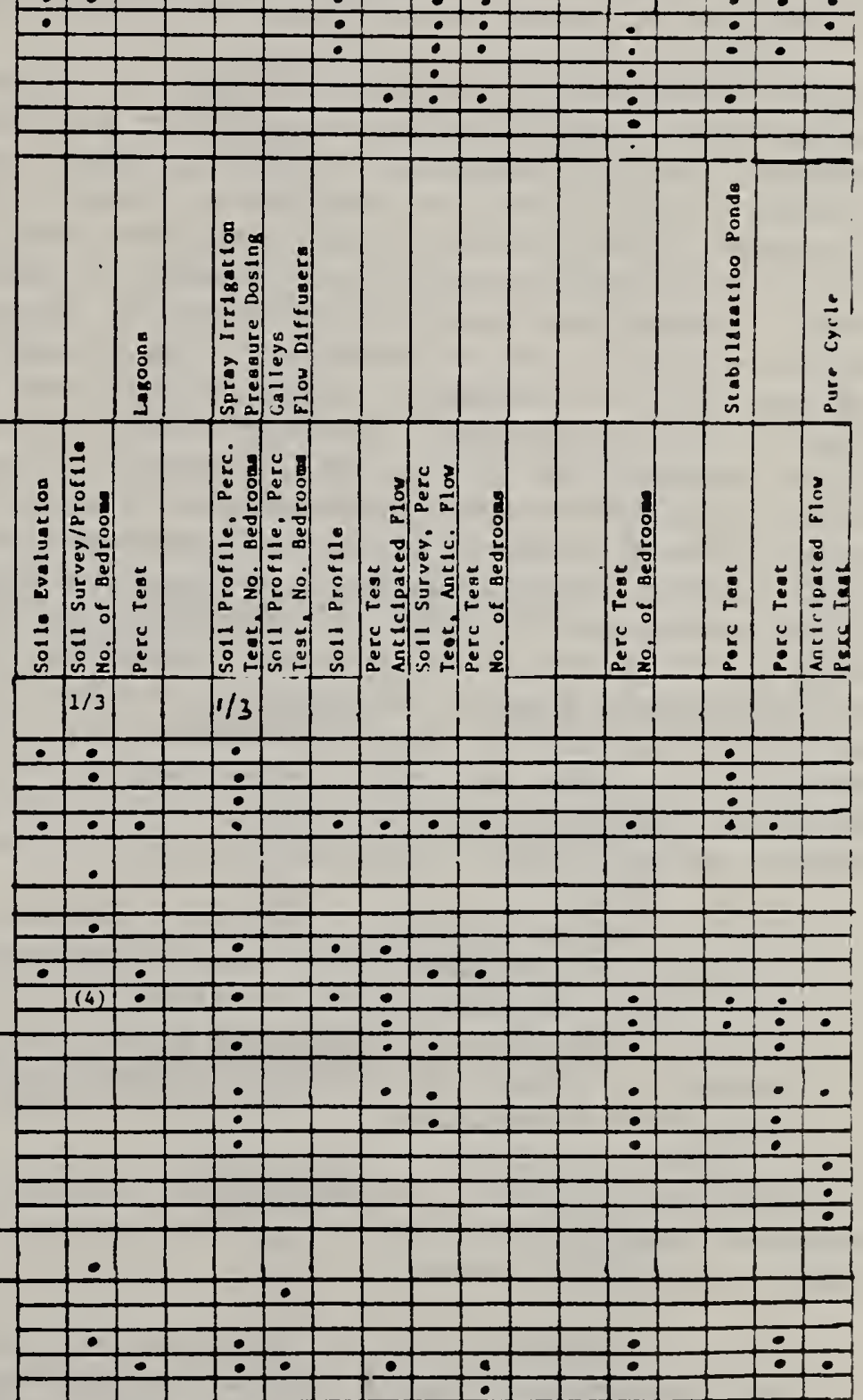

(1) Polley veries fron county to county

(2) Only peralt eepelc tank/tile fleld laotellationo

(3) One vulelple county hesleh departent

(4) NSF or equivalent required

(5) Locel Hesith Departenca are an axtension of the State

ET Zvapotranepiration

ET-1 Evapotranap1ration-Inf 1 leration 
From the theoretical point of view, any safe system must isolate potential disease causing organisms from possible means of transmission by vector, (agents capable of transferring pathogens) human contact, or water pollution. From the practical viewpoint, the system must be relatively "fail-safe," or else adequate provisions must be made to insure that users of the system will operate it in such a way that its performance approaches theoretical criteria.

However, the question of public safety is not the same as public health acceptability. Acceptability implies a value judgment in which potential benefits are weighed against potential risks. Thus "safety" is an objective quantitative measure of performance under theoretical or practical conditions, while a judgment as to acceptability takes into account the human context of the problem including preferences, economics, available resources, and needs.

Tables 15 through 18 indicate outbreak of diseases from various wastewater systems [19]. Health authorities report outbreaks of hepatitis, diarrhea and meningitis as a consequence of failing septic tanks. Reports indicate detection of polio virus in 100 feet deep wells located 300 feet from the edge of a wastewater drain field. Viral tests were conducted by the University of Florida [20] which revealed the presence of virus in 20 foot wells after heavy rains. Alarms have been expressed on the microbiological hazards of household toilets and the role of aerosols in the epidemiology of disease transmission by toilets [21, 22]. Similar questions have been raised in regard to undisinfected spray irrigation systems. For both cases, it was found that the particle size of the aerosols are in the range capable of reaching the lower respiratory tract. How severe these problems are in actual practice has not been established as yet. These problems become more serious with the use of water-saving low flush toilets and recirculating systems since their concentration of pollutance in the wastewater effluent is expected to increase. Test data from the Pure Cycle purified effluents indicate a very high degree of treatment. The question always remains how reliable is that system designed to treat wastewater to potable quality and what is the probability that some unforeseen chemical agent or pathogene may enter the system without being detected by the built in alarm and cause undesirable effects. Some quotations from a report issued by a medical epidemiologist [18] sums up the inherent problems of this matter:

". . In our opinion, it is not possible to do an analytic epidemiological study which would yield conclusive results and the money expended would be wasted . . Accidents with composting and reclamation will occur and though we do not believe that hazard is great, the potential does exist for communicable disease transmission."

The statement cited in reference [18] is more encouraging and has more practical implications, in particular, in policy making for innovative onsite wastewater systems.

" . . acceptability of a particular system must be determined by local public health officers on the basis of the best available information and experience together with particular needs and conditions." 
TABLE 15. WATERBORNE DISEASE OUTBREAKS 1971-1975

\begin{tabular}{llllll}
1971 & 1972 & 1973 & 1974 & 1975 & TOTAL \\
\hline
\end{tabular}

$\begin{array}{lrrrrrr}\text { Outbreaks } & 19 & 29 & 26 & 25 & 24 & 123 \\ \text { Cases of Illness } & 5182 & 1638 & 1774 & 8356 & 10879 & 27829\end{array}$

TABLE 16. ETIOLOGY OF WATERBORNE OUTBREAKS 1971-1975

\begin{tabular}{lrr} 
& OUTBREAKS & CASES OF ILLNESS \\
\cline { 2 - 2 } Acute Gastrointestinal Illness & & 17,752 \\
Hepatitis - A & 14 & 368 \\
Shigelloses & 14 & 2,803 \\
Giardiasis & 13 & 5,136 \\
Chemical Poisoning & 12 & 511 \\
Typhoid & 4 & 222 \\
Salmonelloses & 2 & 37 \\
Enterotoxigenic E. coli & 1 & $\frac{1,000}{27,829}$ \\
Total & 123 &
\end{tabular}

TABLE 17. WATERBORNE OUTBREAKS BY TYPE OF SYSTEM 1971-1975

OUTBREAKS $\quad$ CASES OF ILLNESS

Municipal Systems Semi-Public Systems Individual Systems Total

\begin{tabular}{rr}
37 & 18,633 \\
70 & 9.058 \\
16 & 138 \\
\hline 123 & 27,829
\end{tabular}

TABLE 18. WATERBORNE DISEASE OUTBREAKS BY TYPE OF DEFICIENCY $1971-1975$

Untreated Surface Water*

Untreated Ground Water

Treatment Deficiencies

Distribution System Deficiencies

Miscellaneous

Total

\begin{tabular}{cr} 
OUTBREAKS & CASES OF ILLNESS \\
\cline { 2 - 3 } 19 & 5,729 \\
38 & 3,958 \\
39 & 10,139 \\
15 & 7,468 \\
$\frac{12}{123}$ & 535 \\
\hline & 27,829
\end{tabular}

* Includes seven outbreaks of giardiasis in which surface water was chlorinated but not filtered. 


\section{E. 4 The Aspect of Maintenance}

Most failures observed in the field trips were attributed to the inadequacy of maintenance of the wastewater systems. A system may be highly efficacious in principle; however, lack of proper maintenance will be self-defeating for the system, as its true capabilities could not be demonstrated. This happened to the Composting Toilets which were criticized and attained some degree of notoriety as failing systems. The reason for the failure of composting toilets as observed in the trips was attributed to the user's lack of information on the workings of the system and consequently improper maintenance.

Aerobic systems are very susceptible to malfunction and require a considerable amount of maintenance. As earlier mentioned, a large percentage of aerobics were observed to fail or perform inadequately because of mechanical failures primarily in the control devices of the systems. The major aerobic system manufacturers are under the NSF testing program and these products bear the NSF seal of approval. NSF tests these aerobics under simulated, controlled, field conditions for a period of six months. Although the systems are subjected to rigorous test programs which include elements such as "stress testing" and "shock loading," these procedures do not entirely represent field conditions. At best, one may say that these tests are reasonably good indicators to the performance of actual conditions provided, the systems are treated in the field in a similar way that they are being tested in the NSF laboratories which generally is not the case. These facts strongly indicate that systems should be approved only on condition that the homeowner submits a detailed maintenance program which will be carried out by experienced personnel from the manufacturer's staff or a local representative. Mention should be made of the company John Fancy, Inc [23]. This company operates in the State of Maine as a maintenance and servicing outfit of aerobic wastewater systems. It serves some 450 systems on a contractual basis. Each system is visited at a frequency of at least once in eight weeks for inspection and service. This company also provides emergency service normally taken care of within two days. It appears that in order that proper maintenance will be given, a planned and controlled program, either by a private organization or a legislative unit, is imperative.

\section{E.5 Economic Aspects of Onsite Wastewater Systems}

With the rising cost of conventional centralized wastewater systems, which may reach $\$ 12,000$ per "hook-up," onsite wastewater systems become more and more attractive as an alternative cost effective system. With good soil and site conditions, the septic tank - tile field is by far the most economic wastewater treatment and disposal system. When the soil on the site is of marginal properties, alternative systems should be considered. Aside from performance of the system and capability in meeting effluent quality levels, the costs of the system will be the final factor in the decision making process among the available alternatives. The costs of the system will generally be broken down into the following components:

1. First cost

$\begin{array}{ll}\text { - } & \text { System design } \\ \text { - } & \text { System cost of acquisition } \\ & \text { System construction and installation }\end{array}$


2. Annual or monthly cost

- Maintenance and service charges

- Replacements of parts (pumps, compressors, filters)

- Power costs

- Cost of disinfectants (iodine, chlorine)

Based on present or future forcasted interest rates and the system life, all cost factors are converted to a common basis to furnish a total annual or monthly cost. Water conservation devices and recycle/reuse systems will include a reduction in cost due to the reduced water consumption and reduction in total wastewater influents. Unfortunately, many rating policies adopted by water supply agencies do not provide for reduced rates with reduction of water consumption. Furthermore, some wastewater treatment companies base their charges on the B.O.D. loading; thus a reduction in the wastewater flow will not be reflected in a reduction of the total charges of wastewater treatment and disposal. Whenever possible, it will be more economically feasible to construct a system common to a community or serving a cluster of homes as the total costs are shared by several homeowners.

The following is the first cost for an aerobic wastewater system-mound package as presented by a consultant in a private inquiry for a cluster of homes as compared to a similar system for an individual home:

Individual System: (Jan. 1980 figures) Aerobic Unit-One smalf model Mound System - $600 \mathrm{ft}^{2}$ in area

Total Installation cost

Community System ( 9 homes)

Two large aerobic units

We note an appreciable saving per home for the clustered system, in addition to the advantages in systems management and maintenance which is more sufficient and economical for a community system as compared to an individual home. Other systems are presently manufactured for individual homes only, but probably have greater economic potential when designed for several homes or for an apartment house. The following is cost of a recycled grey water system for toilet water reuse as given by the manufacturer:

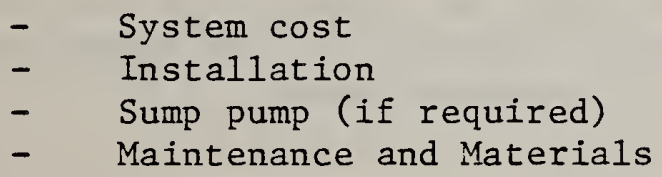

$\$ 3500$
100 (\$250.00 for retrofit)
250 per year

This system can be designed on special orders for more than one family. A package serving a family of four will cost approximately $\$ 6000$, (as quoted by a manufacturer) a substantial reduction in cost per family. Some systems cannot exist unless they are part of a large community. As mentioned earlier, "Pure Cycle" in Boulder, Colorado manufactures wastewater package plants for 
individual homes of wastewater treatment to drinking quality. The total cost of the system is $\$ 10,000$ (including average cost of excavation and construction). However, the company requires some 150 units located in a radius of 50 miles so that they can establish a center for monitoring and prompt servicing.

The concept of innovative onsite systems is relatively new. With the advance of the state-of-the-art and with the incorporation of onsite innovative systems into the public codes, patterns of normal usage will be evolved. As the onsite systems become ordinary consumer products, an economic data base will be established for system economic evaluation.

\section{E. 6 Soil Evaluation for Wastewater Effluents Absorption Systems}

There is no doubt that the soil underlying the homeowner's property is and will always be the most effective and least expensive media for onsite treatment and disposal of the household wastewater. The soils serve several tasks: as a wastewater purifying medium, as a wastewater disposal medium, as means for groundwater recharge and may serve as a medium (if desirable) for replenishing nutrients to the ground. The problem has always been to describe and quantify the soil properties and parameters which play a role in the quality and transport of wastewater from the secondary treatment device (septic tank, aerobic system) to the ground. Construction of septic tank - soil absorption system with no prior soil evaluation or incorrect evaluation may result in the failure of the system.

The procedures and requirements for soil evaluation vary among the various legislative bodies in the country. Some require a "perc test" only and some require a broader, extensive test of general soil evaluation and has to be performed by a registered evaluator. Perc tests have been traditionally used for years. This test measures the percolation rate of water in the underlying soil as an indicator of its capacity in removing the hydraulic loadings of the wastewater effluents to the ground. This test is made by digging several trenches in the lot to depths of four feet and 10 feet, drilling holes of six inches in diameter and 12 inches in depth in the trenches and pre-soaking the holes with water 24 hours before the test. Water is then poured to the holes and the time for the water to drop one inch is recorded. The acceptable values are in the range of five - 60 minutes per inch. It is often argued and established by most professionals that this test is inadequate and certainly insufficient to provide sufficient information on the soil characteristics. In observing "perc tests" conducted in several sites in Montgomery County, Maryland, it was noted in one test site, perc test values varied from seven to 240 minutes per inch. This large spread in values clearly indicate that the validity of soil evaluation based on perc test is questionable.

In considering soil evaluation, the "perc test" as specified by most codes is one component of the soil properties. Soil evaluation in the broader aspect includes the following soil and geological characteristics:

\section{- Soil Classification}

The best known is probably the textural classification of the U.S. Department of Agriculture referred to as "classification triangle" where the percentages of the soil constituents, i.e., sand, silt, clay, are determined (figure 21). 


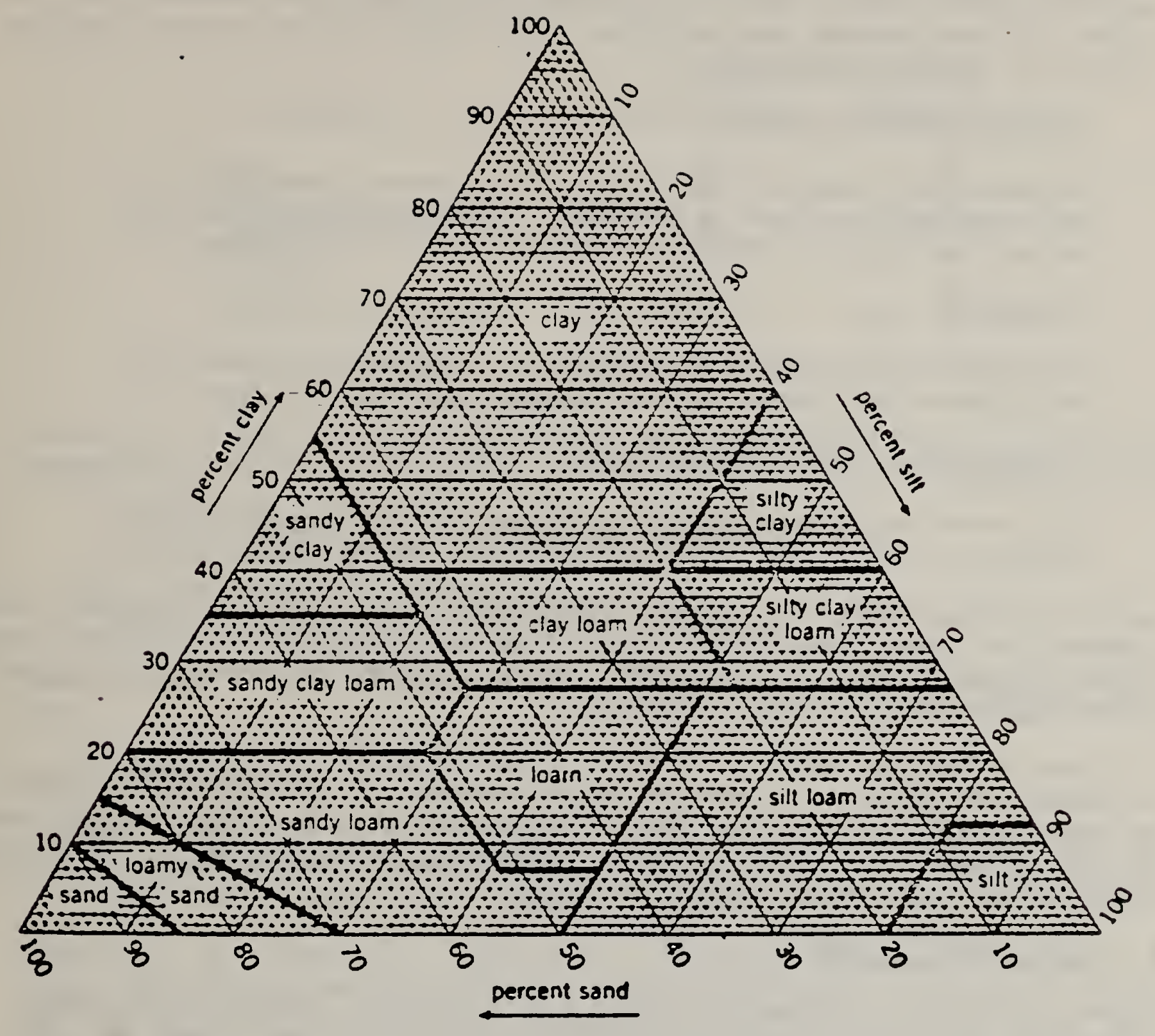

GUIDE FOR USDA SOIL TEXTURAL CLASSIFICATION

Figure 21

USDA Soil Classification 
The nature of the constituents composition will serve to indicate soil attributes such as soil absorption and water infiltration capacity. The smaller the particle size, the larger the water retaining capacity due to surface tension forces. On the other hand, the larger the particle size, the larger the pores between the particles. Clay soils tend to develop a crusty layer which impede infiltration.

\section{- Geologic Characteristics}

Physical and chemical composition and structural properties of the underlying bed rock is examined. A bed containing fractured bedrock may pass the effluents directly to the ground water.

- Topography

The slope of the terrain is determined. Excessive slopes do not retain water and cannot be used as soil absorption systems.

- Determination of High Ground Water

High ground water should not reach close to the soil absorption system to prevent the contamination of the ground water.

Aside from these underlying natural conditions, the treatment of the soil while construction takes place plays a role on the soil capacity. It has been shown through research that soil "smearing" and soil compaction during construction alters appreciably the soil properties.

All these properties make it difficult to describe the soil uniquely in particular for design criteria for onsite systems. In reference to research and demonstration projects, a detailed soil evaluation is of high significance for the purpose of defining the input conditions and concluding for which soil conditions was success or failure attained.

\section{E.7 Grey Water Systems}

Segregation of the wastewater household into grey and black water has been a topic of significant importance and research for the past decade [24, 25]. Wastewater separation to form two distinct household effluent systems offers a potential for efficient handling as grey and black water differ in their characteristics; in their total flow, temperature, chemical constituents and biological aspects. A typical distribution in the home, of the major parameters between the grey and black water is given in Table 19 [24]. 
Table 19

Distribution of Wastewater Loading Between Grey and Black Water

\begin{tabular}{|c|c|c|}
\hline Parameter & $\begin{array}{r}\text { Percent } \\
\text { Grey Uater } \\
\end{array}$ & $\begin{array}{l}\text { stribution } \\
\text { Black Water }\end{array}$ \\
\hline Flow & 65 & 35 \\
\hline $\mathrm{BOD}_{5}$ & 63 & 37 \\
\hline Suspended Solids & 39 & 61 \\
\hline Nitrogen & 18 & 82 \\
\hline Phosphorus & 70 & 30 \\
\hline Pathogenic Organisms & Very low & Vast majority \\
\hline
\end{tabular}

These figures indicate that black water and grey water systems require different wastewater treatment considerations, in particular, for the following aspects:

- Hydraulic loading of the system and physical sizing.

- The oxygen demand of the system.

- Soil absorption systems behavior.

- Aspect of health hazards and disinfection.

Immediate application of wastewater segregation is required in the following areas:

\section{Waterless Toilets}

As waterless toilets gain acceptance, the households greywater treatment and disposal form distinct systems. From the waterless toilets used at present, the composting toilet of the "large type" is most widely used. Depending on regulatory requirements and the user's options, the grey water is either disposed of or reused for irrigation and gardening. Grey water treatment by sand filtration and surface discharge was proposed by the University of Wisconsin, as shown in Figure 22. Similar arrangements were observed at sites in the State of Maine. The State of Maine requires disinfection of the effluents prior to lake or ocean discharge which is carried out by chlorination or $U / V$ disinfection. Clivus Multrum, M.S.A., Inc. designed a "roughing filter" composed of sand and pea gravel as in Figure 23, whose effluents are rendered safe for gardening and green house applications.

Grey Water Recirculation for Toilet Flush Water Reuse

These systems were described in previous sections of this report. These systems offer a substantial reduction in total wastewater loadings and a possible 40 percent reduction for water conservation. 


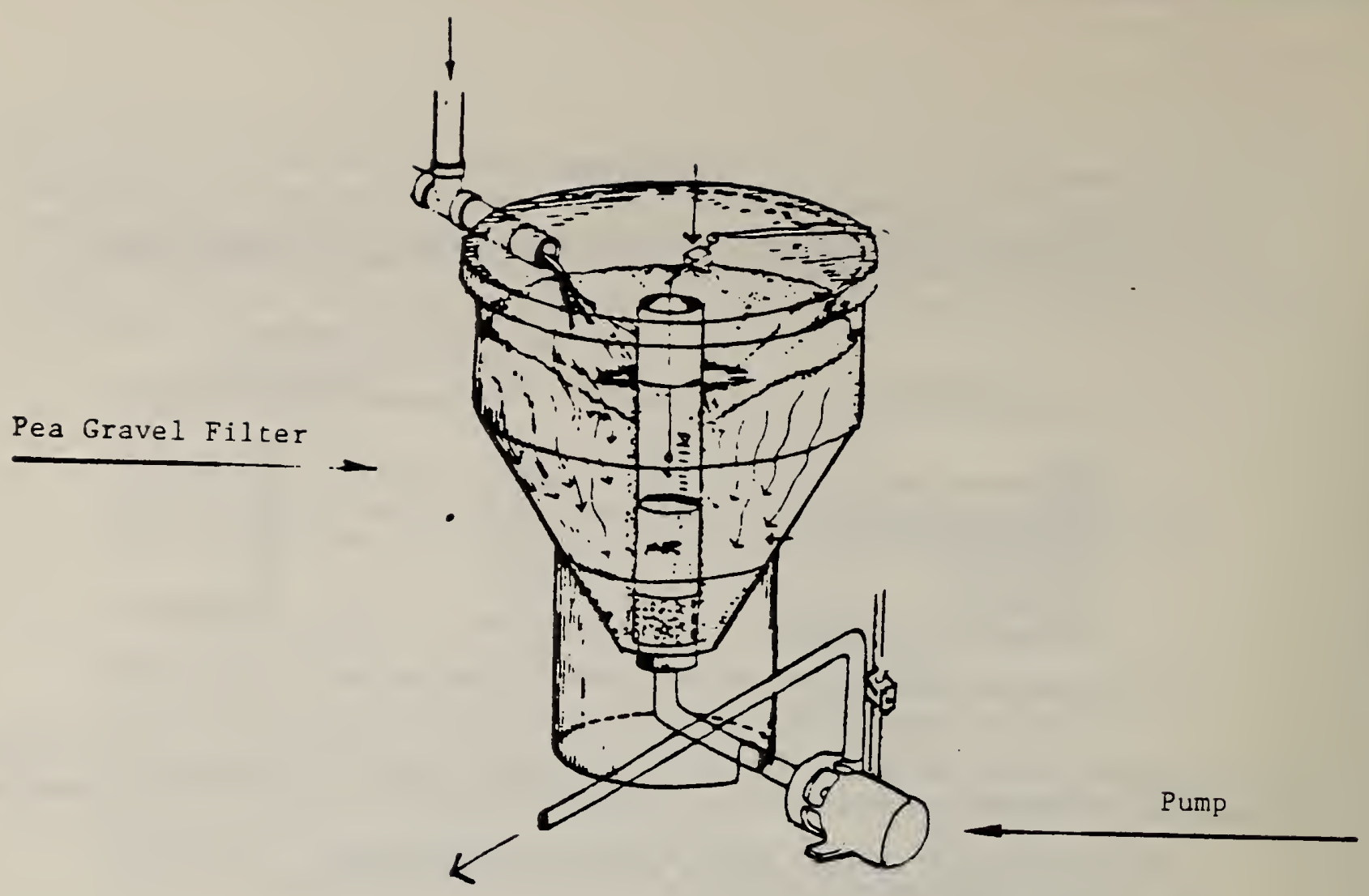

$\underline{\text { Figure } 22}$

The Clivus Multrum Grey Water Filter

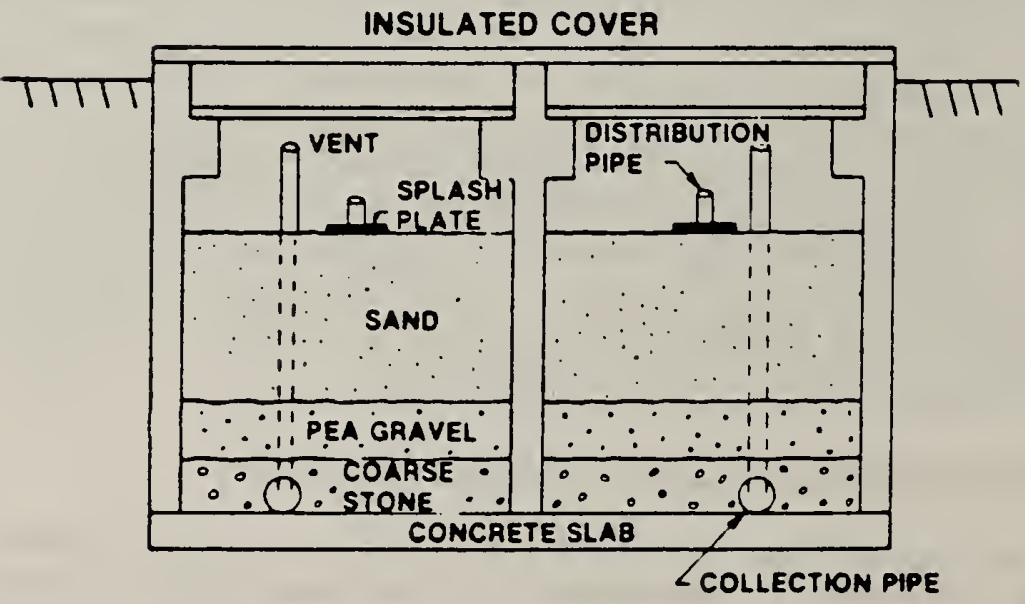

Figure 23

The University of Wisconsin Grey Water Filter 
Grey Water Sweep Systems

Grey water may be used as sweep systems to supplement wastewater transport requirements for efficient drainage performance. Such systems require only storage facilities and control for occassional grey water release and backflow prevention devices.

\section{F. Additional Sources of Information on Onsite Wastewater Systems}

The following sources of information are essential in any study on onsite wastewater systems:

\section{F.1 Literature}

- Aids for Literature Search

NASA - National Aeronautic and Space Administration

Scientific and Technical Information Facility

Baltimore-Washington International Airport

P.0. Box 8757 , MD 21240

Entering key words such as "onsite wastewater systems," "sanitary systems," "water conservation," to the computer Iiterature search system developed by NASA, results in an output of a long list of material related to this subject.

- University of Wisconsin

Small Scale Waste Management Project

University of Wisconsin - Madison

College of Agriculture and Life Sciences

The University of Wisconsin has been very active in onsite wastewater systems. Their finding is documented in numerous publications entitled "Small Scale Waste Management Projects"

- EPA Publication EPA-600/2 - 78 - 173

Management of Small Waste Flows

This publication prepared (under grant) by the University of Wisconsin has valuable information on topics such as management, requirements and research findings of onsite wastewater systems. 


\section{F.2 Conferences Related to Onsite Wastewater Systems}

- National Sanitation Foundation (NSF) Conference on Individual Onsite Wastewater Systems. This conference took place in the fall of 1979 and is given annually in Ann Arbor, Michigan.

This gathering provides an excellent opportunity for a followup of the ongoing research activities and information on experience gained with new onsite wastewater technologies.

- Environmental Protection Agency (EPA) Conference on Alternative and Innovative Wastewater Systems. This conference periodically takes place throughout the country mainly for informing professionals such as contractors and legislators on the activity of EPA and its grant programs. In addition, topics related to the state-of-the-art are presented.

- Water Reuse Symposium. This bi-yearly symposium took place in the spring of 1979 in Washington, D.C. Numerous topics were presented on wastewater reclamation, resulting in three volumes of proceedings with a total of 3,000 pages of printed material, from 155 papers.

F.3 Organizations Dealing with Onsite Wastewater Systems

- The University of Wisconsin

This university is highly active in onsite wastewater systems, in particular, in wastewater soil absorption systems and grey water systems.

- The North Carolina State University

This university has been active in soil mechanics as applied to wastewater soil absorption systems.

- National Sanitation Foundation

This organization has been writing standards for wastewater systems and testing systems which bear the NSF seal of approval, such as, aerobic units and wastewater recirculation devices.

F.4 Manufacturers Marketing Wastewater Package Plants

- Pure Cycle, Boulder, Colorado

This company manufactures individual wastewater recycling package plants, with a degree of treatment of potable water quality. 
- Thetford Corporation, Ann Arbor, Michigan

This company manufactures wastewater recycling systems, with a degree of treatment acceptable for water reuse, for toilet flushing.

- Aqua Saver, Baltimore, Maryland

This company manufactures recirculating grey water systems for toilet reuse. 

NBS-114A (REV. 8.78 )

\begin{tabular}{|c|c|c|c|}
\hline $\begin{array}{l}\text { U.S. OEPT. OF COMM. } \\
\text { BIBLIOGRAPHIC DATA } \\
\text { SHEET }\end{array}$ & $\begin{array}{l}\text { 1. PUBLICATION OR REPORT NO. } \\
\text { NBSIR } 81-2210\end{array}$ & 2.Gov't. Accession No. & 3. Recipient's Accession No. \\
\hline \multirow{2}{*}{\multicolumn{3}{|c|}{$\begin{array}{l}\text { 4. TITLE AND SUBTITLE } \\
\text { ONSITE WASTEWATER SYSTEMS -- Current Practices and } \\
\text { a Proposed Basis for Evaluation }\end{array}$}} & $\begin{array}{l}\text { 5. Publication Date } \\
\text { March } 1981\end{array}$ \\
\hline & & & 6. Performing Organization Code \\
\hline \multicolumn{3}{|l|}{$\begin{array}{l}\text { 7. AUTHOR(S) } \\
\text { Fred Winter }\end{array}$} & 8. Performing Organ. Report No. \\
\hline \multirow{2}{*}{\multicolumn{3}{|c|}{$\begin{array}{l}\text { NATIONAL BUREAU OF STA } \\
\text { DEPARTMENT OF COMMER } \\
\text { WASHINGTON, DC } 20234\end{array}$}} & $\begin{array}{l}\text { 10. Project/Task/Work Unit No. } \\
742-1379\end{array}$ \\
\hline & & & 11. Contract/Grant No. \\
\hline \multirow{2}{*}{\multicolumn{3}{|c|}{$\begin{array}{l}\text { 12. SPONSORING ORGANIZATION NAME AND COMPLETE ADDRESS (Stree, city, State, } z \text { IP) } \\
\text { Department of Housing and Urban Development } \\
4517 \text { th Street, SW } \\
\text { Washington, D.C. } 20410\end{array}$}} & $\begin{array}{l}\text { 13. Type of Report \& Period Covered } \\
\text { Final }\end{array}$ \\
\hline & & & 14. Sponsoring Agency Code \\
\hline \multicolumn{4}{|l|}{ 15. SUPPLEMENTARY NOTES } \\
\hline
\end{tabular}

16. ABSTRACT (A 200-word or less factual summary of most significant information. If document includes a significant bibliography or literature survey, mention it here.)

A review of onsite wastewater systems and wastewater recirculation/reuse devices based on the literature and field inspections of systems in actual settings and usage is presented. Based upon the observations, an evaluation basis for onsite wastewater systems is proposed. Criteria and requirements for conducting and monitoring demonstration projects is presented. Wastewater systems identified as potentials for demonstration projects are suggested. Topics requiring further study are identified and recommended for specific research.

17. KEY WORDS (six to twelve entries; alphabetical order; capitalize only the first letter of the first key word unless a proper name; separated by semicolons)

Onsite wastewater systems; water conservation; wastewater disposal; wastewater recirculation; wastewater reuse; wastewater treatment.

\begin{tabular}{|c|c|c|}
\hline $\begin{array}{l}\text { 18. AVAILAEILITY } \\
\square \text { For Official Distribution. Do INot Release to NTIS }\end{array}$ & $\begin{array}{l}\text { 19. SECURITY CLASS } \\
\text { (THIS REPORT) } \\
\text { UNCLASSIFIED }\end{array}$ & $\begin{array}{l}\text { 21. NO. OF } \\
\text { PRINTED PAGES } \\
111\end{array}$ \\
\hline $\begin{array}{l}\square \text { Order From Sup. of Doc., U.S. Government Printing Office, Washington, DC } \\
20402 \text {, SD Stock No. SNO03-003- } \\
\square_{\text {X Order From National Technical Information Service (NTIS), Springfield, }}^{\text {VA. } 22161}\end{array}$ & $\begin{array}{l}\text { 20. SECURITY CLASS } \\
\text { (THIS PAGE) } \\
\text { UNCLASSIFIED }\end{array}$ & $\begin{array}{l}\text { 22. Price } \\
\$ 11.00\end{array}$ \\
\hline
\end{tabular}





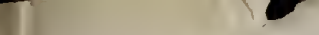


